\title{
Focus on the Child: Preventing the Intergenerational Transmission of Eating Disorders and Dieting Behavior
}

\author{
Elizabeth Claydon
}

Follow this and additional works at: https://researchrepository.wvu.edu/etd

\section{Recommended Citation}

Claydon, Elizabeth, "Focus on the Child: Preventing the Intergenerational Transmission of Eating Disorders and Dieting Behavior" (2018). Graduate Theses, Dissertations, and Problem Reports. 5371.

https://researchrepository.wvu.edu/etd/5371

This Dissertation is protected by copyright and/or related rights. It has been brought to you by the The Research Repository @ WVU with permission from the rights-holder(s). You are free to use this Dissertation in any way that is permitted by the copyright and related rights legislation that applies to your use. For other uses you must obtain permission from the rights-holder(s) directly, unless additional rights are indicated by a Creative Commons license in the record and/ or on the work itself. This Dissertation has been accepted for inclusion in WVU Graduate Theses, Dissertations, and Problem Reports collection by an authorized administrator of The Research Repository @ WVU.

For more information, please contact researchrepository@mail.wvu.edu. 
Focus on the child:

Preventing the intergenerational transmission of eating disorders and dieting behavior

Elizabeth Claydon, MPH, MS

\author{
Dissertation Submitted to the West Virginia University \\ School of Public Health \\ In Partial Fulfillment of the Requirements for the Degree of: \\ Doctor of Philosophy \\ in \\ Public Health \\ Keith Zullig, Ph.D., Chair \\ Danielle Davidov, Ph.D. \\ Lesley Cottrell, Ph.D. \\ Christa Lilly, Ph.D. \\ Stephanie Zerwas, Ph.D. \\ Department of Social and Behavioral Sciences
}

Morgantown, WV

2018

Keywords: Eating Disorders, Intergenerational Transmission, Children, Dieting Behavior, Parenting Copyright 2018 Elizabeth Claydon 


\title{
ABSTRACT \\ Focus on the child: \\ Preventing the intergenerational transmission of eating disorders and dieting behavior
}

\author{
Elizabeth Claydon
}

PURPOSE: There is a paucity of research exploring individuals' recall of parental dieting behavior, engagement in "fat talk", or criticism of weight or eating behavior in childhood. This dearth of literature exists in both community samples and in clinical populations of eating disorder patients. There is also limited information on women with a history of eating disorders and their pregnancy experience or anticipation of their pregnancy experience. This dissertation focuses on the aforementioned areas in order to develop the research literature further to understand whether parental feedback (such as parental comments or parental dieting) is associated with health outcomes such as BMI or eating pathology in community or clinical cohorts respectively. Secondly, there is also research provided to fill the gap on intergenerational transmission of eating disorders and dieting behavior between mother and child in a population of child-bearing women with current or past eating disorders. Together, the research presented aims to provide a framework to both understand and prevent intergenerational transmission of eating disorders and dieting behavior in both community and clinical samples. METHODS: This dissertation explores the topic of intergenerational transmission of eating disorders and dieting behavior in three aims, two quantitative aims, and one qualitative aim. The first quantitative aim comprised a total of 507 participants (78.1\% female; $20.7 \%$ male; and $1.2 \%$ transgender) who participated in an online, self-administered survey. The qualitative study included 15 women -9 of whom were mothers and 6 of whom were nulliparous - who had either a current or past eating disorder and were recruited through purposive sampling. The last aim used convenience sampling to recruit 60 participants, $93.3 \%$ of whom were female. RESULTS: The primary finding from the first aim showed that participants who recalled maternal encouragement to diet reported a significantly higher adult $\mathrm{BMI}(\beta=1.31, \mathrm{SE}=0.32, \mathrm{p}<.0001)$. In the second aim, one of the prevailing major themes that arose from both mothers and nulliparous participants was intergenerational transmission, especially the concern that their children would develop an eating disorder or pick up on some of their behaviors. The primary finding in the last aim showed a significant relationship between parental feedback and eating pathology $(\beta=14.1, \mathrm{SD}=7.0, \mathrm{p}=.05)$. CONCLUSION: Despite the known genetic risk factors for EDs, there remain malleable environmental factors that warrant further study to improve prevention efforts for these serious illnesses. In particular, the family context can be extremely effective in ED recovery for children, but they can also play a role in the development of body dissatisfaction, feeling pressure to diet, and have an association with children having a higher BMI as adults. With this understanding, parents are not to be blamed, but rather can contribute to the solution by reinforcing positive over negative behaviors and focusing on health rather than weight. More research is needed to both confirm and expand some of the findings in these studies. However, the research presented can help to guide interventions with the hope that parents can create environments for children to foster a positive relationship with food and their bodies. 
Dedication

To my little boy, Nathaniel, who makes my world brighter even on the darkest days. 


\section{Acknowledgments}

I want to express a deep gratitude to my Dissertation Chair, Dr. Keith Zullig, and to my entire Dissertation Committee for their time, energy, and support throughout my entire dissertation process. They always treated me with the respect due to a colleague, but always took the time to help me work through problems, never passing judgment on my understanding and always having faith in my abilities as an independent researcher. Dr. Keith Zullig, you have supported me from the start, bringing me back into this program when I thought my $\mathrm{PhD}$ career might be over. For that and for your continued support and mentorship, I am extensively grateful. Having this second chance has meant so much to me and receiving my $\mathrm{PhD}$ from this school will be my most valued accomplishment. Dr. Danielle Davidov, whose class inspired my love of qualitative research and the study that is presented in Chapter 3. It means so much to me personally to give a voice to these women and I am so grateful for your expert guidance in and passion for this project. Dr. Lesley Cottrell, it has been a delight to work with you once again after our work together in CARDIAC, and I have so appreciated your mentorship and invaluable expertise on childhood obesity. Dr. Christa Lilly, I cannot tell you how much I appreciate all the hours spent in your office going over biostatistics questions and your infinite patience with every single one. I have learned so much from you without even taking a class; your support has been essential to my work. Dr. Stephanie Zerwas, I am so grateful that you agreed to be on my committee; it is such an asset to have your perspective and expertise from the eating disorder field which is vital for this dissertation. I am also so appreciative of your support by finding me a second coder and for advertising the revised questionnaire on UNC's Center of Excellence for Eating Disorders' social media. Without this amazing team of mentors, this dissertation would not be possible.

I would also like to give thanks to Dr. Robert Bossarte for funding me during the last year of my doctoral career, so I could finish my dissertation. I am so appreciative to him and all of my colleagues at the Injury Control Research Center for the tremendous support they have been; it has been a joy working alongside all of you.

The research for Aim 1, presented in Chapter 2, would not have been possible without the continued support of Dr. Marney White of Yale School of Public Health. She encouraged me to add a questionnaire to a class survey, helped to advertise the survey and collect data, and continued to allow me to use the data even after I left Yale.

Specific to my Aim 2 research which will be presented in Chapter 3, I want to first and foremost offer heartfelt gratitude to the women who bravely shared their personal stories and struggles in an effort to help others facing similar circumstances. I am also greatly appreciative of Kayti for her incredible support of that study by connecting me with several of the individuals I spoke with. And finally, I would like to express my extensive gratitude to Mary Quattlebaum of University of North Carolina Chapel Hill for her excellent assistance as second coder for the aforementioned qualitative data.

For Aim 3, presented in Chapter 4, I would like to thank the individuals and locations that helped to advertise the questionnaire. Thank you to: Dr. Ashley Solomon of The Eating Recovery Center in Cincinnati, Ohio; Dr. Stephanie Zerwas of the The UNC Center of Excellence for Eating Disorders; Dr. Stephanie Cox of The Chestnut Ridge Center; Dr. Tara Deliberto of the partial hospitalization program (PHP) at New York-Presbyterian Hospital; and Dr. Jessica Luzier of the West Virginia Eating Disorder Network. 


\section{Table of Contents}

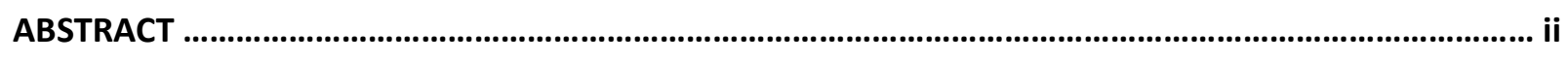

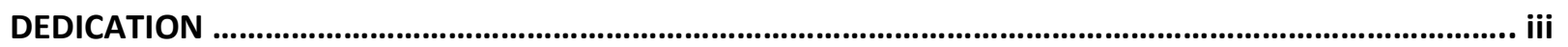

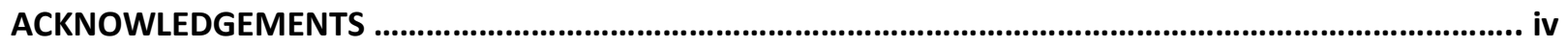

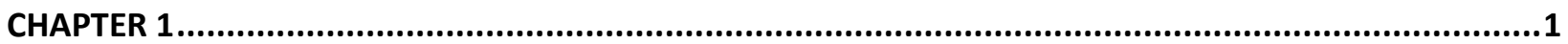

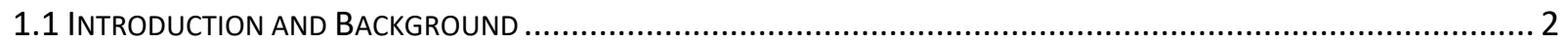

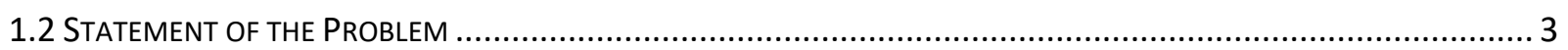

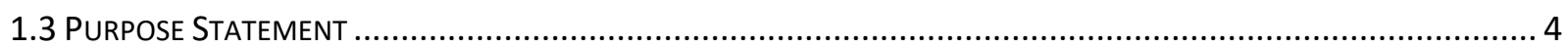

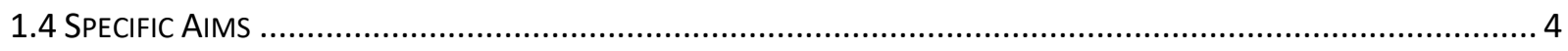

CHAPTER 2

2.1 INTRODUCTION

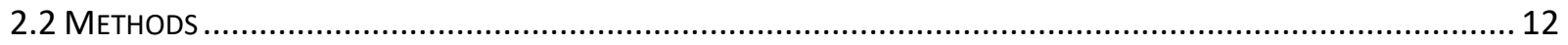

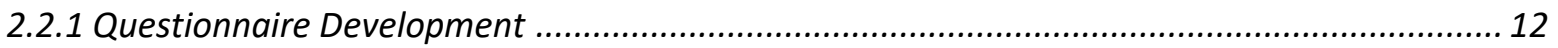

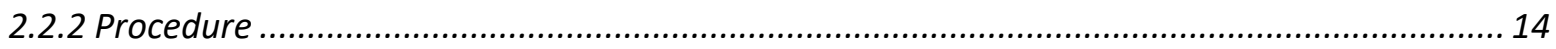

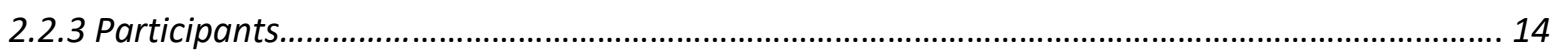

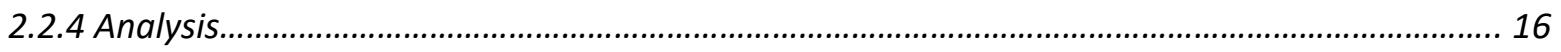

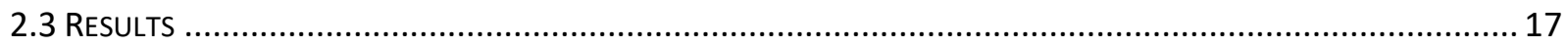

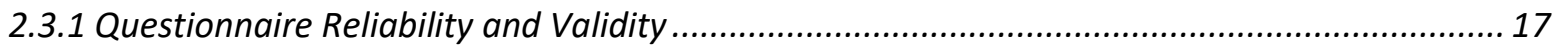

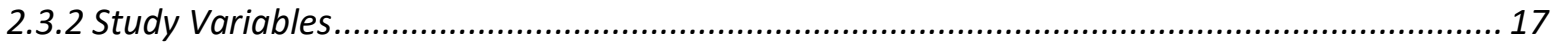

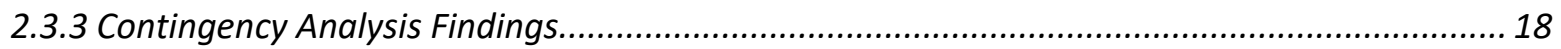

2.3.4 Multivariable Linear Regression Findings................................................................... 20

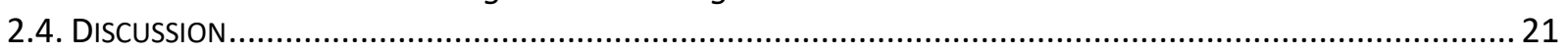

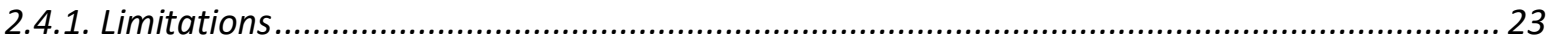

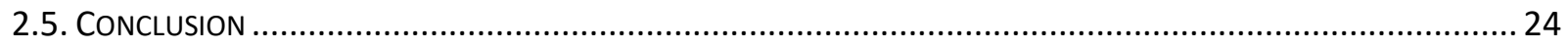

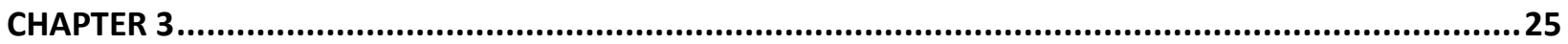

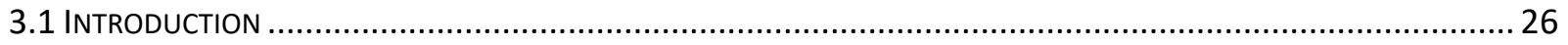

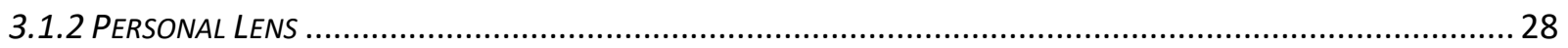

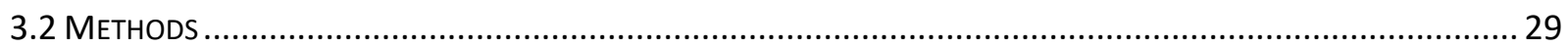

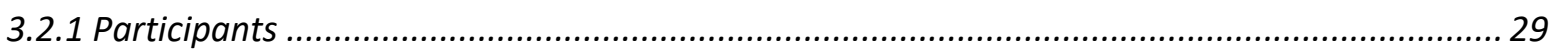

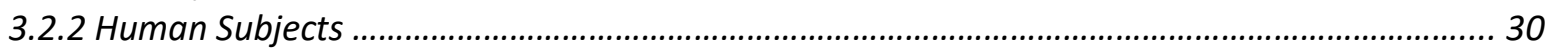

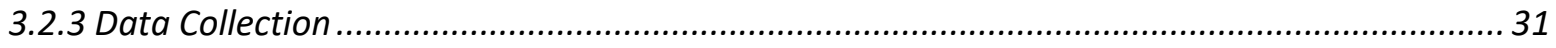

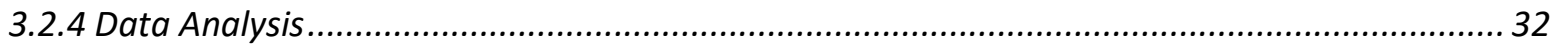

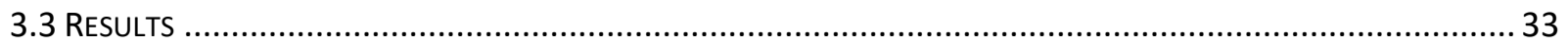

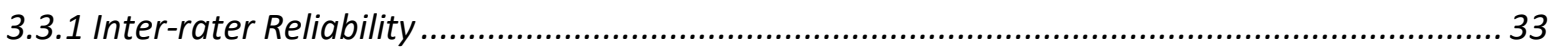

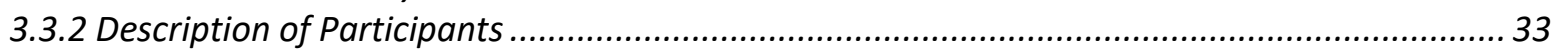

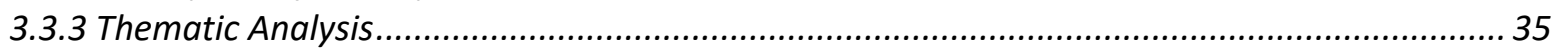

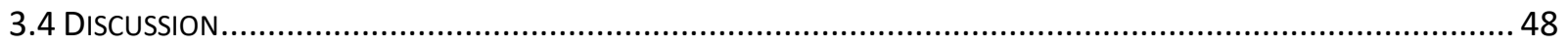

3.4.1. Strengths

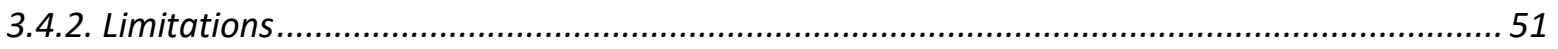

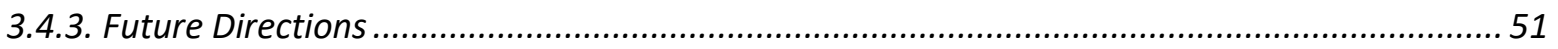

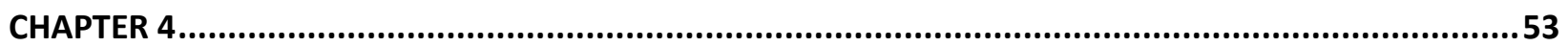

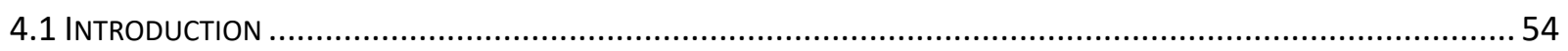

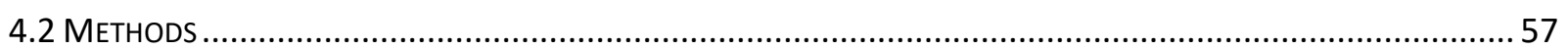

4.2.1 Questionnaire Development/Modification ................................................................. 57 


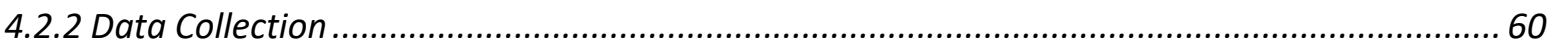

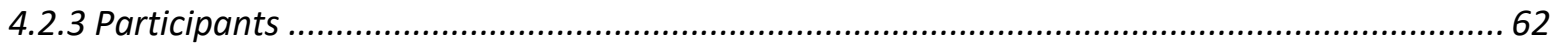

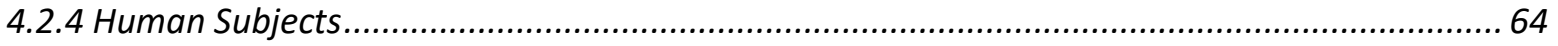

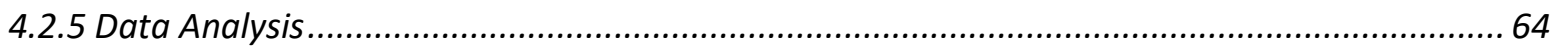

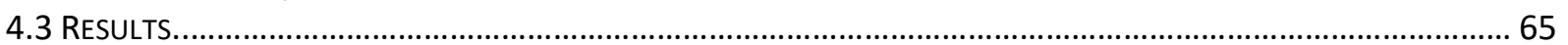

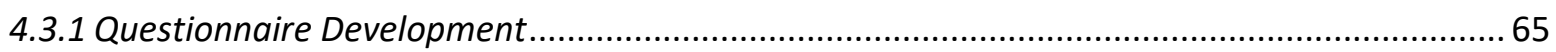

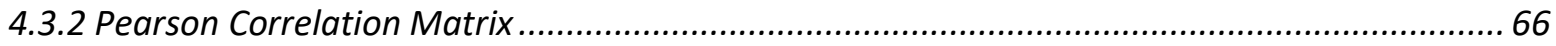

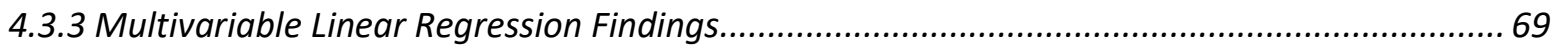

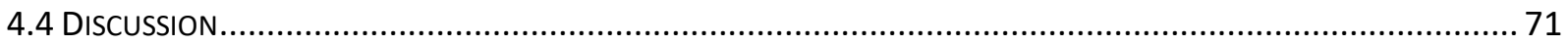

4.4.1. Limitations

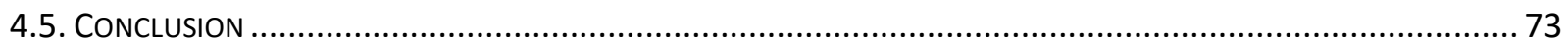

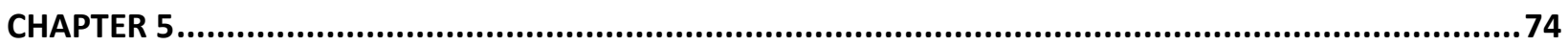

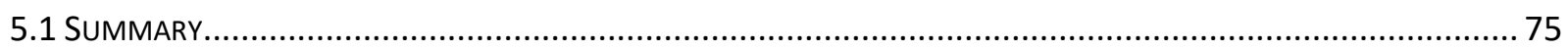

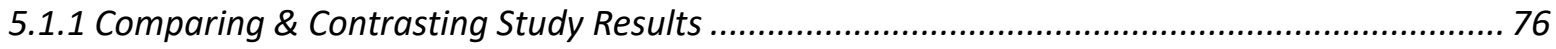

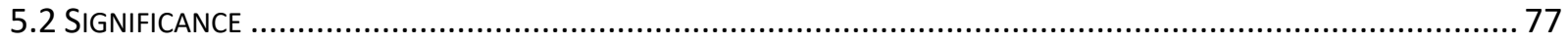

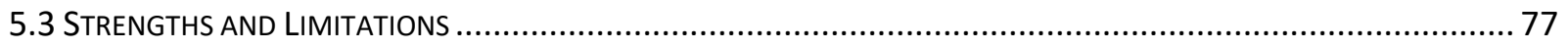

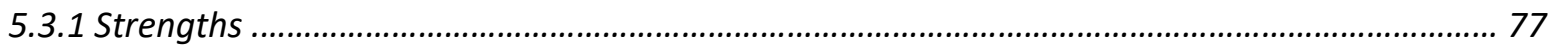

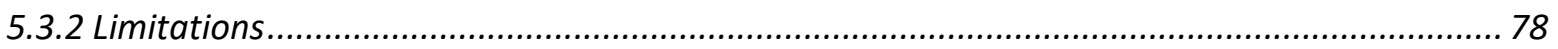

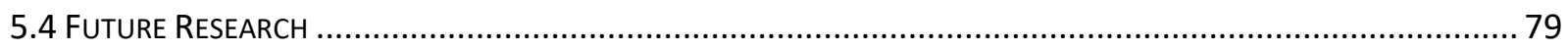

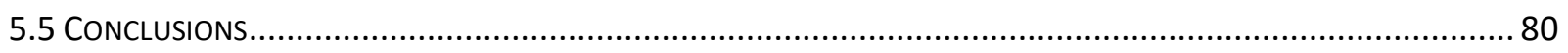

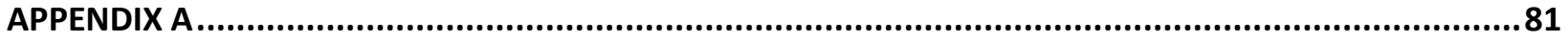

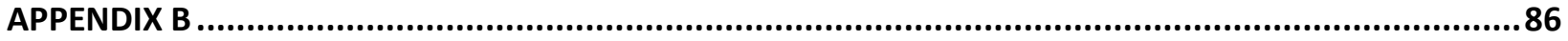

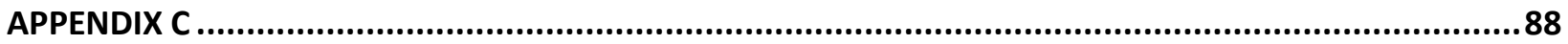

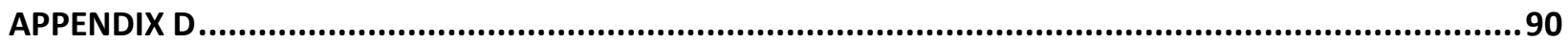

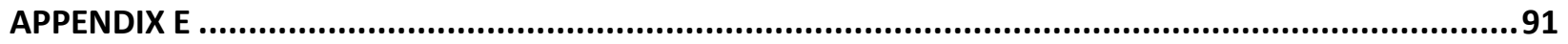

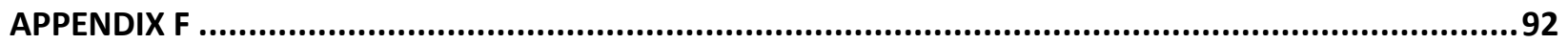

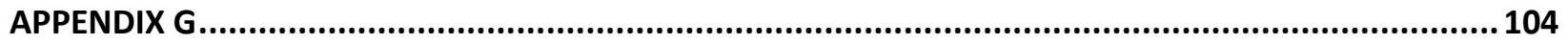

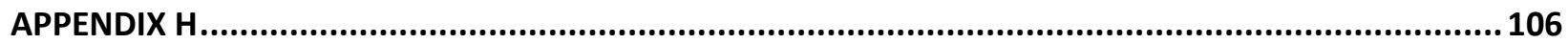

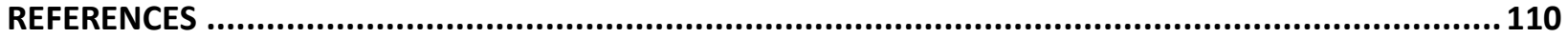


Chapter 1 
Our bodies take us through our daily lives, they are the vessels that transport us, bear witness to our triumphs and struggles, and convey a host of meanings about ourselves and our cultures. And for those reasons, they are beautiful, in every shape, size, and color. We cannot allow ourselves or others to begin a cycle of self-hatred over the bodies that are our lifelong homes. $\sim$ Elizabeth Claydon

\subsection{Introduction and Background}

Eating disorders (EDs) are severe mental disorders with costly and time-intensive treatments, high relapse rates, and higher rates of medical complications, hospitalizations, and mortality than any other psychiatric disorders (Agras, 2001; Klump et al, 2009). Eating disorders span a large age range beginning in childhood and extending far into adulthood. Perhaps most critical, an earlier age of onset for an eating disorder predicts poorer outcomes unless that eating disorder is detected and treated promptly (Fairburn \& Harrison, 2003).

Although the incidence of eating disorders in those younger ages is still low, there is increasing evidence that risk factors for eating disorders are prevalent in early adolescence and are predictive of eating disorders at later ages (Rohde et al., 2015). For young girls, these risk factors included perceived sociocultural pressure to be thin, thin-ideal internalization, and body dissatisfaction; however, male risk factors such as concerns about leanness, muscularity, and the use of muscle building products are also increasingly prevalent which necessitate further research (Rodgers et al., 2014; Calzo et al., 2016)

It is critical to note at this point that ED research focuses on EDs as biological, brain-based disorders (Klump et al., 2009). However, in addition to genetic risk for EDs, the environmental context, and particularly the familial context, offers malleable triggers that may be neutralized or attenuated. Therefore, a focus on an intergenerational cycle of risk offers promise in understanding the interactions between a genetic predisposition that children could face, in addition to triggering factors that could be present in a familial context (Zerwas \& Bulik, 2016). The amount of genetic or environmental influence on an individual will vary; for some individuals, genetics may play the greater role, whereas for others the environment may be more influential. 
Potential social and environmental triggers include indirect pressures such as 'fat talk,' parental modeling of unhealthy dieting practices, and direct pressure from parents to diet or parental criticism of a child's weight. Fat talk has been defined as an "informal dialogue during which individuals express body dissatisfaction" usually among a group of peers; this act of self-degradation is actually considered to be a social norm among women (Britton et al., 2006; p. 247). Although this construct has primarily been studied among females, there is growing research of this phenomenon among men and also within the family context (Engeln et al., 2013; MacDonald et al., 2015). Family dieting and critical comments about eating, shape, or weight from family and others have been hypothesized to be risk factors for the development of an eating disorder (Fairburn \& Harrison, 2003).

The intergenerational cycle of risk was addressed recently by The American Academy of Pediatrics' (AAP) recommendations noting how obesity prevention messages can be counterproductive (Golden et al., 2016). The AAP provided evidence showing that talk by family members about their own weight or a child's weight can be detrimental and lead to a child's unhealthy weight control behaviors. Therefore, the recommendations encourage family members to focus on health and health behaviors rather than weight, weight loss, and dieting. By adopting a family-based lifestyle modification approach to health rather than an intergenerational cycle of dieting and weight commentary, families may be able to prevent both obesity and eating disorders among children and adolescents.

\subsection{Statement of the Problem}

To assume that parents do not play a role in a child's weight, body image, or dieting behavior negates known and accepted behavioral theory. For example, Social Cognitive Theory posits that social reinforcement through comments or actions from close relationships help reinforce behaviors 
(Stice, 1998). Such reinforcement may support and perpetuate perceptions of the thin ideal and the need for weight loss.

Peer influence is also a strong influence through modeling and endorsement of dieting behavior, but families are usually a constant throughout life, whereas peer groups are more susceptible to change (Huon et al., 2000). Therefore, the potential lifetime exposure to family norms and behavior from early childhood into adulthood is far greater.

\subsection{Purpose Statement}

Using a multi-generational understanding of ED transmission may yield a yet-unexplored and beneficial approach to preventing intergenerational transmission of EDs. The issue of intergenerational transmission of eating disorders, dieting behavior and body image dissatisfaction will be addressed in the following three research aims in three chapters.

\subsection{Specific Aims}

\section{Chapter 2: Aim \#1:}

An Exploratory Study on the Intergenerational Transmission of Obesity and Dieting Proneness

A community sample of 673 participants was recruited to participate in an online, self-administered survey using Qualtrics software, which included a unique questionnaire about recall of parental dieting behaviors. The questionnaire asked whether participants remembered their mother or father dieting, engaging in weight-related talk, encouraging them to diet, or critiquing their weight.

- Research Question 1: What is the prevalence of recall for both male and female adults of parental fat talk, dieting, or weight-related criticism in their families of origin? How does 
participant recall differ based on participant sex or recall of maternal or paternal feedback, or type of feedback?

- Hypothesis: Participants would be more likely to recall maternal rather than paternal dieting and/or fat talk due to social pressures on women to diet. We also hypothesized that female participants would be more likely to recall maternal rather than paternal criticism of their eating and weight, as well as encouragement to diet (Costanzo \& Woody, 1985).

- Analysis: Descriptive analyses were used to generate information about the prevalence of the recall in this population. Subgroup analyses were also conducted to determine differences among dieting behavior and criticism among mothers and fathers as well as whether that criticism was directed at a daughter or son. Analyses also explored participant recall of indirect or direct parental feedback, with an expectation that indirect feedback might be associated with direct feedback.

- Research Question 2: Is recalled parental feedback (e.g. parental dieting, fat talk, encouragement to diet, or weight criticism) associated with a participants' adult BMI?

- Hypothesis: Recall of parental feedback would be related to a higher adult BMI.

- Analysis: A Multivariable linear regression was used to test whether recall of direct or indirect parental feedback items was associated with a higher adult participant BMI.

\section{Chapter 3: Aim \#2:}

Waking up every day in a body that is not yours: A Qualitative Research Inquiry into the Intersection between Eating Disorders and Pregnancy

A total of 15 women with a current or past history of an ED were recruited for this qualitative study; there were nine women who had previous pregnancies and six nonparous women. Interviews 
were the primary unit of data collection, which was appropriate because sensitive and confidential information was gathered that might not be as readily shared in a group format, such as through focus groups (Creswell, 2013).

- Purpose: The purpose of this qualitative descriptive study was to understand the intersection between eating disorders and pregnancy from the lived experience of women who have been pregnant or want to or do not want to become pregnant. It is hoped that the themes derived from this qualitative study will help to inform both prenatal and postnatal care and interventions that address intergenerational transmission concerns among mothers with eating disorders.

- Analysis: Data analysis was based on fifteen verbatim transcripts from audio recordings. Each transcript was read post-transcription and continually compared and contrasted. Each transcript was also compared to the field notes taken of that interview. NVIVO 11@ was used to analyze the transcripts of the interviews for emergence of major themes and subthemes.

\section{Chapter 4: Aim \#3}

The purpose of this aim explored a revised questionnaire used in Aim 1 within an eating disorder population. Participants were recruited through the Eating Recovery Center, the UNC Center of Excellence for Eating Disorders, a Partial Hospitalization Program in New York, and Chestnut Ridge Center via Qualtrics. An ED-specific measure, the Eating Pathology Symptom Inventory (EPSI) was added to see how those measures are associated with the questionnaire in order to broaden the questionnaire outcomes (Forbush et al., 2013).

- Hypothesis: Based on previous research of external pressures such as family, peers and media on EDs (Lorasch-Gunderson, 2012, unpublished clinical research paper), the study 
hypothesis expected that participants who recalled greater parental criticism or encouragement to diet would report more ED symptomatology.

- Analysis: Similar to Aim 1, descriptive analyses were used to generate information about the prevalence of the recall in this ED-specific population. Subgroup analyses were also conducted to determine differences among dieting behavior and criticism among mothers and fathers as well as whether that criticism was directed at a daughter or son. Additionally, linear regressions were run with EPSI Total scores to determine whether direct (encouragement to diet, criticism of weight) or indirect (parental dieting or fat talk) factors corresponded with higher eating pathology scores. 


\section{Chapter 2}

Aim 1

An Exploratory Study on the Intergenerational Transmission of Obesity and Dieting Proneness 


\subsection{Introduction}

Parents often are confused about how to communicate health messages about weight to their children effectively. In some circumstances, parental feedback, including critical statements or parental dieting, have been associated with higher body mass index (BMI), weight dissatisfaction, and increased dieting among offspring later in life (Wansink et al., 2017; Coffman et al., 2016).

In Social Cognitive Theory, parents can positively or negatively reinforce certain behaviors or ideas through modeling or feedback (Bandura, 1989). Children model parental behavior and adopt values towards weight and dieting, whether positive or negative, including their parents' relationship with food and/or body image (Berge et al., 2012). For example, positive parental role modeling has been associated with improving a child's varied food intake (Scaglioni et al., 2008).

Although parents can provide positive modeling for children's eating and body image, there is also the potential of parents modeling negative attitudes and behaviors, especially if parents struggle with their own weight (Nickelson et al., 2012). 'Fat talk,' which has been defined as an “informal dialogue during which individuals express body dissatisfaction" (Britton et al., 2006, p. 247), is one of the forms of commentary receiving attention, especially among girls and women (Mills \& FullerTyszkiewcz, 2017). However, parents can provide a negative environment for children's body image, weight, and eating behaviors through modeling, criticism, and/or food restriction. This parental feedback can happen directly through a parent's comments or criticism of their child's weight, or indirectly by a parent's dieting or fat talk (Wansink et al., 2017). For example, indirect parental feedback might include self-criticism of weight and/or body shape, commentary of one's own calorie consumption, or modeling of restrictive or excessive eating.

Costanzo and Woody's (1985) Obesity Proneness Model (OBPM) provides a theoretical underpinning into direct parental feedback (e.g. comments or restrictive feeding practices) to perceived or actual weight problems. This direct parental feedback is guided by the degree to which parents are 
invested in societal values about weight and shape; prior research indicates this relationship is moderated by child sex (Campbell et al., 2006). The direct parental feedback of comments or restrictive feeding could be associated with children's internalization of weight concern and an inability to self-regulate their eating, respectively. However, thus far to our knowledge, indirect parental feedback has not been adequately examined. For example, Nickelson et al. (2012) tested the viability of Costanzo and Woody's (1985) OBPM for an adolescent population, but only considered direct parental feedback on weight and body image. The current study includes indirect feedback.

Two recent studies illustrate associations between parental comments and/or maternal dieting and girls' weight satisfaction, BMI, and early dieting behavior (Wansink et al., 2017; Coffman et al., 2016). Wansink et al.'s (2017) cross-sectional study of adult female participants found a significant relationship between recall of parental comments about their weight as a child and current adult BMI and weight dissatisfaction. Additionally, participants' weight concern was significantly associated with parents' concern about their own weight. Both of these forms of indirect and direct parental feedback were assessed; however, parental comments (direct feedback) were significantly related to children having a higher adult BMI. Coffman et al. (2016) found similar results within a longitudinal study of young girls and their mothers; girls of dieting mothers were more likely to diet prior to age 11 compared to daughters of mothers who were not dieting.

Two studies, based in France and Australia respectively, also examined the association between parental comments and child body satisfaction through the Parental Comments Questionnaire (Rodgers et al., 2009a, 2009b). The French study (Rodgers et al., 2009a) found that parental comments explained more variability in girls' body dissatisfaction and disordered eating than boys. This finding was replicated in the Australian cohort (Rodgers et al., 2009b) with both positive and negative parental comments related to female outcomes, whereas only negative parental comments were related to male body dissatisfaction. 
These quantitative studies are corroborated by a qualitative study that included a focus group with 22 female adolescents (aged 15-22 years) discussing body dissatisfaction and dieting (Sharpe et al., 2013). One emergent theme was direct and indirect pressures from parents. For example, students mentioned direct pressures like a parent making them diet or indirect pressures such as modeling eating habits or lack of parental self-confidence. It is important to note that students felt both direct and indirect pressures were detrimental and helped institute dieting or body negativity as a norm.

Although these studies expand the research on parental weight commentary and dieting, they have several limitations. Many studies only considered parental feedback upon daughters, not sons, and few considered the influence of both maternal and paternal feedback (Wansink et al., 2017; Nickelson et al., 2012; Rodgers et al., 2009a, 2009b). Lastly, there was not one standardized measure used across all studies to aid comparability of findings (Wansink et al., 2017).

The purpose of this study was to investigate potential associations between the recall of direct and indirect parental feedback and weight, body image, and eating behavior. It expands the literature through a novel questionnaire demonstrating the extent to which both male and female adults recall parental fat talk, dieting, or weight-related criticism in their families of origin.

This study had two exploratory hypotheses. The first hypothesis had two components. First, due to the disproportionate number of women with body dissatisfaction and accumulating literature describing female fat talk, we hypothesized that participants would be more likely to recall maternal rather than paternal dieting and/or fat talk. Second, due to the existing evidence, particularly regarding female children and mothers, as well as the OBPM, we hypothesized that female participants would be more likely to recall maternal rather than paternal criticism of their eating and weight, as well as encouragement to diet (Costanzo \& Woody, 1985). Analyses also explored participant recall of indirect or direct parental feedback, with an expectation that indirect feedback might be associated with direct feedback. 
The secondary research question considered whether recalled parental feedback (e.g. parental dieting, fat talk, encouragement to diet, or weight criticism) was related to participants' adult BMI. Therefore, our second study hypothesis was that recall of parental feedback would be related to a higher adult BMI using Wansink et al.'s (2017) study as a basis.

The expected results are theorized to test a revised Obesity \& Dieting Proneness Theoretical Model that incorporates direct as well as indirect parental feedback (Figure 2.1). This theoretical model is not intended to be a mathematical model but underpins the analyses and explicates the complicated relationship of intergenerational transmission of dieting.

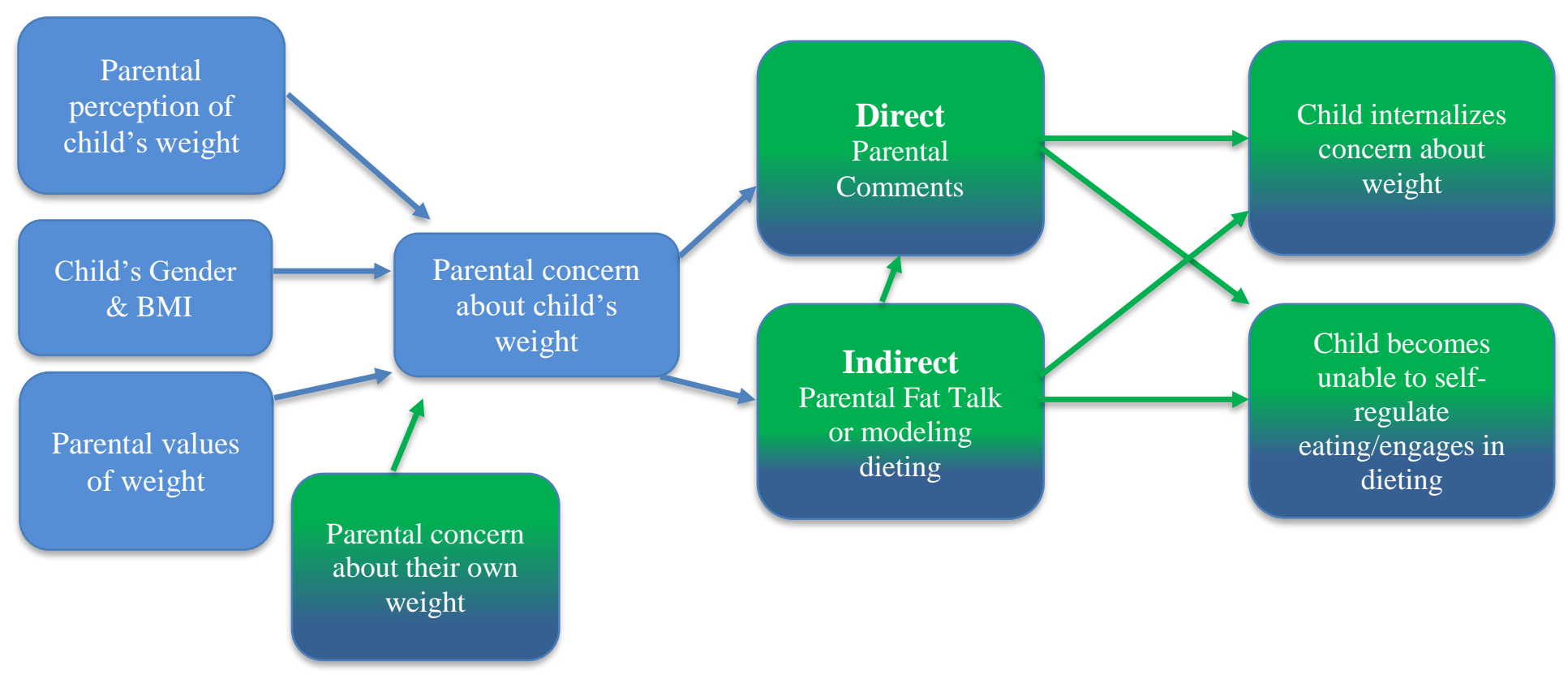

Figure 2.1 Revised Obesity \& Dieting Proneness Theoretical Model*

*Credit to P.R. Costanzo \& E.Z. Woody; permission to use this image received from P.R. Costanzo: Costanzo, P.R., Woody, E.Z. (1985). Domain-specific parenting styles and their impact on the child's development of particular deviance: the example of obesity proneness. Journal of Social and Clinical Psychology, 3, 425-445.

\subsection{Methods}

\subsubsection{Questionnaire Development}

There are two existing questionnaires to capture parental or caregiver feedback: Parental 
Van Diest \& Tylka, 2010). Both have been shown to demonstrate adequate reliability (including internal consistency) and validity. However, the Caregiver Eating Messages Scale only addresses direct messages that a caregiver makes about eating, not messages about body size or weight (Kroon Van Diest \& Tylka, 2010). Additionally, the Parental Comments Questionnaire has not been validated in a US population Rodgers et al., 2009a). Neither questionnaire addresses indirect feedback such as parental dieting or fat talk. There is a questionnaire to address fat talk among family members, The Family Fat Talk Questionnaire (MacDonald et al., 2015). However, this measure is limited because it primarily addresses female fat talk, does not differentiate between maternal or paternal fat talk, and does not address maternal or paternal dieting practices or criticism of children's eating behaviors or weight.

Our questionnaire was developed to fill these gaps and built on the concepts of fat talk, as well as the influence of family fat talk identified by MacDonald et al. (2015). In addition to assessing parental fat talk, dimensions were added to the instrument to measure parental dieting (e.g. Did your mother engage in diets specifically to lose weight?), parental encouragement to diet (e.g. Did your father encourage you to diet?), and parental criticism of a child's weight (e.g. Did your mother criticize your weight, shape, or eating behaviors?). Each dimension contained two items each, with participants asked to recall maternal and paternal feedback independently. Once the final instrument

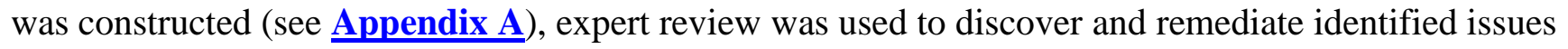
with the developed questionnaire. Social desirability was also assessed using the short-form MarloweCrowne scale, where a score above 5 indicated high social desirability and a score equal to or below 5 indicated low social desirability (Reynolds, 1982). The final questionnaire contained 15 items, not including demographic questions.

Parental Dieting Behavior \& Fat Talk: Participants were asked the following dichotomous (yes/no) questions regarding parental dieting behavior and fat talk (separately asked to mothers and 
fathers): "Did your mother/father engage in diets specifically to lose weight?" and "Did your mother/father engage in 'fat talk,' that is degrading talk specifically about her/his weight, shape, or size?" Follow-up questions to each of these questions inquired how often and at what age each happened but were not analyzed as part of this study.

Parental Criticism \& Pressure to Diet: Four questions (separately asked to mothers and fathers) were: "Did your mother/father criticize your weight, shape, or eating behaviors?" and "Did your mother/father encourage you to diet?" Response options were yes/no to each. Participants were asked these same questions about whether their parents provided this feedback once participants were adults (over 18 years-old), with yes/no response choices.

\subsubsection{Procedure}

Participants were recruited over a 2-week period in Spring 2014 to participate in this online, self-administered survey via internet and social media-based advertising. Advertisements asked individuals to participate in this questionnaire, which was part of a class research project; no incentives were provided in exchange for participation, except for the opportunity to advance research. Qualtrics software was used to host and distribute the survey. The study was granted an exemption by Yale University's Institutional Review Board because it did not collect any identifying information.

\subsubsection{Participants}

A convenience sample of 673 participants was recruited; participants were included in the analysis only if they had lived with both their mother and father at least part of the time when they were a child, reducing the sample to 507 . The majority of respondents were female $(n=396,78.1 \%)$, Whites $(n=338)$, had at least a college degree $(n=386,76.1 \%)$, and lived in the United States $(n=391$, 77.1\%). Most were young and in the normal weight range, although there was high variance on both age (mean age 31.9 years \pm 12.9 ) and BMI (24.6 \pm 5.2 full sample; $25.4 \pm 5.0$ for men; $24.4 \pm 5.3$ for 
women). Annual family income was normally distributed, but the majority made less than $\$ 50,000$ per year. Approximately 27\% $(\mathrm{n}=135)$ of the respondents were parents themselves (See Table 2.1).

Table 2.1. Demographic Characteristics

\begin{tabular}{|c|c|c|}
\hline Characteristic & $\begin{array}{c}\text { Total } \\
\mathbf{N}=\mathbf{5 0 7} \mathbf{N}(\%) \\
\end{array}$ & $\begin{array}{c}\text { Mean } \pm \text { SD N }= \\
507\end{array}$ \\
\hline Age & & $31.9 \pm 12.9$ \\
\hline \multicolumn{3}{|l|}{ Gender } \\
\hline Male & $105(20.7)$ & \\
\hline Female & $396(78.1)$ & \\
\hline Transgender or Other & $6(1.2)$ & \\
\hline Hispanic or Latino/a & $26(5.1)$ & \\
\hline \multicolumn{3}{|l|}{ Race/ethnicity $^{\mathbf{a}}$} \\
\hline White/Caucasian & 338 & \\
\hline Black/African-American & 10 & \\
\hline Asian & 135 & \\
\hline American Indian, Alaskan Native & 7 & \\
\hline Native Hawaiian, Pacific Islander, East & & \\
\hline Indian & 3 & \\
\hline Other & 16 & \\
\hline \multicolumn{3}{|l|}{ Country of Residence } \\
\hline United States & $391(77.1)$ & \\
\hline Canada & $61(12.0)$ & \\
\hline Other/Prefer not to answer & $56(11.0)$ & \\
\hline BMI & & $24.6 \pm 5.2$ \\
\hline \multicolumn{3}{|l|}{ Education } \\
\hline College or Higher & $386(76.1)$ & \\
\hline Some college or vocational school & $74(14.6)$ & \\
\hline High School/GED & $36(7.1)$ & \\
\hline Less than High School & $11(2.2)$ & \\
\hline \multicolumn{3}{|l|}{ Annual Family Income } \\
\hline$<\$ 50,000$ & $191(37.7)$ & \\
\hline$\$ 50,000-\$ 99,999$ & $133(26.2)$ & \\
\hline$\$ 100,000+$ & $116(22.9)$ & \\
\hline Prefer not to answer & $65(12.8)$ & \\
\hline \multicolumn{3}{|l|}{ Parent } \\
\hline Yes & 135 (26.6) & \\
\hline No & $372(73.4)$ & \\
\hline \multicolumn{3}{|l|}{ Relationship Status } \\
\hline $\begin{array}{l}\text { Married/Civil Union/Living with } \\
\text { Partner }\end{array}$ & $194(38.3)$ & \\
\hline
\end{tabular}


Committed Relationship

Single

Other
$111(21.9)$

$184(36.3)$

$18(3.6)$

a Wording of this question was "Check all that apply", therefore percentages are not appropriate.

\subsubsection{Analysis}

First, the psychometrics of the questionnaire were evaluated through calculating internal consistency estimates via Kuder-Richardson (KR20) and Item Response Theory (IRT). IRT uses a mathematical function to relate an individual's probability of endorsing an item to a latent (i.e., not directly measured) trait of that individual. A two-parameter logistic model (2PL model) was employed, which includes 2 sets of parameters including $a$ (item discrimination, i.e., probability of endorsing an item for people with high levels of the trait than for those with low levels) and $b$ (item difficulty, i.e., percent of people who endorse the item). Item characteristic curves (ICC) that demonstrate the $2 \mathrm{PL}$ model were examined; the 2 parameters are presented. Descriptive analyses including contingency analyses (analyses that allow for the exploration of a nominal or ordinal variable across the levels of a second categorical variable) and subgroup analyses were conducted using SAS JMP® 12.0 software. Specifically, to assess the first hypothesis that participants were more likely to recall their mother dieting and/or participating in fat talk, a contingency analysis was used to compare the proportion of recall of maternal and paternal commentary and dieting. For the second component of the first hypothesis, subgroup analyses were conducted to calculate the odds of participants recalling maternal or paternal encouragement to diet or weight/shape criticism based on the sex of the participant. A linear regression was used to test the second hypothesis of whether recall of direct or indirect parental feedback was associated with a higher participant BMI in adulthood. 


\subsection{Results}

\subsubsection{Questionnaire Reliability and Validity}

Internal consistency estimates were calculated for the questionnaire through Kuder-Richardson (KR20), with a resulting value of 0.8; acceptable values range from 0.7 to 0.9 (Bland \& Altman, 1997).

This survey had a score of $4.7(S D=2.1)$ on the Marlowe-Crowne scale, indicating that there could be the presence of possible moderate social desirability.

Additionally, IRT was used to assess the specific binary items within the questionnaire and to evaluate test items and latent constructs (An \& Yung, 2014). Item discrimination (factor loadings) and difficulty (intercept) was calculated for each of the primary study questions. Items with similar discrimination and difficulty indicated that those items were measuring a common construct consistently (Cappelleri et al., 2014).

IRT positive scores on item difficulty indicated less than $50 \%$ answered positively to the item (stated 'yes'), which was corroborated with all items having less than a 50\% endorsement. Although all items were fairly similar for difficulty (ranging between 0.71-2.17) and discrimination (ranging from 0.70-2.19), some items were more similar to each other, suggesting three potential constructs or clusters (Table 2.II). For example, one cluster could be conceptualized as maternal dieting behaviors and encouragement to diet including items 1-4 (although item 3 is less similar). A second cluster, paternal dieting behaviors, comprised items $5 \& 6$, regarding paternal dieting or fat talk. The last cluster, paternal encouragement/criticism, had almost identical discrimination and difficulty: 1.4, 2.2 and 1.2, 2.1. Collectively, IRT results suggest the items displayed evidence of measurement validity (Yang \& Kao, 2014).

\subsubsection{Study Variables}

Regarding the variables of interest (See Table 2.2), $40 \%(n=216)$ of participants recalled maternal dieting and 34\% $(\mathrm{n}=182)$ recalled maternal fat talk. Twenty-five percent of participants 
endorsed maternal encouragement to diet. Thirty-two percent of participants $(n=175)$ recalled that their mothers were critical of the participants' weight, shape, or eating behaviors. Paternal dieting was recalled less $(\mathrm{n}=120 ; 24 \%)$ and only $11 \%$ recalled paternal fat talk $(\mathrm{n}=58)$. Fifteen percent reported paternal encouragement to diet $(n=76)$, while $20 \%$ indicated that their fathers had been critical of their weight, shape, or eating behaviors. Additionally, $18 \%$ of participants recalled maternal encouragement to diet once the participant was an adult (over 18), $21 \%$ recalled maternal criticism, and $12 \%$ reported both paternal encouragement to diet and paternal criticism.

\begin{tabular}{|c|c|c|c|}
\hline Item & Difficulty & Discrimination & $\mathrm{N}(\%)^{\mathrm{a}}$ \\
\hline $\begin{array}{l}\text { 1. Did your mother engage in } \\
\text { diets specifically to lose weight? }\end{array}$ & 0.8 & 0.7 & $216(40.1)$ \\
\hline $\begin{array}{l}\text { 2. Did your mother engage in } \\
\text { 'fat talk,' that is degrading talk } \\
\text { specifically about her weight, } \\
\text { shape, or size? }\end{array}$ & 0.8 & 1.1 & $182(33.8)$ \\
\hline $\begin{array}{l}\text { 3. Did your mother encourage } \\
\text { you to diet? }\end{array}$ & 1.0 & 1.5 & $136(25.4)$ \\
\hline $\begin{array}{l}\text { 4. Did your mother criticize } \\
\text { your weight, shape, or eating } \\
\text { behaviors? }\end{array}$ & 0.7 & 1.3 & $175(32.7)$ \\
\hline $\begin{array}{l}\text { 5. Did your father engage in } \\
\text { diets specifically to lose weight? }\end{array}$ & 2.0 & 0.7 & $120(23.8)$ \\
\hline $\begin{array}{l}\text { 6. Did your father engage in 'fat } \\
\text { talk,' that is degrading talk } \\
\text { specifically about his weight, } \\
\text { shape, or size? }\end{array}$ & 2.2 & 1.2 & $58(11.7)$ \\
\hline $\begin{array}{l}\text { 7. Did your father encourage } \\
\text { you to diet? }\end{array}$ & 1.4 & 2.2 & $76(15.2)$ \\
\hline $\begin{array}{l}\text { 8. Did your father criticize your } \\
\text { weight, shape, or eating } \\
\text { behaviors? }\end{array}$ & 1.2 & 2.1 & $100(20.3)$ \\
\hline
\end{tabular}

${ }^{a}$ Sample size differs by question due to the skip pattern inherent in the questionnaire. Therefore, not every participant will answer all the questions if they answer "no" to one of the initial questions in that series.

\subsubsection{Contingency Analysis Findings}

The contingency analysis suggested that participants had significantly greater odds of remembering maternal (rather than paternal) dieting, fat talk, encouragement to diet, or criticism of 
participant weight, shape, or eating behavior. Participants had 5.8 times (95\% CI: 3.46, 9.81) greater odds of reporting that their mother (rather than their father) encouraged them to diet and 4.0 times (95\% CI: $2.5,6.4)$ greater odds of recalling maternal (rather than paternal) criticism of their weight, shape, or eating behavior. (Table 2.3)

Table 2.3. Odds ratios (OR) and $95 \%$ confidence intervals $(95 \%$

CI) of recall of maternal dieting, fat talk, and criticism by paternal dieting, fat talk, and criticism $(\mathrm{N}=507)$

\begin{tabular}{|c|c|c|}
\hline Variable & OR $(95 \% \mathrm{CI})$ & $\mathbf{p}$ \\
\hline Dieting $(n=502)$ & & $.017 *$ \\
\hline Father $(n=119)$ & 1.00 & \\
\hline Mother $(n=202)$ & $1.7(1.1,2.5)$ & \\
\hline Fat Talk $(n=493)$ & & $.0002 *$ \\
\hline Father $(\mathrm{n}=57)$ & 1.00 & \\
\hline Mother $(\mathrm{n}=161)$ & $2.8(1.6,4.9)$ & \\
\hline $\begin{array}{l}\text { Encouraging Dieting } \\
(n=498)\end{array}$ & & $<.0001 * *$ \\
\hline Father $(\mathrm{n}=74)$ & 1.00 & \\
\hline Mother $(n=120)$ & $5.8(3.5,9.8)$ & \\
\hline $\begin{array}{l}\text { Criticizing Weight, } \\
\text { Shape, or Eating } \\
(n=491)\end{array}$ & & $<.0001 * *$ \\
\hline Father $(\mathrm{n}=98)$ & 1.00 & \\
\hline Mother $(n=154)$ & $4.0(2.5,6.4)$ & \\
\hline
\end{tabular}

Subgroup analyses suggested that participants had greater odds of remembering maternal encouragement to diet and criticism than paternal. This was consistent for both male and female participants. Female participants were 3.1 times more likely to recall maternal than paternal encouragement to diet $(95 \%$ CI: $1.9,5.2)]$ and 4.1 times more likely to recall maternal criticism $(95 \%$ CI: $2.5,6.8)$. Male participants had almost 60 times $[\mathrm{OR}=58.1(6.47,522.05)]$ greater odds of recalling maternal than paternal encouragement to diet (a Fisher's Exact Test was used due to small cell size) and 3.4 times $(95 \% \mathrm{CI}: 1.1,11.2)$ greater odds of recalling maternal rather than paternal criticism. 
Further contingency analyses showed how recalled indirect parental feedback was associated with recalled direct parental feedback. If a participant recalled maternal fat talk, they were $7.6(95 \%$ CI: $4.9,11.7)$ times more likely to recall that their mother also encouraged them to diet and $4.2(95 \%$ CI: $2.8,6.1)$ times more likely to remember maternal criticism of their shape or weight $(\mathrm{p}<.0001)$. Similarly, recall of maternal dieting was significantly associated with increased odds of recalled maternal encouragement to diet (OR: 3.0; 95\% CI: 2.0, 4.4; $\mathrm{p}<.0001)$. Paternal influences were also significant with recall of paternal fat talk significantly associated with paternal encouragement to diet (OR: 3.3; 95\% CI: 2.0, 5.4; $\mathrm{p}<.0001)$ and paternal criticism (OR: 2.2; 95\% CI: 1.4, 3.5; $\mathrm{p}=.0016$ ). Additionally, if participants recalled their father dieting, they were 6.6 (95\% CI: 3.6, 12.0) times more likely to recall that their father also encouraged them to diet and 8.8 (95\% CI: 4.8, 16.0) times more likely to remember paternal criticism of their shape or weight $(\mathrm{p}<.0001)$. The only non-significant association was recall of maternal dieting with recall of maternal criticism of the participant's weight or shape $(\mathrm{OR}=1.4 ; 95 \% \mathrm{CI}: 1.0,2.0 ; \mathrm{p}=.07)$.

\subsubsection{Multivariable Linear Regression Findings}

Results of the multivariable linear regression are displayed in Table 2.4. There was no evidence of multicollinearity and model assumptions were met. Findings suggested a significant relationship between BMI and recall of maternal encouragement to diet. For those who recalled maternal encouragement to diet, adult BMI was 1.3 points higher than the intercept of $25.4(\mathrm{p}<.0001)$. When stratified by gender, men did not have any significant associations with BMI, while women still demonstrated a significant relationship between BMI and maternal encouragement to diet $(\beta=1.3$; $\mathrm{p}=.0003)$. 
Table 2.4. Unstratified multivariable linear regression with indirect and direct predictors of adult $\mathrm{BMI}(\mathrm{N}=507)$

\begin{tabular}{|c|c|c|c|c|c|c|}
\hline & & & $\mathbf{F}$ & df & $\mathbf{p}$ & $\mathbf{R}^{2}$ adj. \\
\hline Overall model & & & 4.8 & 8 & $<.0001$ & 0.06 \\
\hline Predictors of BMI & $\boldsymbol{B} \pm \mathrm{SE}$ & $\mathbf{p}$ & & & & \\
\hline Intercept & $25.4 \pm 0.4$ & $<.0001$ & & & & \\
\hline Maternal Dieting & $0.3 \pm 0.3$ & 0.20 & & & & \\
\hline Maternal Fat Talk & $0.2 \pm 0.3$ & 0.57 & & & & \\
\hline $\begin{array}{l}\text { Maternal } \\
\text { Encouragement to Diet }\end{array}$ & $1.3 \pm 0.3$ & $<.0001 *$ & & & & \\
\hline Maternal Criticism & $0.0 \pm 0.3$ & 0.98 & & & & \\
\hline Paternal Dieting & $0.0 \pm 0.3$ & 0.92 & & & & \\
\hline Paternal Fat Talk & $-0.6 \pm 0.4$ & 0.17 & & & & \\
\hline $\begin{array}{l}\text { Paternal Encouragement } \\
\text { to Diet }\end{array}$ & $0.5 \pm 0.4$ & 0.27 & & & & \\
\hline Paternal Criticism & $0.1 \pm 0.4$ & 0.84 & & & & \\
\hline
\end{tabular}

\subsection{Discussion}

Preliminary study findings highlight three main findings. First, among non-clinical participants, there is a high recall of direct and indirect parent behaviors around weight and dieting. Second, both male and female participants recall maternal feedback more frequently than paternal feedback.

In line with our first hypothesis, participants are significantly more likely to recall maternal dieting, fat talk, encouragement to diet, and criticism of weight and shape than paternal feedback. Additionally, both female and male participants are more likely to recall maternal direct and indirect feedback rather than paternal. This may be due to the societal norm of female dieting or that mothers 
may have spent more time with their children in this sample than fathers. One interpretation of these results is that these factors were significant enough for the participants to remember them years later and could be potentially detrimental, especially for individuals with a genetic predisposition for an eating disorder.

Consistent with our secondary hypothesis, participants who recalled maternal encouragement to diet reported a higher adult BMI. This is consistent with existing literature and highlights the association between maternal feedback and offspring BMI (Wansink et al., 2017). Because this study is correlational it is hard to determine the direction of effect. It may be that maternal encouragement to diet was in response to higher childhood BMI or that greater maternal encouragement to diet led to a later higher adult BMI.

We analyzed additional constructs to Costanzo \& Woody's (1985) original OBPM, including child gender, parental concern about their own weight, and indirect and direct parental feedback that may be significant influences in forming perceptions of body image and eating behavior practices. We observed that both female and male participants were more likely to recall maternal rather than paternal feedback. Thus, this topic needs to be addressed among men since this recall of maternal feedback is not limited to female participants. Recent research has examined disordered eating and body image among men, however, many of the studies examining maternal and paternal direct and indirect feedback did not include male participants (Wansink et al., 2017; Coffman et al., 2016; Sharpe et al., 2013). Parental weight concern is an important example of indirect feedback that has been addressed by some studies. In the current study, there is a considerable recall of both maternal and paternal fat talk and parental dieting, suggesting that participants were aware of this indirect feedback - and potentially susceptible to this feedback - as children. Lastly, indirect and direct feedback were included in our proposed Obesity \& Dieting Proneness Theoretical Model separately because they appear to influence each other, as evidenced by our findings. Results suggest that participant recall of 
parental indirect feedback (e.g. parental fat talk or dieting) was also significantly associated with recall of direct parental feedback (e.g. encouraging a child to diet or criticizing a child's weight or eating). This relationship is shown by the arrow between indirect and direct feedback in Figure 1.

Parents, especially those with eating disorder histories, often express worries about modeling healthy eating or talking with their children about weight and health (Runfola et al., 2013). These results suggest the need for parental interventions to educate parents about potential indirect and direct feedback to children around eating, weight, and shape. Nonetheless, additional research is necessary to further replicate our findings.

\subsubsection{Limitations}

This study has several notable limitations. First, the questionnaire used in this study was exploratory; however, it demonstrated preliminary acceptable estimates of internal consistency, reliability, and validity. Second, the greater recall of maternal dieting, fat talk, and criticism or encouragement to diet could be due to the heightened weight and size pressures on women. There could be additional recall bias from adults with greater body/weight concerns more likely to recall childhood issues or the association could be mediated by genetic vulnerabilities rather than environmental factors. Third, the linear regression is limited by not having access to childhood BMI, providing the likelihood that the relationship between BMI and recall of maternal encouragement to diet could be in response to a higher childhood BMI. However, there were no significant associations for recall of paternal feedback in the linear regression or for any other maternal predictors. Fourth, the sample had a large proportion of female participants, which appeared to explain the significant association between recalling maternal encouragement to diet and adult BMI in the linear regression. When analyses were stratified by gender, there was no significant relationship between recall of maternal encouragement to diet and adult BMI for male participants. Therefore, future research with a more equal proportion of male and female participants will be needed to understand this association. 
Fifth, findings cannot be considered causal owing to the cross-sectional study design. It could be that participants with more weight and body image concerns now are more likely to recall parental feedback. Longitudinal studies will be needed to clarify this association. Sixth, due to constraints with the length of the questionnaire, we did not ask about - and therefore, could not control for - body image, body dissatisfaction, or disordered eating among participants. Finally, results are not considered generalizable because of the convenience sampling methodology.

\subsection{Conclusion}

Results from this preliminary study suggest how adult participants remember potential environmental childhood triggers. Additionally, participants who recalled parents providing indirect feedback, such as dieting or talking negatively about their weight or shape, are also more likely to report that their parents encouraged them to diet as children. Future research is needed to expand this topic and the potential implications of these forms of social modeling. A modified Obesity and Dieting Proneness Theoretical Model proposes factors that may be central to understanding this topic. Further research will need to capture information on body image, body dissatisfaction, and disordered eating among participants in order to control for those variables to elaborate this relationship. Additionally, translational research is needed to find the best ways to educate parents about modeling healthy lifestyles and discussing health rather than weight with their children. 


\title{
Chapter 3
}

\author{
$\operatorname{Aim} 2$ \\ Waking up every day in a body that is not yours: \\ A Qualitative Research Inquiry into the Intersection between Eating Disorders and Pregnancy \\ IRB Protocol \#: 1602021245
}




\subsection{Introduction}

"Waking up every day in a body that is not yours" is a quote that may resonate with many pregnant women, but for a pregnant woman with an ED or history of an ED, this bodily disconnect is even more pronounced. Although they realize the bodily changes are necessary for the baby to grow, it is harder for women with, or history of, an ED to accept those changes. Instead, the weight and shape changes become constant triggers, making pregnancy a time of particular physical and psychological strain (Zerwas \& Claydon, 2014).

The purpose of this qualitative descriptive study was to describe the intersection between pregnancy and EDs for women with these disorders who have experienced or want to or do not want to experience a pregnancy. A qualitative study is necessitated for this area of research because the topic is complex and requires the participants' perspectives and in-depth insight to truly understand their lived experiences. Only through such rich detail can we hope to understand the intersection between EDs and pregnancy from the experience of women who face those issues.

\subsubsection{Background}

Women with EDs experience many battles throughout their disease, but considerably more when they face the prospect of pregnancy. Women with EDs are more likely to negatively react to finding out they are pregnant, although this difference in attitudes between women with EDs and controls disappears at 18-weeks' gestation (Easter et al., 2011). These negative reactions are thought to be due to a few different factors (Zerwas \& Claydon, 2014). First, women with anorexia nervosa (AN) are significantly younger at their first pregnancy than comparison groups, making them potentially less emotionally or developmentally prepared for the pregnancy (Bulik et al., 2009; Micali et al., 2007). Another factor is that women with EDs are more likely than women without EDs to experience an unplanned pregnancy. Those with AN, for example, are twice as likely to have an unplanned 
pregnancy and those with bulimia nervosa $(\mathrm{BN})$ have a 30-fold increased chance compared with healthy controls (Bulik et al., 2010; Morgan, Lacey, \& Chung, 2006). It is still not completely clear why there are these considerably elevated rates of unplanned pregnancy among women with eating disorders, but one theory is that it could be due to patients' belief that amenorrhea (cessation of menstruation) or oligomenorrhea (infrequent menstrual periods) are related to fertility and therefore indicate they cannot get pregnant (Bulik et al., 2010). Due to this mistaken belief of unlikely pregnancy, women with EDs may also be less likely to use adequate contraception. Therefore, with their negative attitudes towards pregnancy and higher risk of unplanned pregnancies, pregnancy and the transition to motherhood can be an extremely traumatic time for these women both psychologically and physically. Understanding that process is critical to helping improve pregnancy outcomes and maternal-fetal bonding among these women, as well as helping improve and tailor prenatal care to their unique needs.

There is limited research on the intersection of EDs and pregnancy (e.g. Abraham et al., 2001; Bulik et al., 2010; Micali et al., 2007; Morgan, Lacey, \& Chung, 2006; Zerwas \& Claydon, 2014) and very few studies are qualitative in nature (Clark et al., 2009; Tierney et al., 2011), which inhibits understanding this connection from a lived experience perspective. Two qualitative studies in particular built upon this gap but have limitations in describing the nature of this experience. For example, Clark et al. (2009) described that women found pregnancy experiences (like feeling the baby kick) to be protective against body dissatisfaction during pregnancy, although that body positivity did not extend into postpartum. Tierney et al. (2011) identified three types of women in their interviews: women who went into recovery during pregnancy and maintained that ED recovery postpartum, those that temporarily recovered during pregnancy, and those that were unable to give up ED behaviors during pregnancy. Both studies cited a need to be able to provide more information to women with EDs about expected body changes during pregnancy and to provide professional support to these 
women so that they can overcome issues of control that could inhibit a positive and healthy pregnancy. However, neither of the current qualitative studies compared participants across countries nor included participants from the United States; one was based in the United Kingdom (Tierney et al., 2011) and the other in Australia (Clark et al., 2009). Additionally, both studies also specifically included women who were or had been pregnant but did not look at women with EDs who were hoping to become pregnant one day, let alone address the concerns such women might have about becoming pregnant.

The purpose of this qualitative study is to describe the experience of pregnancy for women who have a current or past ED. The philosophical underpinning of this study was feminist theory, which addresses the various situations and institutions that women face, shaping their experience of the world (Olsen, 2011). The aim of most feminist theory approaches is to "correct both the invisibility and distortion of female experience in ways relevant to ending women's unequal social position" (Lather, 1991, p. 71). A transformative framework also guided our description because it operates under the tenet that knowledge is not neutral but based on a complicated web of power dynamics that reflect social relationships and that therefore, must be used to improve society (Mertens, 2003). This transformative framework is aligned with the purpose of this study - to aid a marginalized population, specifically women with past or present EDs - in order to help people and thus improve society (Mertens, 2009).

The specific aims of this study were to: 1) Describe the concerns that women with EDs feel in becoming pregnant, 2) Understand some of the unique barriers in prenatal care that women with EDs face and 3) Learn how women with EDs can be better supported throughout pregnancy to improve both maternal and child health outcomes.

\subsubsection{Personal Lens}

Qualitative research requires investigators to provide their own personal lens and background on research in order to check biases and ensure the trustworthiness of the data. This is a topic that the 
PI is very passionate about on a personal level, having struggled with AN for several years. The PI is in recovery now after relapsing twice; however, during her last relapse, she became pregnant, which drastically changed her need and desire to take care of herself for the sake of her child. The PI received extensive support from doctors, psychiatrists, and nutritionists during her pregnancy, had a healthy pregnancy and subsequently, a healthy baby. However, the process of recovering from AN during pregnancy was incredibly challenging on an emotional level and the PI encountered many individuals who did not understand the pregnancy process from the viewpoint of a woman with an ED. Because of this experience, the PI felt it was imperative to understand this experience from women who have been pregnant and also the unique concerns that women have who want to (or do not want to) become pregnant and how their EDs affect these goals. The PI's own experience is the reason for taking a transformative framework approach to this study because she understood the importance of translational research to change practice and prenatal care so that women with EDs are better supported during their pregnancies.

\subsection{Methods}

\subsubsection{Participants}

Study participants were recruited via personal referral and Facebook by asking for women (aged 18 and older) who have an eating disorder or a history of an eating disorder, and have been pregnant and those who want or do not want to become pregnant. Inclusion criteria were as follows: current eating disorder or history of an ED, past pregnancy (either planned or unplanned), or desire/lack of desire to have a pregnancy. Individuals who were currently pregnant were excluded due to ethical concerns about enrolling pregnant women with EDs who may be nutritionally deprived. An advertisement was also used in recruitment and all interested participants were provided a cover letter further explaining the study (See Appendix B for IRB-approved advertisement and cover letter). 
Due to the PI's history of an eating disorder and her transparency on social media about her history, she was better positioned to have access to individuals who met the inclusionary criteria. Pseudonyms were used to protect the participants' identities and were chosen using a random name generator. A total of 15 participants were interviewed. Eight participants who volunteered to participate were acquaintances or friends of the PI. Another friend acted as a gatekeeper to provide the PI with a total of five women who had been pregnant. Four of the five women were interviewed for this study; the fifth agreed to be in the study and was scheduled, but could not participate due to a family emergency, after which the PI was unable to get back in contact with her. A dissertation committee member suggested two further participants: specifically, mothers who had blogged about their experiences of being pregnant with an ED. Therefore, this was a convenience sample, but purposive since individuals were specifically selected who could help to answer the research questions (Creswell, 2013). Additionally, all participants were made aware that the PI had a history of an ED and had been pregnant.

\subsubsection{Human Subjects}

Participants were asked if the sessions could be audio-recorded and were assured that identifying information would be removed and would not be used in any reports or published materials. Any documents (such as diaries or blogs) were also de-identified before quotes were used. This study was filed with West Virginia University's Institutional Review Board and approval was obtained (IRB: 1602021245). A copy of the interview protocol including questions and probes can be found in Appendix C. A list of resources and referrals for ED treatment and support was created for the purpose of being provided to any women who became distressed during the interviews or who expressed interest in ED resources (see Appendix D). None of the participants became distressed, but one expressed a desire for more resources and one mentioned wanting to get treatment at some point; the resource and referral list was sent to both women. 


\subsubsection{Data Collection}

Interviews were the primary unit of data collection, which is appropriate given that there was very sensitive and confidential information to be gathered that might not be as readily shared in a group format, such as through focus groups (Creswell, 2013). The PI conducted individual interviews with participants, each lasting approximately a half-hour. These interviews were conducted by phone or Skype, depending on the participant's convenience and preference. Participants were read a consent script and asked if they consented to participate before interview questions were asked. Participants also completed a one-page demographic form prior to the interview, in order to gather information regarding their age, highest level of education, current weight and height (if women did not feel comfortable providing their weight, they were not required to), number of children and year of first delivery, and current employment (See $\underline{\text { Appendix E)}) . ~ T h i s ~ f o r m ~ w a s ~ s e n t ~ o u t ~ a h e a d ~ o f ~ t i m e ~ t o ~ s a v e ~}$ time during the scheduled interview and to allow for the collection of some sensitive information such as weight that participants might feel more comfortable answering in writing.

Audio recording was conducted using QuickTime Player` for phone interviews and eCamm® for Skype interviews. Field notes were also taken throughout the interview on a printed interview protocol with information written under each pertinent question. Member-checking is a technique commonly used in qualitative research to improve the accuracy, credibility, and internal validity of a study and involves giving the informants the opportunity to check the authenticity of the material that is being collected (Creswell, 2013). In this study, member-checking was conducted by verifying information or repeating statements back to participants during interviews to check the validity of the information being captured. Member-checking was also conducted by circling back with participants, post-interview, to clarify any areas that remained unclear.

A few $(n=4)$ participants volunteered to share pertinent diary or blog entries from during the times they were pregnant. Therefore, method triangulation was used and quotes from the diaries and 
blogs were also captured in this study through document analysis (consistent with triangulation recommendations from Creswell, 2013 to use "multiple and different sources, methods, investigators, and theories to provide corroborating evidence"; p. 251). We also employed source triangulation by drawing perspectives from women who had children as well as nulliparous women.

\subsubsection{Data Analysis}

Data analysis was conducted in the form of thematic analysis, which is the act of gleaning major and subthemes from qualitative data (Creswell, 2013). The analysis was based on 15 verbatim transcripts from audio recordings; transcription of five interviews was conducted by the study's PI using VideoLan's VLC® (Version 2.2.2) multimedia player to slow the audio recordings. The other 10 interviews were transcribed using the transcription service Rev.com. A non-disclosure agreement was put into effect with this service due to the sensitive information within the interviews. All interviews transcribed by Rev.com were then reviewed by the PI while listening to the original audio content.

The coding of the transcripts followed a standard qualitative methodological process (e.g., Creswell, 2013), starting with an iterative transcript assessment and ending with theme development. For example, each transcript was read post-transcription, and each one was iteratively read once another transcript was complete. In this way, and according to standard practice, transcripts were continually compared and contrasted between each other in order to assist with thematic analysis. Each transcript was also compared to the PI's interview notes. After those initial readings, the PI went through each transcript and inductively assigned codes to sections of text that addressed a similar issue. NVIVO 11@ was used facilitate all aspects of data management and coding. Some codes were in vivo using the guiding theories for the study and the rest were based on subjective assessment of the best encompassing descriptor (Creswell, 2013). Once all transcripts were coded, the codes on each transcript were reviewed in light of any new codes that may have emerged. 
All codes from the transcripts were tagged and then similar codes were grouped to create categories. Codes and categories that were repeatedly portrayed in transcripts then rose to the level of themes. Codes and categories were reviewed several times by the PI to ensure that codes and categories were collapsed or split as necessary into major themes. During that process - and according to standard qualitative research analysis - a few themes were again collapsed when it appeared that the lines between different themes blended better into one comprehensive theme (Saldãna, 2009).

A second coder also reviewed a total of four transcripts (26.7\% of the sample), after training on the protocol, procedure, and coding system; this proportion of the transcripts is adequate according to Loewen \& Plonsky (2015, p. 164) who recommend a second coder to code at least $20 \%$ of the sample. This second coder was also trained with two sample interviews prior to coding to ensure inter-rater reliability. Cohen's Kappa was calculated by both hand calculation and through NVIVO 11@.

\subsection{Results}

\subsubsection{Inter-rater Reliability}

Hand calculation of Cohen's Kappa was conducted according to Bakeman \& Gottman's (1997) method for calculating inter-rater reliability for qualitative research. Kappa values were calculated for each of the four transcripts and then averaged, resulting in an average kappa value of 0.79 , which indicates good agreement (Altman, 1991). NVIVO 11( kappa values were consistent with the hand calculation, varying only by two to three hundredths places.

\subsubsection{Description of Participants}

Of the 15 participants interviewed, there were nine women with children and six nulliparous women. Participant demographics can be additionally seen in Tables $\mathbf{3 . 1}$ and 3.2, but the women will also be briefly described here. Ages listed are ages at time of interview. The nine mothers were named 
via the random name generator: Amelia, Nancy, Charlotte, Ann, Kathryn, Ruby, Nicole, Rose, and Laura. Amelia, age 27, is a mother of one, the result of an unplanned pregnancy at age 19. She continues to suffer from an Eating Disorder Not Otherwise Specified (EDNOS) - although EDNOS was the self-reported diagnosis, this diagnosis is now classified as 'Other Specified Feeding or Eating Disorder' in DSM-5 (APA, 2013). Nancy, 38, is a mother of three, with a past history of AN (purging subtype); she was only just in recovery when she became pregnant with her first, at age 28. Charlotte, 30, suffers from BN, which impacted all of her three pregnancies, two of which were unplanned. Ann, age 55, has a history of AN, which influenced both of her pregnancies and continued for several years after her giving birth. Ann's biological mother had AN, but Ann was raised by an adopted family from the age of 18 months. Kathryn, 31, also has a past diagnosis of AN, and had one child after being in recovery for several years. Ruby, also age 31, has a history of $\mathrm{BN}$ and had one child while in recovery although experienced some disordered eating symptoms throughout pregnancy. Nicole, 34, has a history of EDNOS, and became pregnant with her first child soon after coming out of inpatient treatment; her pregnancy, although not unplanned, was also not expected to occur so soon after. Rose, 32, had BN when she was much younger and had been in recovery for almost 20 years before having her first child. Laura, 41, also experienced AN when she was younger and had also been in recovery for about 20 years at the time of her pregnancy.

Six participants did not have children and had mixed feelings about future pregnancies due to their EDs; the six are: Melissa, Maria, Marilyn, Kimberly, Sarah, and Louise. Melissa, age 28, had a previous abortion from an unplanned pregnancy in 2014 and continues to suffer from BN. Maria, age 29, with a past history of EDNOS, had recently become engaged and expressed a desire to become pregnant after a few years of marriage. Marilyn, 25, has a history of binge eating disorder (BED) and was currently experiencing $\mathrm{BN}$ at the time of this study; due to her ED, she was not actively thinking of becoming pregnant, although theoretically considered surrogacy or adoption. Kimberly, 28, has a 
history of $\mathrm{AN}$ and $\mathrm{BN}$, and does not want to have children, in part because of her ED history. Sarah, 25 , has current $\mathrm{BN}$, and is considering potentially adopting a child in the future. Louise, age 29 , has a history of $\mathrm{AN}$ and $\mathrm{BED}$, and is considering becoming pregnant in the next few years.

Due to the high rates of unplanned pregnancy in the ED population, it is also important to note the prevalence within this group of women. There were a total of 17 pregnancies reported by the women, including two abortions; of those, six were unplanned, including those two abortions, and eleven pregnancies were planned.

\subsubsection{Thematic Analysis}

A total of six themes emerged from the iterative process of coding and categorizing. They were: Control, Disclosure to Others, Battle Between Mothering \& ED, Intergenerational Transmission, Weight and Body Image Concerns, and Coping Strategies. One theme, Battle Between Mothering \& ED also had three subthemes. A detailed description of these themes and subthemes can be found in Table 3.3. 
Table 3.1. Maternal Demographic Characteristics

\begin{tabular}{|c|c|c|c|c|c|c|c|c|c|}
\hline Participant & Amelia & Nancy & Charlotte & Ann & Kathryn & Ruby & Nicole & Rose & Laura \\
\hline Age & 27 & 38 & 30 & 55 & 31 & 31 & 34 & 32 & 41 \\
\hline $\begin{array}{l}\text { Relationship } \\
\text { Status }\end{array}$ & In a relationship & Married & Married & Married & Married & Married & Married & Married & Divorced \\
\hline Location & New York, U.S. & $\begin{array}{l}\text { Virginia, } \\
\text { U.S. }\end{array}$ & England, UK & California, US & Wisconsin, US & New Jersey, US & Georgia, US & Maryland, US & $\begin{array}{c}\text { Massachusetts, } \\
\text { US }\end{array}$ \\
\hline Race & Slavic/White & Caucasian & White, British & Caucasian & White & White/Caucasian & Caucasian & Caucasian & Caucasian \\
\hline ED Type & $\begin{array}{l}\text { EDNOS* } \\
\text { current }\end{array}$ & $\begin{array}{l}\text { Past AN } \\
\text { (purging } \\
\text { type) }\end{array}$ & Bulimia & Past AN & Past AN & Past BN & Past EDNOS & Past BN & Past AN \\
\hline $\begin{array}{l}\text { ED Active in } \\
\text { Pregnancy }\end{array}$ & No & No & Partially & Yes & No & No & No & No & No \\
\hline BMI & 17.8 & 26.6 & 24.2 & 18.5 & 21.1 & 30.7 & $\begin{array}{c}\text { Height 5'9", } \\
\text { weight not } \\
\text { provided }\end{array}$ & 21.5 & 29 \\
\hline Education & High School & College & College & $\begin{array}{l}\text { Graduate } \\
\text { School }\end{array}$ & Graduate School & Graduate School & College & Graduate School & Graduate School \\
\hline $\begin{array}{l}\text { No. of } \\
\text { Children }\end{array}$ & 1 & 3 & 3 & 2 & 1 & 1 & 2 & 1 & 1 \\
\hline Child Sex & $\mathrm{F}$ & $\mathrm{F}, \mathrm{M}, \mathrm{M}$ & $\mathrm{F}, \mathrm{F}, \mathrm{F}$ & $\mathrm{F}, \mathrm{F}$ & $\mathrm{F}$ & $\mathrm{F}$ & $\mathrm{M}, \mathrm{F}$ & $\mathrm{M}$ & M \\
\hline $\begin{array}{l}\text { 1st }^{\text {st }} \text { Child's } \\
\text { Birth Year }\end{array}$ & 2009 & 2006 & 2005 & 1986 & 2014 & 2015 & 2012 & 2016 & 2013 \\
\hline Current Job & Pharmacy Tech & $\begin{array}{c}\text { Digital } \\
\text { Marketing } \\
\text { Consultant }\end{array}$ & $\begin{array}{l}\text { Not currently } \\
\text { employed }\end{array}$ & $\begin{array}{c}\text { Certified } \\
\text { Psychotherapist }\end{array}$ & $\begin{array}{l}\text { Research } \\
\text { Associate } \\
\text { (Postdoc) }\end{array}$ & $\begin{array}{l}\text { Graduate } \\
\text { Teaching } \\
\text { Assistant }\end{array}$ & $\begin{array}{l}\text { Executive } \\
\text { Director }\end{array}$ & Biologist & $\begin{array}{l}\text { Not currently } \\
\text { employed }\end{array}$ \\
\hline
\end{tabular}

*Eating Disorder Not Otherwise Specified, now labeled 'Other Specified Feeding or Eating Disorder' in DSM-5

$\mathrm{AN}=$ anorexia; $\mathrm{BN}=$ bulimia $; \mathrm{BED}=$ binge eating disorder; EDNOS = Eating Disorder Not Otherwise Specified 
Table 3.2. Nulliparous Demographic Characteristics

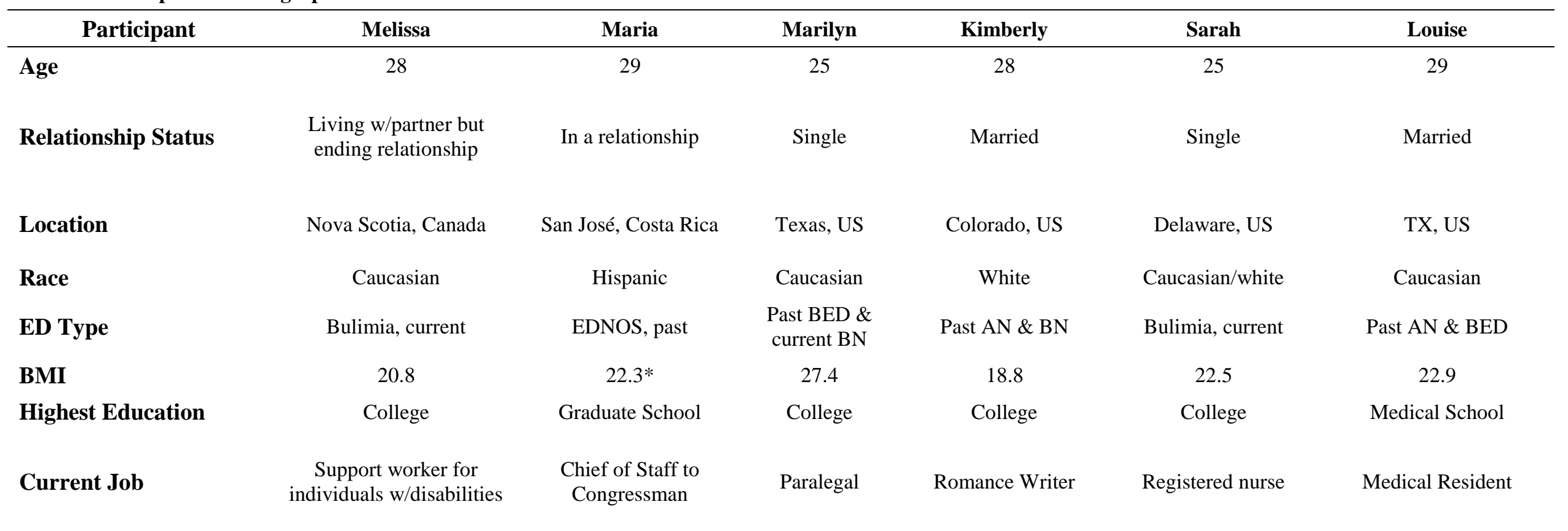

* Since last weighing, but has not varied much

$\mathrm{AN}=$ anorexia; $\mathrm{BN}=$ bulimia; $\mathrm{BED}=$ binge eating disorder; EDNOS = Eating Disorder Not Otherwise Specified 
Table 3.3: Themes/Subthemes

\begin{tabular}{|c|c|}
\hline Theme/Subtheme & Description \\
\hline Control & $\begin{array}{l}\text { Mentions of control either regarding their } \\
\text { eating disorder or pregnancy/future pregnancy }\end{array}$ \\
\hline Disclosure to Others & $\begin{array}{l}\text { Choice ( } \& \text { decisions in choice) to tell others } \\
\text { about their ED, including family/friends or } \\
\text { medical professionals }\end{array}$ \\
\hline Battle Between Pregnancy \& ED & $\begin{array}{l}\text { The internal battle expressed between a } \\
\text { woman's ED \& her mothering instinct }\end{array}$ \\
\hline Decision to Have Child & $\begin{array}{l}\text { The factors involved in decided whether to } \\
\text { have a future child or keep/abort an } \\
\text { unplanned pregnancy }\end{array}$ \\
\hline Emotions Towards Pregnancy & $\begin{array}{l}\text { Emotions towards pregnancy or initial } \\
\text { reactions upon becoming pregnant }\end{array}$ \\
\hline Focus on Child/Greater Good & $\begin{array}{l}\text { Focusing on the wellbeing of the child or } \\
\text { sacrificing oneself for the 'greater good' }\end{array}$ \\
\hline Intergenerational Transmission & $\begin{array}{l}\text { Worry regarding whether their children or } \\
\text { future children would also suffer from EDs or } \\
\text { body image concerns }\end{array}$ \\
\hline Weight \& Body Image Concerns & $\begin{array}{l}\text { Concerns about body image or weight } \\
\text { primarily regarding pregnancy (including } \\
\text { pregnancy weight gain \& loss, as well as OB } \\
\text { weight checks) }\end{array}$ \\
\hline Coping Strategies & $\begin{array}{l}\text { Ways expressed to cope with the challenges } \\
\text { of a past or future pregnancy }\end{array}$ \\
\hline
\end{tabular}

\section{Control}

Individuals with EDs often feel that the ED provides them with a sense of control. Typically, when other aspects of their life feel unmanageable, the ED with its behaviors and rules acts as their constant. It is not surprising perhaps, then, that control stood out as a major theme for these women, in terms of how they talked about their eating disorder and their view on pregnancy and the need to feel an aspect of control going into, or during, pregnancy. 
Amelia spoke about the aspects of control that initiated and maintained her eating disorder and how being able to track everything helped her cope with the stress in her life. She also expressed how hard it was to have to give up that level of control because tracking her calories during pregnancy would, in her words, "completely drive me insane":

That was the hardest for me, because at the end of the day, I didn't have those numbers to look back on. I didn't know how I did that day. I didn't know like any of that so, it was a complete kind of loss of control and having to give that up because otherwise it was going to completely drive me insane. (Amelia, personal communication, Spring 2016)

Melissa recounted her dread of not being in control of her body and how her belief that she could control her body by starving it was invalidated when she became pregnant unexpectedly. I had that false, grandiose thought that I was in control of my body and I was calling the shots. And I wasn't and it was kind of surprising. It was a humbling experience ... I can't just march ahead and not take any precautions thinking that I can just starve my body into compliance. (Melissa, personal communication, 2016)

In contrast, Ann discussed trying to reassert control during her second pregnancy, since she felt she let others dictate what she did during her first pregnancy too much, which limited her ED behaviors and allowed her to gain more weight than she was comfortable with. Ann stated: "I am not doing whatever I did last time. No one's going to tell me how much I can exercise. No one's going to control me. I am never going in that body again."

\section{Disclosure to Others}

The issue of maintaining secrecy or disclosing information about the disorder relates to the previous theme of control. The women discussed reasons why they kept their disorder secret or when and why they would disclose it to others. Melissa said: "I kind of just latched onto an eating disorder, 'cause [sic] it was my best friend, my little secret, it was just mine." Similarly, Amelia revealed: 
I have never sought treatment and I am incredibly private about it and sort of like my one secret that I've always had and it's sort of one of those things, like they can take everything else away from me, but they can never take this away. (Amelia, personal communication, Spring 2016)

Even when women disclosed it to close others, such as their spouses, those partners still were not able to understand the depths of the problem, which still left the women feeling isolated. Ruby shared:

My husband has no conception of it. He knows a little bit about that I had an eating disorder and that I've yo-yo dieted and things like that, but he really doesn't understand the mental processes that go behind it, and the constantly being, I'm going to say obsessed. (Ruby, personal communication, Summer 2018)

This secrecy or disclosure in relation to medical professionals was also pertinent for women who had been pregnant, as well as those who were contemplating a future pregnancy. The decision whether to discuss information about their eating disorder with an obstetrician or midwife was mixed based on their concerns and what they hoped to gain from sharing that information. Some voiced that it was important to be completely open whereas others, like Amelia, expressed: "I wanted no treatment, no therapy, nothing like that. My OBs are physical doctors ... if I could physically take care of it myself, there was no need for me to involve them." Ann also strongly agreed with that sentiment: "My doctor never knew any of this because I kept everything. Everything. No one knew anything. No one in the whole world. Only me.”

Meanwhile, Charlotte discussed some of the challenges that were involved in trying to disclose an ED to medical professionals and wanting treatment:

I certainly felt a lack of ... communication between psychiatric care and maternity care and needing some sort of, it doesn't have to be a specialized midwife but just someone who can 
cross barriers and help you navigate your way through the pregnancy from both perspectives and not just one or the other. (Charlotte, personal communication, Spring 2016)

\section{Battle Between Pregnancy \& ED}

One of the most predominant themes for all of the women was the battle between pregnancy and their ED. This battle played out in various different subthemes, including their decision whether to have a child (including whether to keep or abort an unplanned pregnancy), their emotions (both positive and negative) towards pregnancy, and their focus on the child or the greater good of sacrificing themselves or their ED behaviors for a child.

However, the most prevalent theme was the overall internal battle that these women expressed having when trying to balance the demands of pregnancy and mothering with their ED or history of an ED. Many adopted a 'mama bear' standpoint once they became pregnant, which would force them to change their behaviors, but others stated that being pregnant and having an ED or history of an ED could not be mutually exclusive and were bound to interact.

Those who had been pregnant recounted that battle vividly. Amelia stated: "I swear to god, I had like a countdown to when she was born, and I didn't have to eat anymore." And Charlotte expressed frustration because of "the guilt of not being able to get myself together for the sake of the baby."

Ruby also mentioned how it was challenging not to use pregnancy as an excuse to engage in ED behaviors:

It becomes that battle where you're like well, I've got morning sickness. Should I use that as an excuse? I'm not going to say that I didn't do it once or twice, but it was mainly due to the fact that I was already throwing up anyway. (Ruby, personal communication, Summer 2016) Some dealt with this battle by figuratively disconnecting themselves from the pregnancy in order to push away the impact that their actions were having: 
Rosie Robot was who carried the babies, but when you think about a robot carrying a baby, they don't have any emotion. There's nothing there. Then there was me who was trying to be me. I tried. I didn't know I was doing this stuff at that time. I had no idea. I never wore any maternity clothes, ever. I wouldn't wear maternity clothes. I hid it. I hid my pregnancy. Our next-door neighbors ... didn't know I was pregnant until I was nine months pregnant. (Ann, personal communication, Summer 2016)

Even women who had not been pregnant speculated about their concerns of not being able to win this battle. For example, Kimberly expressed feeling: "so incredibly selfish ... I feel like that kind of hidden darkness could be brought out by something like pregnancy, so I don't know how that would work."

Subtheme: Decision Whether to Have Child:

Although many women wanted to become pregnant and planned to do so, several women had unplanned pregnancies and ultimately made different decisions about whether to continue with their pregnancies. Marilyn, when asked - like the other nulliparous women about a potential future pregnancy - expressed thinking about adoption or surrogacy because of the effect of pregnancy on the body and her ED.

Melissa recounted her decision to have an abortion:

I just couldn't do 9 months of that. Regardless of the after part, it was the process. So, I scheduled myself for a D\&C and had that procedure done I think the day before Christmas Eve and then went home for Christmas. (Melissa, personal communication, Spring 2016) Ann also had an abortion in college before having two later pregnancies that were planned and carried to term. "I just thought okay, I guess I'm having an abortion. I remember I scheduled my abortion on the day of a final. It was like I had a final at 11:00 and had the abortion at 2:00." 
Like Marilyn, Maria had considered surrogacy in the past during her ED, stating that: "I would rather carry my own kids. But at that time, I was ... seriously considering it just because I didn't trust myself enough I think to carry them." Sarah agreed, suggesting that she was more in favor of adoption than carrying a child herself.

Kimberly's decision not to have children was partially influenced by her ED history. "By the time I recovered I was well into my twenties and I just was so used to not wanting children that, you know, I didn't start at that point."

Subtheme: Emotions Towards Pregnancy

Although all women undergo a multitude of both positive and negative emotions towards pregnancies, especially unplanned pregnancies, these emotions can be even more fraught for women with EDs because of the personal struggles they face. The women with unplanned pregnancies described being scared, isolated or having an 'earth-shattering' moment upon finding out they were pregnant, whereas women with planned pregnancies expressed being delighted. Nulliparous women also weighed in on their emotions towards a theoretical future pregnancy.

Amelia, although, faced with an unplanned pregnancy, did recount in her personal diary at 5 months pregnant that she was "Getting kind of obsessed with the idea of being perfect. Perfect lover. Perfect wife. Perfect mother. Perfect anorexic."

Melissa, however, had a different reaction to her unplanned pregnancy:

I'd missed a period, but I didn't really think too much of that because ... that was normal for me and so ... I took a pregnancy test and it came up positive and it was probably the most earth-shattering moment of my life. (Melissa, personal communication, Spring 2016)

Women generally reacted to planned pregnancies with positive attitudes, although some women talked about how their ED affected their responses to pregnancy even during planned pregnancies. For example, during her one planned pregnancy, Charlotte expressed the disconnect between wanting her 
child and the negative emotions of being unable to change her ED behavior: "She was just very much loved and wanted ... even though I couldn't help but go through the exact same pattern.”

Many nulliparous women had concerns about future pregnancies, which Kimberly voiced.

"Yeah, I could see ... the whole something being inside your body as a little weird to me. And it kind of gives me that same itchy feeling I would get when I'd like eat food I considered bad."

Subtheme: Focus on Child/Greater Good

Many pregnant women also turn their focus to their baby or make sacrifices for what is seen as the greater good. Even women who did not plan on becoming pregnant described needing to 'bite the bullet' and deal with the challenges for the sake of the baby. This focus on the child or the greater good was what helped or might help them come out of their EDs enough to be able to have healthy pregnancies.

Amelia used her 'mama bear' instinct to force herself to eat or gain weight for the sake of the baby. "You have to keep telling yourself over and over you know ... this isn't about you anymore like it's never going to be about you again; it's about this child."

However, even women who had been in recovery for years had to use their focus on the child to help them through challenges in pregnancy associated with their history of an ED. Kathryn stated: “Eating disorder behaviors really just didn't feel like an option. Kind of like a, 'this isn't about me, this is about someone else." Ruby agreed, saying that: "You don't want to not eat because if you don't eat then your baby's not getting nutrition. It's more than just about you at that stage."

\section{Intergenerational Transmission}

All the women spoke about their concerns revolving around a theme of intergenerational transmission, which is defined here as the transmission of beliefs or norms around dieting, eating, and weight or shape across generations. This theme of intergenerational transmission reflected both the women's recollection of parental comments or actions growing up or their concerns about how their 
comments or actions could influence their child or a potential child. For example, Amelia described being very careful about trying to create normalcy for her child, to not label foods as good or bad, and to not talk about her body negatively. Still, she was concerned by the body hyper-awareness that her daughter displayed at a young age and was also concerned that she was a hypocrite by promoting advice that she herself did not follow:

I think my hardest thing is I'm a total hypocrite, because I'm telling her you know, well as long as you are healthy, and you drink enough water and you get enough sleep, and you exercise and everything, you're going to be fine ... while at the same time, I don't do that at all. (Amelia, personal communication, Spring 2016)

Melissa expressed her worries about the health ramifications on her child, which influenced her decision to abort her pregnancy. She also felt that it was hard for her to be a support worker for those with disabilities when she had her own struggles:

It's difficult to have an eating disorder and then be in the role that I'm in because I feel you know, it's the imposter syndrome, right like how am I trying to guide these kids into healthy decision making when secretly I'm you know, I'm participating in my own kind of battle? (Melissa, personal communication, Spring 2016)

Similarly, Maria divulged concern about having girls in a future pregnancy due to her history of an eating disorder, out of fear that they would be more likely than boys to also develop an eating disorder. 'I'm sort of scared of having girls ... I mean like it's a stereotype because guys can also have eating disorders. But like I'm more scared of having girls like, being a mother to girls."

Many women also shared how they felt they had been influenced by their parents' behaviors or weight commentary.

I've done a lot of reading about this, I think part of the reason that I feel like I have a weight problem is because my mother had a weight problem, and I was never really able to accept 
myself as beautiful. Just from this body image perspective ... I never learned what was healthy. (Ruby, personal communication, Summer 2016)

When I started dieting in middle school, she [Louise's mother] actually taught me how to diet. She taught me how to count calories. She taught me how to weigh food, and how to prepare food, and encouraged me in dieting until it became a little more obvious that it was out of hand. I mean obviously, she didn't mean for that to happen. (Louise, personal communication, Summer 2016)

Some women also expressed confidence that they would know the warning signs if their child developed an eating disorder and would therefore be able to get them into treatment earlier. Ann discussed a more direct intervention of how her husband stepped in to try to break the cycle for their children:

Fortunately, my husband, when they were in second grade and third grade ... because I was making like bizarre food. He completely took over food. He brought in chips. He normalized food for my girls. I think that probably saved them, considering that my own biological mother had an eating disorder and then I did. (Ann, personal communication, Spring 2016)

\section{Weight \& Body Concerns}

Weight and body image concerns are central to all eating disorders and so it is understandable that they would feature as a central theme among concerns about pregnancy. A common theme arose that although the women described the weight gain as being for a positive reason, they still could not reconcile it with their fear of weight gain.

A few also mentioned concerns about how to lose the baby weight healthily without triggering their eating disorder again. Maria expressed that, "objectively I know that people gain weight in pregnancy, but I think another fear would be how I would lose it afterward ... like how to do it in like 
the healthiest way possible." Sarah affirmed this fear, stating that "feeling like you have to lose weight is definitely a trigger for an eating disorder."

Weight checks with obstetricians during pregnancy were also an expressed fear, as well as how doctors would deliver information regarding weight gain. Some realized that being weighed at prenatal visits would be very stressful and thought about opting for, or did opt for, blind weighing. Maria thought she would choose that option, because she has chosen not to weigh herself and hoped that "somebody could know and do the checks, but it's information that I'd rather not know." However, the women differed in how they approached that experience. Kathryn was able to frame her weight checks positively, saying that "it didn't feel as revealing the way I think being weighed when not pregnant does ... it was kind of a relief ... it didn't really mean that I was a big, fat pig."”

Many women cited body image concerns as issues that they had or feared they would face during pregnancy. As Amelia's body changed she expressed feeling like she was losing her body or felt trapped in her body. "I feel so fleshy, swollen, flabby, jiggly, sloppy, oily, nasty, just FAT. It's fucking killing me. I miss restricting so badly ... this body is like a prison and I want out." Amelia, personal diary, c. 5 months pregnant

For Louise, projected body image issues included the expectation of the 'ideal' pregnant woman's body and her concern that she would not conform to that ideal.

This is going to sound terrible, but I'm not going to be one of those girls who look pretty when they're pregnant. They've got this nice slender body, and then they just have this little bump ... No, mine's going to be one of those like, "Well, I look like a marshmallow," because that's just how my body carries weight ... I know that that's how I'm going to look, and how I'm going to feel, and it scares me. (Louise, personal communication, Summer 2016) 


\section{Coping Strategies}

Both Amelia, during her pregnancy, and Maria when thinking about future pregnancy, noted some coping strategies that they did or would employ in order to help them through challenges.

Amelia particularly used distraction as a coping mechanism, as well as reframing the pregnancy as a "temporary medical condition." "I completely threw myself relentlessly into school at that point ... because I had to distract myself somehow." She also let go of her accountability with tracking her eating and calorie intake:

I forced myself to not keep track of things anymore ... because at the end of day I knew I had to be consuming at least 2300 calories and if I hit that, I'd be upset, but then if I didn't hit that,

I'd be upset. So, either way, you're never going to win in that situation ... I just had to give up accountability all together and just say fuck it. (Amelia, personal communication, Spring 2016)

Maria, however, thought she would rely on professional and social support throughout pregnancy. She believed she would need this help because, she stated: "I don't trust myself to make the best decisions regarding pregnancy. Maybe I would and I'm underestimating myself, but I would rather just have the outside support."

Ruby attempted to avoid engaging in eating disorder behaviors through conscious effort and her knowledge that the behaviors were unhealthy:

I go to the bathroom at the end of the meal and it's like I have to remind myself not to do it. I choose not to because I know it's not healthy, but it's a choice that I make. (Ruby, personal communication, Summer 2016)

\subsection{Discussion}

From these conversations with women discussing the intersection between EDs and pregnancy, a total of seven themes rose to the forefront. Some, such as Weight and Body Image Concerns and 
Control were expected due to the nature of EDs. However, others like Intergenerational Transmission were not. The fact that this theme arose to salience supports the results from $\underline{\text { Chapter } 2}$ by indicating that the transmission of dieting behavior is something that individuals recall or are concerned about. Additionally, it is critical to note that all these women expressed concerns about intergenerational transmission of their EDs or ED behaviors, even when the prospect of pregnancy was so frightening. For them to all raise this as a concern indicated that despite the battle between pregnancy and their ED that had existed or would exist, their focus on the well-being of the child won out.

The women's expressed concern regarding disclosure to their doctors indicates an area of potential improvement within prenatal care, but also within the educational systems. Medical professionals could benefit from further training about EDs in order to help provide more sensitive information and care - particularly around weight and weight gain - to women who have or have had an ED. It also would be beneficial to explore these women's coping strategies further to help provide psychological or social support on adjusting to pregnancy, especially since many pregnancies in women with EDs are unplanned.

Based on Tierney et al.'s (2011) assessment of the three routes women with eating disorders take during and after pregnancy, we also grouped the women who had been pregnant into those categories. Research from large prospective studies shows that remission rates are $78 \%$ for purging disorder (PD); $34 \%$ for BN for full remission and an additional 29\% for BN for partial remission (Bulik et al.; 2007). However, there are no estimates available for AN because there are currently no clear criteria to establish maternal underweight during pregnancy. This study focused on women with a previous pregnancy who had current or past AN, BN, and EDNOS. Kathryn (past AN), Ruby (past BN), Nicole (past EDNOS), Rose (past BN), and Laura (past AN) all went into recovery or were in recovery when they became pregnant and maintained that recovery postpartum. Nancy (with AN purging subtype) and Amelia (with EDNOS) recovered during pregnancy and Amelia went back to ED 
behaviors immediately postpartum. Nancy was able to maintain her recovery after her first pregnancy and had a minor relapse after her second pregnancy before going back into recovery. Both Charlotte (BN) and Ann (past AN) continued ED behaviors during their pregnancies. Charlotte was able to stop her behaviors when she was 5-6 months pregnant during each of her three pregnancies, but never went into recovery, and went back to behaviors immediately after pregnancy. Ann continued her ED behaviors throughout both her pregnancies and did not go into recovery until years after.

\subsubsection{Strengths}

The current study overcomes some of the limitations of previous qualitative studies by having a more international perspective, finding common themes across participants from the U.S., the United Kingdom, Canada, and Central America. Additionally, this study captures the experiences of childless women with EDs who did or did not want to become pregnant and how their eating disorder affected that choice. Those women who did have children also had a mixture of planned and unplanned pregnancies, providing a more nuanced understanding of those experiences.

Given the sensitive nature of these interviews and the personal details that interviewees were asked to share, conducting the interviews over the phone or via audio Skype actually may have facilitated sharing more personal information due to the increased distance between participant and interviewer.

Other strengths of this study were the steps taken to ensure its trustworthiness and internal validity (Lincoln \& Guba, 1985). For example, the method and source triangulation employed ensured credibility and confirmability of findings, as did member-checking to verify that transcripts were accurate and that the themes were representative. We used negative case analysis by including women who had not been pregnant; the fact that they highlighted similar concerns provides additional credibility. We provided a thick description of the methodology employed, allowing for the transferability of these findings. The dependability of the data was enhanced by using a second coder 
for over $20 \%$ of the sample; the resulting inter-rater reliability indicated good agreement between the coders. Additionally, we reached thematic saturation, reinforcing the internal validity of the selected themes.

\subsubsection{Limitations}

There are several limitations that need to be acknowledged. First, there is limited method triangulation because only a few $(n=4)$ provided documents for document analysis, so primarily thematic analysis from interviews was used. However, source triangulation was ensured by using both nulliparous women with children, which adds to the trustworthiness of the study and its data. Second, the transferability of the study is limited because the sample is comprised entirely of Caucasians, with only one identifying as Hispanic. Therefore, we cannot know if the results would vary in different racial or ethnic groups. The majority of the women were also highly educated, so again, future studies would need to include different demographic groups to understand the transferability of the results.

\subsubsection{Future Directions}

The compelling insights on pregnancy gathered from women who suffer from EDs provide useful areas for future intervention to improve the prenatal, pregnancy, and postpartum period for similar women. Their concerns, challenges, and experiences resonate with each other despite the differences in their situations, lending credence that the themes gathered in this qualitative descriptive study may be generalizable to a larger group of women. Future research will need to explore both racial and cultural differences, as well as differences in socioeconomic backgrounds that were not as varied among these 15 women.

For the PI, from a personal perspective, this research is both critically important, but also emotionally charged. Having experienced a pregnancy while in recovery from an ED, the PI could empathize with these women over their concerns and battles between the strength of their mothering instinct versus the power of their ED. Many of the women interviewed were appreciative of a study on 
this topic because they felt lost in a society that could not understand the battle that they had undergone or would one day face. Maria mentioned her worry that others would think some of her concerns superficial or vain. These are worries that women should not have to have. This research is playing a part in giving a voice to this population's concerns in order to help them through such an emotionally and physically challenging process. 


\title{
Chapter 4
}

\author{
$\operatorname{Aim} 3$ \\ An Exploratory Study of a Questionnaire on the Intergenerational Transmission of Dieting Behavior \\ within an Eating Disorder Population \\ IRB Protocol Number: 160928271
}




\subsection{Introduction}

Complex diseases, especially mental health conditions, commonly have a genetic underpinning as well as social or environmental factors or triggers; eating disorders are no different. The purpose of this study was to explore these social and environmental triggers to understand the intergenerational transmission of dieting behavior within an ED sample. This study builds on information garnered from Chapter 2 and using a further-refined questionnaire developed for a clinical population.

Weight dissatisfaction and dieting are associated with greater disordered eating (i.e., subclinical symptoms associated with EDs such as fasting to lose weight) and diagnosable eating disorders (EDs), especially for those genetically predisposed to an ED (Jacobi et al., 2004). Although EDs have largely been considered biological, brain-based disorders, the socio-environmental context is an underresearched area that provides triggers that could be mediated through intervention.

One area that has received less attention in the ED literature recently is the association between familial factors and EDs. A focus on an intergenerational cycle of risk offers promise in understanding both the genetic predisposition that children of parents with EDs will face, as well as some of the triggering factors that could be present in that familial context (Zerwas \& Bulik, 2016).

There has been a considerable push in the ED field towards a genetic understanding of EDs and less research on socio-cultural factors. Much of this is due to the parent-blaming that was previously inherent in EDs research especially in the 1980s and 1990s (Le Grange et al., 2010). That blame created a counter-movement led by parent and caregiver groups such as the International Eating Disorder Action (IED Action) and Families Empowered and Supporting Treatment of Eating Disorders (F.E.A.S.T) which have effectively demonstrated how imperative parents and caregivers are in ED recovery (FEAST, 2009). Parents and families do not cause EDs and their involvement is a crucial piece in recovery, especially recovery for a child or adolescent. However, parents simultaneously 
provide a social and environmental context for a child's eating and weight that cannot be completely discounted, as was illustrated in Chapter 2.

This connection can theoretically be understood as social reinforcement, which is part of Social Cognitive Theory (Bandura, 1986). Social reinforcement consists of comments or actions from close others that help reinforce a certain behavior or idea. In this context, parental or family social reinforcement helps to support and perpetuate the thin ideal through weight-related criticism, encouragement to diet, or modeling dieting behaviors (Stice, 1998). These external comments can then be internalized by individuals, potentially leading to body dissatisfaction and eating pathology. It is important to note that social reinforcement can also be used to support positive behaviors, emphasizing the need for positive rather than negative reinforcement (Bandura, 1986). Although genetics may determine who will be likely to internalize triggers within this context and in which individuals eating pathology will occur, without those triggers that gene-environment nexus may not occur (Bulik, 2005). Additionally, Objectification Theory was also used as a theoretical underpinning for this study to understand the lived experiences and mental health risks based on the sexual objectification of primarily women's bodies, but also men's bodies (Fredrickson \& Roberts, 1997). This theory posits that girls and women particularly are acculturated to internalize another's perspective as the primary view of their physical selves. Therefore, if another person tells them that they need to lose weight or criticizes their shape or weight, they will internalize that perspective and view themselves through that observer's lens rather than how they previously saw themselves.

For example, a recent meta-analysis of peer and family associations in adolescents found moderate effect sizes of family behavior with dieting, body dissatisfaction, and bulimic symptomatology $(r=0.221,0.224,0.225$ respectively; Marcos et al., 2013). Only one article considered the effect of parental modeling behavior (i.e. modeling eating or dieting behavior), so this indirect behavior could not be assessed; therefore, these effect sizes are from the direct association of 
parental encouragement to diet. However, among peers, modeling had a greater association with bulimic symptoms than encouragement to diet or weight-related teasing. Thus, there is empirical support for sociocultural theoretical models of EDs that suggest the family context could be a mediator of weight concerns and disordered eating (Marcos et al., 2013). More research is necessary, however, to understand both direct and indirect means of family feedback on a child's weight and body satisfaction.

Qualitative results from of $\underline{\text { Chapter } 3}$ of this dissertation with 15 women (both with and without children) who had EDs or a history of an ED provided first-person accounts of intergenerational transmission. Thematic analysis of these 15 interviews showed that women were highly concerned about intergenerational transmission of their EDs and wanted to model good behaviors and practice positive commentary for their children. Both direct and indirect pressures were consistently mentioned, both in terms of the participants' own upbringing (e.g. having a mother who dieted or encouraged them to diet, etc.) and in their fears of parenting their children (e.g. modeling ED behaviors, not knowing how to discuss weight). Therefore, even though parents do not cause EDs, parental modeling helps shape subsequent lifelong behaviors and this qualitative research showed that many parents and potential parents are concerned that their children could be susceptible to their behaviors or words.

The primary objective in this study was to understand the direct and indirect parental associations on a participant's weight and body image within a clinical cohort of patients with a current or past eating disorder. Additionally, based on previous research of external pressures such as family, peers and media on EDs (Lorasch-Gunderson, 2012, unpublished clinical research paper), we hypothesized that participants who recalled greater parental criticism or encouragement to diet would report greater ED symptomatology with higher Eating Pathology Symptom Inventory (EPSI) subscale scores (Forbush et al., 2013). Due to the uncertainty of whether direct or indirect associations exert more pressure upon children, these were individually explored with their relation to ED 
symptomatology as an exploratory study aim. The same revised Obesity and Dieting Proneness

Theoretical Model was used as in Chapter 2, except the outcomes also considered disordered eating (See Figure 4.1). Due to the nature of this questionnaire, we were better able to test the relationship between direct and indirect associations on a child's concern about their weight and disordered eating.

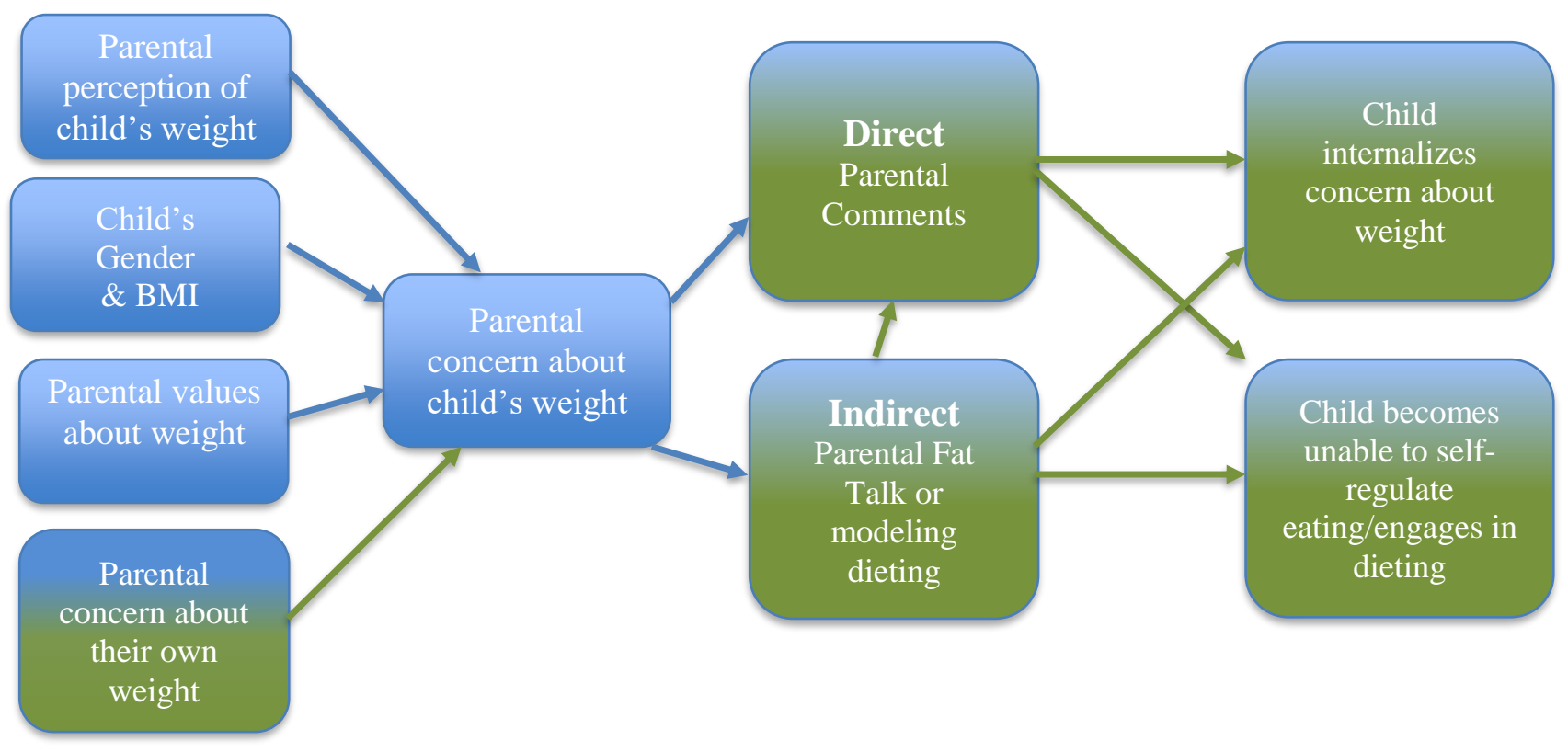

Figure 4.1. Revised Obesity \& Dieting Proneness Theoretical Model

*Credit to P.R. Costanzo \& E.Z. Woody; permission to use this image received from P.R. Costanzo: Costanzo, P.R., Woody, E.Z. (1985). Domain-specific parenting styles and their impact on the child's development of particular deviance: the example of obesity proneness. Journal of Social and Clinical Psychology, 3, 425-445.

\subsection{Methods}

\subsubsection{Questionnaire Development/Modification}

The original questionnaire from the study in Chapter 2 was revised using feedback from experts in psychometrics, EDs, and social and behavioral research (See $\underline{\mathbf{A p p e n d i x} \mathbf{F}}$ for survey). In addition, an ED-specific measure, the Eating Pathology Symptom Inventory (EPSI) was added to identify which ED symptoms are associated with direct and indirect feedback in order to broaden questionnaire outcomes (Forbush et al., 2013). This measure contains a total of 45 items on a Likert scale (ranging 
from Never to Very Often) and is comprised of eight subscales: Body Dissatisfaction, Binge Eating, Cognitive Restraint, Purging, Restricting, Excessive Exercise, Negative Attitudes towards Obesity, and Muscle Building. The EPSI has excellent convergent and discriminatory validity, as well as internal consistency (0.84-0.89) and reliability over a 2 and 4-week period (mean retest $r=0.73$ ). Participants were also asked whether their mother or father had a history of an eating disorder.

In order to determine whether direct or indirect associations exert more pressure, the questionnaire was revised to include both types of influences in two separate subscales with summary measures for each. Scores were averaged from individual items for each subscale, with higher scores in each subscale indicating greater negative indirect or direct parental influences.

Negative Indirect Parental Feedback Subscale: These types of feedback centered on parental behavior directed towards the participant, a participant's sibling, or another close relative. They included the following questions:

Q16 \& Q25 Did your MOTHER (FATHER) engage in diets specifically to lose weight (primarily for appearance-related concerns)?

O Never (1)

O Almost never (2)

O Some of the time (3)

O Usually (4)

O Almost always (5)

Q17 \& Q26 Did your MOTHER (FATHER) engage in 'fat talk,' that is degrading self-talk specifically about her/his weight, shape, or size?

O Never (1)

O Almost never (2)

O Some of the time (3)

O Usually (4)

O Almost always (5) 
Q20 \& Q29 Did your MOTHER (FATHER) ever encourage a sibling or close family member to diet to lose weight?

O Never (1)

Almost never (2)

Some of the time (3)

O Usually (4)

Almost always (5)

Q22 \& Q31 Did your MOTHER (FATHER) ever criticize a sibling or close family member's weight, shape, or eating behaviors?

Never (1)

O Almost never (2)

O Some of the time (3)

O Usually (4)

Almost always (5)

Negative Direct Parental Feedback Subscale: These types of feedback involved direct parental behavior towards the participant in question. They included the following items:

Q19 \& Q28 Did your MOTHER (FATHER) encourage you to diet to lose weight?

O Never (1)

Almost never (2)

Some of the time (3)

Usually (4)

Almost always (5)

Q21 \& Q30 Did your MOTHER (FATHER) ever criticize your weight, shape, or eating behaviors?

O Never (1)

Almost never (2)

O Some of the time (3)

O Usually (4)

O Almost always (5) 
Q33 \& Q35 Now that you are an adult (over 18), does your MOTHER (FATHER) encourage you to diet?

Never (1)

Almost never (2)

Some of the time (3)

O Usually (4)

Almost always (5)

Q34 \& Q36 Now that you are an adult (over 18), does your MOTHER (FATHER) criticize your weight, shape, or eating behaviors?

O Never (1)

O Almost never (2)

Some of the time (3)

Usually (4)

Almost always (5)

\subsubsection{Data Collection}

Participants were recruited through four distinct ED treatment sites due to existing connections and collaborations with the PI: The Eating Recovery Center, The UNC Center of Excellence for Eating Disorders, The Chestnut Ridge Center, and the eating disorders partial hospitalization program (PHP) at New York-Presbyterian Hospital. Letters of support from all four sites were submitted to the IRB and can be found in $\underline{\text { Appendix } \mathbf{H}}$. We also obtained permission to advertise this survey on a provider listserv, the West Virginia Eating Disorder Network (personal communication from Dr. Jessica Luzier).

A power analysis using $\mathrm{G}^{*}$ Power 3.1 was calculated for the primary aim, using the odds ratio of 3.12 found for female participants recalling their mothers encouraging them to diet in $\underline{\text { Chapter } 2}$ (Faul et al., 2007). For a two-tailed odds ratio of 3.12 with a prevalence of .25 (also gathered from Chapter 2), an alpha of .05 and a power of .90 , a sample of 58 participants was suggested.

Below is a brief description of the four recruitment sites:

1) Chestnut Ridge: Morgantown, WV: The medical center draws from a large catchment area of West Virginia with many patients residing in rural areas. Patients seen are predominately 
female (83\%) and White (97\%) with a mean age of 47 and a BMI of 51. An average of 2-3 unique ED patients is seen per week at this site, the majority of which have binge-eating disorder (BED), which is defined as having numerous binge episodes (at least 2 per week) without compensatory behavior such as purging or excessive exercise (American Psychiatric Association, 2013). (Dr. Stephanie Cox, Chestnut Ridge, personal communication)

2) Eating Recovery Center (ERC): Cincinnati, $\mathrm{OH}$ : The ERC sees about 35 patients with EDs at any given time, with an average length of stay of 4-6 weeks for the partial-hospitalization program (PHP) and 6 weeks for the intensive outpatient program (IOP). The majority of patients seen there are female (95\%) and $80 \%$ are over the age of 18 (for purposes of this study those under age 18 are excluded). Patients are predominantly non-Hispanic white and from Ohio, although $25 \%$ are from out-of-state. The ED diagnosis breakdown is: $37.1 \%$ anorexia nervosa - restrictive subtype, $29.9 \%$ anorexia - binge/purge subtype, $19.4 \%$ bulimia, and 13.5\% other specified feeding and eating disorder (OSFED). There is also a separate BED program at ERC, which was also part of the recruitment. (Ashley Solomon, PsyD, ERC, personal communication)

3) PHP at New York-Presbyterian Hospital: New York, NY: This new PHP houses 5-6 ED patients at a time, for about 6 weeks at a time. (Dr. Tara Deliberto, New York-Presbyterian Hospital, personal communication). This PHP began in August 2016, so it was too early at the time of recruitment to have accurate demographic data.

4) UNC Center of Excellence for Eating Disorders (CEED): Chapel Hill, NC: This treatment and research center is world renowned for their research and clinical care. It was founded by Dr. Cynthia Bulik, a leader in the field of EDs heading global research on the biological basis of EDs. Clinical treatment at UNC is directed by Dr. Stephanie Zerwas and some of the treatment 
provided is free as a part of a clinical trial. (Dr. Stephanie Zerwas, UNC CEED Clinical Director, personal communication)

Recruitment commenced in January of 2017 and ended in March 2017. Based on a conservative $50 \%$ response rate and the age requirement (>18 years), we expected 15 participants from CRC [(2.5 patients $x 4$ weeks $x 3$ months $) / 2=15], 35$ from the ERC [( $35 \times .80 \times 2.5) / 2=35]$, and 6 participants from the PHP in New York $[(5 \times 2.5) / 2=6.25]$. Since UNC was exclusively advertising through social media, we estimated 10 participants from that medium for a total of 66 participants, in addition to those recruited from the West Virginia Eating Disorder Network.

\subsubsection{Participants}

A total of 65 participants were recruited during the recruitment period; participants were included in the analysis if they had demographic information, completed the EPSI, and had completed at least $25 \%$ of the questionnaire (if a participant had only lived with their mother, they would have been able to complete $50 \%$ of the questionnaire due to the built-in skip pattern), reducing the total sample to 60 . The majority of respondents were female $(n=56,93.3 \%)$, Whites $(n=59 ; 98.4 \%)$, had at least a college degree $(n=47,78.3 \%)$, and were privately insured $(n=47,78.3 \%)$. Most were young and in the normal weight range, although there was high variance on both age (mean age 31.8 years \pm 9.9 ) and BMI (22.0 \pm 6.8$)$. Annual family income was normally distributed, but most made between $\$ 46,000$ - $\$ 100,000$ per year. Twenty-one percent $(n=13)$ of the respondents were parents themselves (See Table 4.1).

Table 4.1. Demographic Characteristics

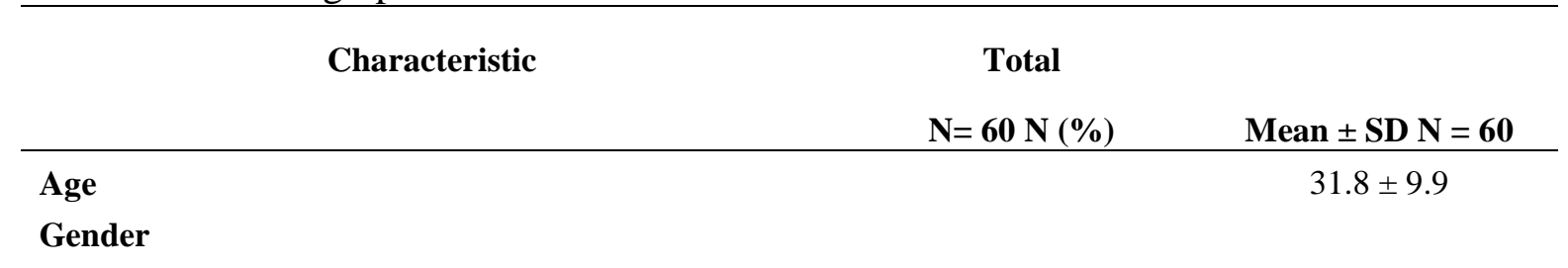




$$
\text { Male }
$$

$4(6.7)$

Female

Hispanic or Latino/a

Yes

No

\section{Race/ethnicity*}

White/Caucasian

Asian

\section{BMI}

\section{Education}

College or Higher

High School/GED

Less than High School

Annual Family Income

$<\$ 46,000$

$\$ 46,000$ - $\$ 100,000$

$>\$ 100,000$

Prefer not to answer

\section{Parent}

Yes

No

\section{Insurance Type}

Privately Insured

Medicare

Uninsured

Medicare

\section{Maternal Eating Disorder History ${ }^{\mathrm{a}}$}

Yes, professionally diagnosed

Yes, undiagnosed

No

Unsure

\section{Paternal Eating Disorder History ${ }^{b}$}

Yes, professionally diagnosed

Yes, undiagnosed

No

Unsure

Past Eating Disorder Diagnoses ${ }^{c}$

Anorexia

Bulimia

Binge Eating Disorder

Eating Disorder Not Otherwise Specified ${ }^{\mathrm{d}}$

Current Eating Disorder Diagnoses ${ }^{\mathrm{c}}$
$56(93.3)$

$1(1.7)$

$60(98.4)$

$59(98.4)$

$1(1.7)$

$22.0 \pm 6.8$

47 (78.3)

$12(20.0)$

$1(1.7)$

$14(23.3)$

$21(35.0)$

18 (30.0)

7 (11.1)

13 (21.3)

47 (78.7)

45 (75.0)

$8(13.3)$

4 (6.7)

$3(5.0)$

2 (3.4)

15 (25.9)

$32(55.2)$

9 (15.5)

0 (0)

2 (3.9)

46 (88.5)

4 (7.7)

30

14

7

12

14 
$\begin{array}{ll}\text { Bulimia } & 7\end{array}$

Binge Eating Disorder 3

Eating Disorder Not Otherwise Specified $^{\mathrm{d}} 2$

a Missing information for 2 participants

${ }^{\mathrm{b}}$ Missing information for 9 participants

${ }^{\mathrm{c}}$ Since one individual can have multiple eating disorders and both present and past eating disorders, these columns will not necessarily add up to the total $\mathrm{N}$ and therefore, percentages are not appropriate.

${ }^{\mathrm{d}}$ Eating Disorder Not Otherwise Specified (EDNOS), now labeled 'Other Specified Feeding or Eating Disorder' in DSM-5; EDNOS was used in the questionnaire because more patients are still familiar with that terminology.

\subsubsection{Human Subjects}

This study was filed with West Virginia University's Institutional Review Board and exempt status has been acknowledged (IRB: 1609282716). A copy of the complete survey can be found in Appendix F. Signed informed consent was not required due to the anonymous survey nature of the project, but a cover letter explaining the study was presented prior to the survey and all participants had to select that they agreed to participate in order to continue to the survey (See $\underline{\mathbf{A p p e n d i x} \mathbf{G}}$ ). Qualtrics software was used to host and distribute the survey online. A list of resources and referrals for ED treatment and support groups was provided at the end of the survey for all individuals (See Appendix G). No protected health information (PHI) was obtained and all data was anonymized. Participants were able to provide their email address for entry into drawing for a $\$ 50$ Amazon gift card, but they were not required to do so; all email addresses were kept confidential and were separated from the rest of the data.

\subsubsection{Data Analysis}

Psychometric analyses including internal consistency estimates as well as a principal component analysis (PCA) were conducted to explore the revised questionnaire more thoroughly. A multivariate analysis including a correlation matrix was generated to describe the relationship between recall of parental feedback in this ED-specific population. ANOVAs were run to assess the subscales by different current diagnosed EDs. Multivariable linear regressions were run using stepwise 
regression with EPSI total scores to determine whether direct (encouragement to diet, criticism of weight) or indirect (parental dieting or fat talk) feedback corresponded with higher scores. We used the total score since we were interested in total eating pathology, rather than particular subscales. We controlled for confounders such as parental eating disorder history to account for some genetic influences and we also controlled for body mass index (BMI), which could confound many of the subscales on the EPSI. There were not enough male patients to conduct subgroup analyses. All data analysis was conducted using SAS JMP® 13.0.

\subsection{Results}

\subsubsection{Questionnaire Development}

Twenty-seven participants had complete data for the questionnaire and twelve participants had only one item missing. Twenty $(n=12)$ percent had 2 or 3 missing while $15 \%(n=9)$ had four or more items missing. Single imputation was conducted for missing items when adding up questionnaire subscales, but items were averaged where possible.

Internal consistency estimates were calculated for the questionnaire with Cronbach's alpha, with a resulting value of 0.90; acceptable values range from 0.70 to 0.95 (Bland \& Altman, 1997).

We first ran the PCA for both questionnaire subscales separately: the Negative Indirect Parental Feedback Subscale and the Negative Direct Parental Feedback Subscale. This was done to determine if the subscales grouped together shared variance as hypothesized. For the Negative Indirect Parental Feedback Subscale, one component accounted for $41.5 \%$ of the total variance, with all items loading above 0.55. Similarly, the Negative Direct Parental Feedback Subscale had a one component solution which accounted for $42.3 \%$ of the total variance, with all items loading above 0.49 , suggesting that the items were moderately to highly correlated with that component. 
Item by item responses for both subscales are reported in Table 4.2, including number of participants endorsing the category with the valid percentage reported. Notably, stronger positive patterns of endorsement were seen for maternal than paternal items. There were especially low levels of endorsement for current items about maternal and paternal feedback.

None of the ANOVAS for the Negative Indirect Parental Feedback Subscale or Negative Direct Parental Feedback Subscale were significant when compared with current ED diagnoses.

\subsubsection{Pearson Correlation Matrix}

The Pearson correlation matrix (See Table 4.3) showed that the Negative Indirect Parental Feedback Subscale was significantly positively correlated with the Negative Direct Parental Feedback Subscale $(\mathrm{r}=0.58 ; \mathrm{p}<.0001)$. The EPSI total score was significantly positively correlated with the Negative Direct Parental Feedback Subscale ( $\mathrm{r}=0.28 ; \mathrm{p}=0.04)$, but not with the Negative Indirect Parental Feedback Subscale ( $\mathrm{r}=0.06 ; \mathrm{p}=0.68)$. BMI was significantly positively correlated with both questionnaire subscales $(\mathrm{r}=0.26, \mathrm{p}=0.05$ for the Negative Indirect Parental Feedback Subscale; $\mathrm{r}=0.33$, $\mathrm{p}=0.05$ for the Negative Direct Parental Feedback Subscale), but not the total EPSI score. 


\begin{tabular}{|c|c|c|c|c|c|c|}
\hline Subscale & Item & & & & & \\
\hline \multirow[t]{9}{*}{$\begin{array}{l}\text { Negative Indirect Parental } \\
\text { Feedback Subscale }\end{array}$} & & Never & $\begin{array}{c}\text { Almost } \\
\text { Never }\end{array}$ & $\begin{array}{c}\text { Some of the } \\
\text { Time }\end{array}$ & Usually & $\begin{array}{l}\text { Almost } \\
\text { Always }\end{array}$ \\
\hline & $\begin{array}{l}\text { Q16. Did your MOTHER engage in diets specifically to lose } \\
\text { weight (primarily for appearance-related concerns)? }\end{array}$ & $16(28.1 \%)$ & $8(14.0 \%)$ & $13(22.8 \%)$ & $12(21.1 \%)$ & $8(14.0 \%)$ \\
\hline & $\begin{array}{l}\text { Q17. Did your MOTHER engage in 'fat talk,' that is degrading } \\
\text { self-talk specifically about her weight, shape, or size? }\end{array}$ & $13(22.4 \%)$ & $11(19.0 \%)$ & $17(29.3 \%)$ & $7(12.1 \%)$ & $10(17.2 \%)$ \\
\hline & $\begin{array}{l}\text { Q20. Did your MOTHER ever encourage a sibling or close family } \\
\text { member to diet to lose weight? }\end{array}$ & $30(51.7 \%)$ & $11(19.0 \%)$ & $13(22.4 \%)$ & $3(5.2 \%)$ & $1(1.7 \%)$ \\
\hline & $\begin{array}{l}\text { Q22. Did your MOTHER ever criticize a sibling or close family } \\
\text { member's weight, shape, or eating behaviors? }\end{array}$ & $19(32.8 \%)$ & $17(29.3 \%)$ & $13(22.4 \%)$ & $6(10.3 \%)$ & $3(5.2 \%)$ \\
\hline & $\begin{array}{l}\text { Q25. Did your FATHER engage in diets specifically to lose } \\
\text { weight (primarily for appearance-related concerns)? }\end{array}$ & $26(50.0 \%)$ & $14(26.9 \%)$ & $5(9.6 \%)$ & $3(5.8 \%)$ & $4(7.7 \%)$ \\
\hline & $\begin{array}{l}\text { Q26. Did your FATHER engage in 'fat talk,' that is degrading self- } \\
\text { talk specifically about his weight, shape, or size? }\end{array}$ & $28(53.8 \%)$ & $14(26.9 \%)$ & $6(11.5 \%)$ & $3(5.8 \%)$ & $1(1.9 \%)$ \\
\hline & $\begin{array}{l}\text { Q29. Did your FATHER ever encourage a sibling or close family } \\
\text { member to diet to lose weight? }\end{array}$ & $30(57.7 \%)$ & $12(23.1 \%)$ & $8(15.4 \%)$ & $0(0.0 \%)$ & $2(3.8 \%)$ \\
\hline & $\begin{array}{l}\text { Q31. Did your FATHER ever criticize a sibling or close family } \\
\text { member's weight, shape, or eating behaviors? }\end{array}$ & $26(50.0 \%)$ & $13(25.0 \%)$ & $9(17.3 \%)$ & $4(7.7 \%)$ & $0(0.0 \%)$ \\
\hline \multirow[t]{9}{*}{$\begin{array}{l}\text { Negative Direct Parental } \\
\text { Feedback Subscale } \\
\end{array}$} & & $\begin{array}{l}\text { Strongly } \\
\text { Disagree }\end{array}$ & Disagree & $\begin{array}{c}\text { Neither Agree } \\
\text { nor Disagree }\end{array}$ & Agree & $\begin{array}{l}\text { Strongly } \\
\text { Agree }\end{array}$ \\
\hline & Q19. Did your MOTHER encourage you to diet to lose weight? & $29(50.0 \%)$ & $13(22.4 \%)$ & $6(10.3 \%)$ & $2(3.5 \%)$ & $8(13.8 \%)$ \\
\hline & $\begin{array}{l}\text { Q21. Did your MOTHER ever criticize your weight, shape, or } \\
\text { eating behaviors? }\end{array}$ & $18(31.0 \%)$ & $9(15.5 \%)$ & $22(37.9 \%)$ & $4(2.9 \%)$ & $5(8.6 \%)$ \\
\hline & Q28. Did your FATHER encourage you to diet to lose weight? & $32(61.5 \%)$ & $12(23.1 \%)$ & $3(5.8 \%)$ & $2(3.8 \%)$ & $3(5.8 \%)$ \\
\hline & $\begin{array}{l}\text { Q30. Did your FATHER ever criticize your weight, shape, or } \\
\text { eating behaviors? }\end{array}$ & $21(40.4 \%)$ & $15(28.9 \%)$ & $11(21.2 \%)$ & $3(5.8 \%)$ & $2(3.8 \%)$ \\
\hline & $\begin{array}{l}\text { Q33. Now that you are an adult (over 18), does your MOTHER } \\
\text { encourage you to diet? }\end{array}$ & $37(75.5 \%)$ & $11(22.4 \%)$ & $0(0.0 \%)$ & $1(2.0 \%)$ & $0(0.0 \%)$ \\
\hline & $\begin{array}{l}\text { Q34. Now that you are an adult (over 18), does your MOTHER } \\
\text { criticize your weight, shape, or eating behaviors? }\end{array}$ & $16(41.0 \%)$ & $16(41.0 \%)$ & $1(2.6 \%)$ & $5(12.8 \%)$ & $1(2.6 \%)$ \\
\hline & $\begin{array}{l}\text { Q35. Now that you are an adult (over 18), does your FATHER } \\
\text { encourage you to diet? }\end{array}$ & $45(85.0 \%)$ & $7(13.2 \%)$ & $0(0.0 \%)$ & $1(1.9 \%)$ & $0(0.0 \%)$ \\
\hline & $\begin{array}{l}\text { Q36. Now that you are an adult (over 18), does your FATHER } \\
\text { criticize your weight, shape, or eating behaviors? }\end{array}$ & $30(62.5 \%)$ & $16(33.3 \%)$ & $0(0.0 \%)$ & $2(4.2 \%)$ & $0(0.0 \%)$ \\
\hline
\end{tabular}




\begin{tabular}{|c|c|c|c|c|c|c|c|c|c|}
\hline Measure & 1 & 2 & 3 & 4 & 5 & 6 & 7 & 8 & 9 \\
\hline 1. Negative Indirect Parental Feedback & & & & & & & & & \\
\hline Subscale & - & & & & & & & & \\
\hline 2. Negative Direct Parental Feedback Subscale & $0.58 * * *$ & - & & & & & & & \\
\hline $\begin{array}{l}\text { 3. Eating Pathology Symptoms Inventory } \\
\text { (EPSI) Total Score }\end{array}$ & 0.06 & $0.28 *$ & - & & & & & & \\
\hline 4. Maternal eating disorder, diagnosed & -0.07 & -0.13 & -0.15 & - & & & & & \\
\hline 5. Maternal eating disorder, undiagnosed & $0.58 * * *$ & $0.29 *$ & 0.16 & -0.12 & - & & & & \\
\hline 6. Maternal eating disorder, none & $-0.58 * * *$ & $-0.42 * *$ & -0.11 & -0.21 & $-0.66 * * *$ & - & & & \\
\hline 7. Paternal eating disorder, undiagnosed & 0.16 & -0.03 & -0.17 & $0.46 * *$ & 0.12 & -0.22 & - & & \\
\hline 8. Paternal eating disorder, none & $-0.30 *$ & -0.24 & 0.14 & -0.23 & -0.06 & 0.25 & $-0.55 * * *$ & - & \\
\hline 9. Body Mass Index (BMI) & $0.26 *$ & $0.33 *$ & -0.12 & -0.11 & 0.17 & -0.21 & -0.05 & -0.10 & - \\
\hline $\begin{array}{l}\text { Descriptive statistics } \\
(\mathbf{N}=)\end{array}$ & 58 & 60 & 56 & 2 & 15 & 32 & 2 & 46 & 52 \\
\hline Mean & 2.1 & 1.8 & 112 & & & & & & 22.0 \\
\hline STD or \% & 0.7 & 0.8 & 30.3 & $3.4 \%$ & $25.9 \%$ & $\begin{array}{l}55.2 \\
\%\end{array}$ & $3.8 \%$ & $88.5 \%$ & 6.8 \\
\hline
\end{tabular}




\subsubsection{Multivariable Linear Regression Findings}

Results of the multivariable linear regression with stepwise regression are displayed in Table 4.4. There was no evidence of multicollinearity and model assumptions were met. Additionally, the EPSI total score was internally reliable for this population with a Cronbach's alpha of 0.93 . The regression was conducted in two steps, first including only demographic variables or covariates and finally including the variables of interest, the Negative Indirect Parental Feedback Subscale and the Negative Direct Parental Feedback Subscale. The amount of variance explained by the final model increased by about $10 \%$ in comparison to the initial model (Model 1 : $\mathrm{R}^{2}$ $=.09$, Model 2: $\mathrm{R}^{2}=0.20$ ). Findings suggest a significant relationship between the Negative Direct Parental Feedback Subscale scores and total EPSI scores. For every additional one point on the Negative Direct Parental Feedback Subscale, EPSI total scores increased by an average of 14.1 points $(\mathrm{SD}=7.0 ; \mathrm{p}=.05)$. 


\begin{tabular}{|c|c|c|c|c|c|c|c|}
\hline & & del 1 & & & & el 2 & \\
\hline \multirow{2}{*}{ Overall Model } & df & $\mathbf{p}$ & $\mathbf{R}^{2}$ & $\mathbf{F}$ & df & $\mathbf{p}$ & $\mathbf{R}^{2}$ \\
\hline & 0.6 & .77 & 0.09 & 1.1 & 9 & .41 & 0.20 \\
\hline Predictors of EPSI & $\mathbf{B} \pm \mathrm{SE}$ & $\mathbf{p}$ & & & $\mathbf{B} \pm \mathrm{SE}$ & & $\mathbf{p}$ \\
\hline Intercept & $131.5 \pm 21.1$ & $<.0001 *$ & & & $98.3 \pm 28.2$ & & $.0012 *$ \\
\hline Indirect Feedback & & & & & $0.9 \pm 8.6$ & & 0.92 \\
\hline Direct Feedback & & & & & $14.1 \pm 7.0$ & & $0.05 *$ \\
\hline \multicolumn{8}{|l|}{ Maternal Eating Disorder } \\
\hline Yes, Diagnosed & $-19.4 \pm 24.5$ & 0.43 & & & $-7.4 \pm 24.3$ & & 0.76 \\
\hline Yes, Undiagnosed & $-0.7 \pm 12.6$ & 0.96 & & & $-0.55 \pm 13.4$ & & 0.97 \\
\hline No & $-10.5 \pm 10.9$ & 0.34 & & & $-0.13 \pm 11.6$ & & 0.99 \\
\hline \multicolumn{8}{|l|}{ Paternal Eating Disorder ${ }^{a}$} \\
\hline Yes, Undiagnosed & $-13.1 \pm 26.9$ & 0.63 & & & $-5.1 \pm 26.1$ & & 0.85 \\
\hline No & $1.7 \pm 14.8$ & 0.91 & & & $9.4 \pm 14.8$ & & 0.53 \\
\hline Past ED Diagnosis & $-2.6 \pm 4.5$ & 0.57 & & & $-4.1 \pm 4.7$ & & 0.39 \\
\hline BMI & $-0.7 \pm 0.6$ & 0.26 & & & $-1.0 \pm 0.6$ & & 0.92 \\
\hline
\end{tabular}

\footnotetext{
${ }^{a}$ No reported cases of diagnosed paternal eating disorders; ${ }^{*} \mathrm{p}<.05$
} 


\subsection{Discussion}

The results of this study showed several important findings. First, psychometric analyses illustrated that the revised questionnaire from Chapter 2 had good internal consistency and the PCAs confirmed the two subscales we hypothesized as Negative Indirect Parental Feedback and Negative Direct Parental Feedback. Second, the correlation matrix indicated that many maternal and paternal feedback items were significantly positively correlated and that many indirect and direct items were also significantly positively correlated. These results are similar to the contingency analysis findings in Chapter 2 that found increased odds of participants recalling direct feedback if they recalled indirect feedback. It lends additional credence to our reasoning for including indirect and direct feedback separately in our proposed Obesity \& Dieting Proneness Theoretical Model, as they appear to influence each other (See Figure 4.1).

Additionally, the multivariable linear regression showed that there was a significant association between the Negative Direct Parental Feedback Subscale on the questionnaire and the EPSI total score. This relationship was significant even after controlling for maternal and paternal eating disorder history in the model, suggesting that social and environmental factors appear to contribute to eating pathology in this clinical sample. Conversely, Negative Indirect Parental Feedback Subscale items were not found to be significantly associated with EPSI scores in this sample. This suggests that in this clinical sample, the direct parental feedback (such as parental encouragement to diet or parental comments about the participants' weight or shape) were associated with eating pathology, whereas indirect parental feedback (i.e. parental dieting) was not. This reinforces some of the results from the community sample in Chapter 3 where a direct example of parental feedback (recall of maternal encouragement to diet) was associated with a higher BMI for participants as adults. This may suggest that direct parental feedback is more salient for the child and therefore more likely to have an association with eating behavior or weight. However, just because the other factors in the model were 
not statistically significant, it does not mean that they were not clinically significant or that they may not be significant for another population.

Results from this study suggest the need for carefully planned and executed parental interventions about how direct feedback (e.g., parental encouragement to diet, parental criticism of weight or shape, etc.) regarding eating, weight, and shape is associated with potentially negative outcomes for children, including eating disorders. In support of this rationale, the American Academy of Pediatrics recently released recommendations to prevent both eating disorders and obesity among children and adolescents (AAP, 2016). These recommendations included having pediatricians encourage more frequent family meals and emphasizing families not talk about weight, but rather frame discussions around health and healthy behaviors. The AAP suggested that families try to facilitate healthy eating without a focus on dieting or eating to lose weight while encouraging physical activity for both the child and larger family unit. Even if parents employ these strategies, children still might struggle with EDs; regardless, it is crucial for parents to provide positive environments in which children can foster a constructive relationship with food and their bodies.

One other important piece to note is that there could be a possible cohort effect in parental direct and indirect feedback. Parental behavior may have changed either positively or negatively in the time since these participants were children. However, especially with the continued and increased use of social media, it is important for parents to provide positive feedback to counter negative messages that their children might be receiving from other sources.

\subsubsection{Limitations}

This study has several limitations. First, although the questionnaire used in this study had been further refined from Chapter 2, it still has not been validated. However, it demonstrated acceptable estimates of internal consistency and reliability. Second, there is the possibility of recall bias due to the nature of the questions asking about childhood. Additionally, because this was a clinical cohort of ED 
patients, there could additional recall bias due to their heightened shape and weight concerns making them more likely to recall childhood issues. The association could also be mediated by genetic vulnerabilities rather than environmental factors. Third, relying on second-hand diagnostic information about maternal and paternal ED history, rather than having direct diagnostic confirmation limits the linear regression. Fourth, the sample only had four male participants, preventing subgroup analyses between male and female participants on recall. Therefore, future research with a more equal proportion of male and female ED participants is warranted. Fifth, findings cannot be considered causal owing to the cross-sectional study design. It could be that ED participants with more weight and body image concerns now are more likely to recall parental feedback. Longitudinal studies are needed to clarify this association. Sixth, some of these results could be due to a cohort effect and more research will need to be done with participants who are children today in order to understand the type and extent of current parental feedback. Finally, results are not considered generalizable because of the convenience sampling methodology.

\subsection{Conclusion}

Parents are not to blame for child's eating disorder and can be their best allies for treatment (Schaumberg et al., 2017). However, developing research, including findings reported here, suggest social and environmental factors may trigger a genetic predisposition for EDs and there is evidence of increased body dissatisfaction, weight problems, and eating pathology among teens and adults who recalled parental feedback (Coffman et al., 2016; Nickelson et al., 2012; Rodgers et al., 2009a\&b; Sharpe et al., 2013; Wansink et al., 2017). The finding in the current study of increased eating pathology associated with direct parental feedback in a clinical population of ED participants even when controlling for parental ED history suggests greater attention is needed within the ED literature 
on social and environmental factors and their potential associations with eating pathology.

Nonetheless, additional research is necessary to further replicate our findings.

\section{Chapter 5}

Conclusion 


\subsection{Summary}

Despite the known genetic risk factors for EDs, there remain malleable environmental factors that warrant further study to improve prevention efforts for these serious illnesses. In particular, the family context can be extremely effective in ED recovery for children (Schaumberg et al., 2017), but they can also play a role in the development of body dissatisfaction and feeling a pressure to diet (Coffman et al., 2016; Nickelson et al., 2012; Rodgers et al., 2009a\&b; Sharpe et al., 2013; Wansink et al., 2017). The three studies explored intergenerational transmission of dieting behavior and body dissatisfaction as well as disordered eating. Chapter 2 explored recall of parental feedback in a large, non-clinical, convenience sample to show how intergenerational transmission of dieting behavior can occur in the general population. Chapters 3 and $\underline{4}$ also investigated this transmission with ED populations by exploring concerns of intergenerational transmission among women of reproductive age with a history of EDs and also considering intergenerational transmission within a cohort of ED patients. Maternal EDs during pregnancy or even EDs and other weight-related issues among women of childbearing age have been hypothesized to lead to a cycle of risk for the development of EDs and weight-related issues in subsequent generations (Bulik et al., 2005; Bulik, 2013). Due to this potentical cycle of risk, Chapter 3 also addressed intergenerational transmission among women of childbearing age with a past or current ED. Those critical periods present opportunities for intervention both to improve maternal and child outcomes, and potentially provide ways of breaking the cycle of risk that may be perpetuated by maternal EDs during pregnancy.

There are several important findings that need to be highlighted from the three studies. First, in a community sample, there was a high recall of both direct (e.g. encouragement to diet and criticism of participants' weight or shape) and indirect (e.g. parental dieting and parental fat talk) parental feedback by both male and female participants. Recall of maternal direct and indirect feedback was higher among both male and female participants than recall of paternal feedback. Second, one indicator of 
direct feedback — maternal encouragement to diet—was associated with higher adult BMIs among participants in the community sample. Third, a qualitative inquiry among 15 women found a prevailing theme of intergenerational transmission; women both discussed parental factors they felt had played a role in their disordered eating or body dissatisfaction as well as the fear that their children would model their ED behaviors or comments. Fourth, the revised questionnaire presented in Chapter 4 had good internal consistency and a PCA confirmed the two subscales we had developed: the Negative Indirect Parental Feedback Subscale and the Negative Direct Parental Feedback Subscale. Finally, a Multivariable linear regression in our clinical sample showed that there was a significant association between the Negative Direct Parental Feedback Subscale and the EPSI total score, even when controlling for participant-reported maternal and paternal ED history. Specifically, for every additional one point on the Negative Direct Parental Feedback Subscale, EPSI total scores increased by an average of 14.1 points $(\mathrm{SD}=7.0 ; \mathrm{p}=.05)$.

\subsubsection{Comparing \& Contrasting Study Results}

It is important to draw some comparisons between the three studies in order to understand how they individually and jointly contribute to the literature and highlight what gaps still remain. The findings from Chapters 2 and 4 support the qualitative study in Chapter 3 by showing that these women's endorsed fear of intergenerational transmission was bolstered by recall of negative parental indirect and direct feedback in both a community and clinical sample. The community and clinical studies presented in Chapters 2 and 4, respectively, were comparable on several items. Recall of maternal than paternal feedback was higher in both studies; in Chapter 2, we found this pattern held for both male and female participants, although we could not conduct these same subgroup analyses for Chapter 4. The two Multivariable linear regressions in Chapters 2 and 4 also highlighted the relative importance of recalled direct versus indirect parental feedback. Chapter 2 showed that direct parental feedback, specifically maternal encouragement to diet, was associated with a higher adult BMI for 
participants, while Chapter 4 indicated that participants who scored higher on the Negative Direct Parental Feedback Subscale had higher levels of eating pathology. These comparable results suggest that recall of direct parental feedback may be more prominent for children and therefore have a stronger association with later indices such as weight or eating pathology.

\subsection{Significance}

Research surrounding familial factors on childhood dieting and weight - especially parental factors in relation to ED development - has been limited in recent years out of concern that it will be misconstrued as parent blaming. There are a multitude of genetic and environmental factors that coalesce in a gene-environment nexus to influence a person's weight or lead to the development of a disorder such as an ED (Bulik, 2007). Therefore, this research is meant only to direct attention to one of those many factors, which could serve as a potential point of intervention.

This research stands to make a considerable contribution to the literature with both quantitative and qualitative support illustrating that there are recalled social and environmental triggers that are associated with dieting and weight for those children later in life. It is hoped that the findings from these studies will help to inform interventions that help parents be more conscious of their comments and dieting practices. The qualitative research also highlights the importance of treating mothers with EDs to break the cycle of transmission to their children (Bulik, 2005).

\subsection{Strengths and Limitations}

\subsubsection{Strengths}

This dissertation has several strengths that are specific to the individual studies that comprise it. First, Chapter 2 had a large sample size in a community sample, which illustrated the issue of intergenerational transmission among non-clinical participants. Second, both the original questionnaire used in Chapter 2 and the questionnaire revised for Chapter 4 had good internal consistency estimates. 
Both questionnaires also either showed evidence of hypothesized latent constructs using item response theory for Chapter 2 or subscales using PCA for Chapter 4. Third, Chapter 3 used appropriate qualitative techniques to ensure the trustworthiness of the data collected. And finally, a second-coder was used to double-code at least $20 \%$ of the qualitative transcripts in order to ensure inter-rater reliability.

\subsubsection{Limitations}

There are several key limitations across the three studies presented in this dissertation. The primary limitation is that all the data presented in this dissertation is self-reported, either on questionnaires or through interviews. This leaves the data susceptible to social desirability bias and self-report bias. Chapter 2 incorporated the Marlowe-Crowne scale into the questionnaire, with a resulting score of $4.7(S D=2.1)$, indicating a presence of possible moderate social desirability (Reynolds, 1982). We did not include this scale into the questionnaire used in Chapter 4's study to reduce the possibility of respondent fatigue (Lavrakas, 2008), since it was already a lengthy survey that included our unique questionnaire, demographic items, and the 45-item Eating Pathology Severity Inventory. However, we can assume there were also moderate levels of social desirability present in this sample, based on the finding in Chapter 2. The qualitative data was also self-reported, but steps were taken according to standard qualitative research methods to ensure the trustworthiness of the data collected (Creswell, 2013). Still, there is a possibility of social desirability in the qualitative data collected; phone interviews rather than in-person interviews may have lessened this bias and enabled the likelihood that more sensitive information was conveyed, but it is still a relevant bias to note. Therefore, all results presented in this dissertation must be framed with the knowledge of this selfreport and potential social desirability bias.

The second predominant limitation for this dissertation was that all the studies included asked participants to recall certain events, experiences, or comments that were made, sometimes years ago. 
This recall bias could have influenced the results and therefore the conclusions emanating from those results. However, this limitation was acknowledged throughout and even if recall bias played a role in the results, that alone is interesting. Individuals with more eating and weight problems as adults may be more likely to recall negative parental feedback. Similarly, for women with current or past EDs in the qualitative study, their histories may have made them more likely to recall parental interactions or experiences that they felt contributed to their disordered eating or body image disturbance.

Third, Chapters 2 and 4 both employed convenience sampling for recruitment, allowing for the potential of sampling bias. However, the study in Chapter 2 was widely distributed through various online outlets, including social media. Chapter 3 also used a convenience sample, but through employing purposive sampling, which is commonly used in qualitative methods in order to answer a specific question (Creswell, 2013).

Finally, in Chapter 4, there were not enough males in the clinical sample to conduct subgroup analyses needed to make some comparisons with the community sample in Chapter 2 . Therefore, we do not know whether the results in Chapter 4 would be similar among both male and female participants.

\subsection{Future Research}

Future research will be needed in order to both confirm and expand some of the findings from the studies presented here. First and most important, large, prospective cohort studies including both male and female participants will be needed in order to remove the possibility of recall bias in the association between parental feedback and participant weight or eating pathology. Based on the prevalence of recall of parental feedback in our community sample, these prospective cohort studies are warranted both in community and clinical samples. 
Additional research will also need to find ways to mitigate self-report bias. For example, this could involve providing a similar version of the questionnaire to the parents or other siblings to help validate the participant's report. For the clinical sample, we controlled for parental ED history based on participant report; however, this is again susceptible to self-report bias. Therefore, future studies would benefit from gathering diagnostic data from both participant and parents in order to control for this more accurately. As genetic advances continue in the ED field, gathering genetic data is also a possibility.

Interventions with parents will also be needed to see whether making changes to direct or indirect parental feedback helps reduce levels of eating pathology among children or improves their weight status. Since parents (especially those with ED histories) express concerns about how to model healthy eating or talk about weight and health with their children, it is hoped that such interventions would be embraced as an opportunity to improve (Runfola et al., 2013).

\subsection{Conclusions}

Based on Social Cognitive Theory (Bandura, 1986), parents and families can provide either a positive or negative environment for their child's relationship with food and their bodies through social reinforcement. The studies presented in this dissertation support that theory through both quantitative and qualitative results. With this understanding, parents are not to be blamed, but rather can contribute to the solution by reinforcing positive over negative behaviors and focusing on health rather than weight (AAP, 2016). 


\section{Appendix A}

\section{Questionnaire Intergenerational Transmission of Dieting Behavior}

Did you live with your mother at least part of the time when you were a child?

Yes

No

While you were growing up, during your first 18 years of life:

1. Did your mother engage in diets specifically to lose weight?

Yes

No

a. If yes, how often do you recall your mother engaging in a diet?

- None or hardly any of the time

- About a quarter of the time

- About half of the time

- About three-quarters of the time

- Nearly all of the time

b. How old were you when you first recall your mother dieting?

- As far back as I can remember

- Before grade school

- Sometime in grade or elementary school

- Middle school/early adolescence

- High school

2. Did your mother engage in 'fat talk,' that is degrading talk specifically about her weight, shape, or size?

Yes

No

a. If yes, how often do you recall her engaging in this type of talk?

- None or hardly any of the time

- About a quarter of the time

- About half of the time

- About three-quarters of the time

- Nearly all of the time

b. How old were you when you first recall your mother engaging in 'fat talk'?

- As far back as I can remember

- Before grade school

- Sometime in grade or elementary school

- Middle school/early adolescence

- High school 
3. How many times (approximately) do you remember your mother losing 20 pounds or more when she wasn't sick - and then gaining it back?

- Never

- Once or twice

- Three or four times

- Five times or more

4. Did your mother encourage you to diet?

\section{Yes}

No

a. If yes, how often do you recall your mother encouraging you to diet?

- None or hardly any of the time

- About a quarter of the time

- About half of the time

- About three-quarters of the time

- Nearly all of the time

b. How old were you when you first recall your mother encouraging you to diet?

- As far back as I can remember

- Before grade school

- Sometime in grade or elementary school

- Middle school/early adolescence

- High school

5. Did your mother criticize your weight, shape, or eating behaviors?

Yes

No

a. If yes, how often do you recall your mother criticizing your weight, shape or eating behaviors?

- None or hardly any of the time

- About a quarter of the time

- About half of the time

- About three-quarters of the time

- Nearly all of the time

b. How old were you when you first recall your mother criticizing your weight, shape, or eating behaviors?

- As far back as I can remember

- Before grade school

- Sometime in grade or elementary school

- Middle school/early adolescence

- High school 
Did you live with your father at least part of the time when you were a child?

Yes

No

6. Did your father engage in diets specifically to lose weight?

Yes

No

a. If yes, how often do you recall your father engaging in a diet?

- None or hardly any of the time

- About a quarter of the time

- About half of the time

- About three-quarters of the time

- Nearly all of the time

b. How old were you when you first recall your father dieting?

- As far back as I can remember

- Before grade school

- Sometime in grade or elementary school

- Middle school/early adolescence

- High school

7. Did your father engage in 'fat talk,' that is degrading talk specifically about his weight, shape, or size?

Yes

No

a. If yes, how often do you recall him engaging in this type of talk?

- None or hardly any of the time

- About a quarter of the time

- About half of the time

- About three-quarters of the time

- Nearly all of the time

b. How old were you when you first recall your father engaging in fat talk?

- As far back as I can remember

- Before grade school

- Sometime in grade or elementary school

- Middle school/early adolescence

- High school

8. How many times (approximately) do you remember your father losing 20 pounds or more when he wasn't sick - and then gaining it back?

- Never

- Once or twice

- Three or four times

- Five times or more 
9. Did your father encourage you to diet?

Yes

No

a. If yes, how often do you recall your father encouraging you to diet?

- None or hardly any of the time

- About a quarter of the time

- About half of the time

- About three-quarters of the time

- Nearly all of the time

b. How old were you when you first recall your father encouraging you to diet?

- As far back as I can remember

- Before grade school

- Sometime in grade or elementary school

- Middle school/early adolescence

- High school

10. Did your father criticize your weight, shape, or eating behaviors?

Yes

No

a. If yes, how often do you recall your father criticizing your weight, shape or eating behaviors?

- None or hardly any of the time

- About a quarter of the time

- About half of the time

- About three-quarters of the time

- Nearly all of the time

b. How old were you when you first recall your mother criticizing your weight, shape, or eating behaviors?

- As far back as I can remember

- Before grade school

- Sometime in grade or elementary school

- Middle school/early adolescence

- High school

11. How old were you the first time you lost at least 10 pounds by dieting, or in some way by limiting how much you ate? If you are not sure, what is your best guess?

- As far back as I can remember

- Before grade school

- Sometime in grade or elementary school

- Middle school/early adolescence

- High school

- Never

12. Now that you are an adult (over 18), does your mother encourage you to diet? 


\section{Yes \\ No}

13. Now that you are an adult (over 18), does your mother criticize your weight, shape, or eating behaviors?

\section{Yes}

No

14. Now that you are an adult (over 18), does your father encourage you to diet?

Yes

No

15. Now that you are an adult (over 18), does your father criticize your weight, shape, or eating behaviors?

Yes

No 


\title{
Appendix B
}

\section{$\underline{\text { IRB-Approved Advertisement }}$}

\author{
West Virginia University \\ Pregnancy and Eating Disorders Study \\ (IRB: 1602021245) \\ Volunteers Wanted for Research Study
}

Eligible participants will be interviewed about their experiences or expectations about pregnancy and that relationship with their eating disorder/history of an eating disorder. Interviews will last no more than an hour and all information will be kept confidential.

Eligibility criteria include: English-speaking, women (age 18 and older) with a self-reported diagnosis of an eating disorder or past eating disorder, who have had a pregnancy, or want to become pregnant.

WVU IRB is on file

Please contact Dr. Danielle Davidov with any questions.

Dr. Danielle Davidov

Department of Emergency Medicine \& Department of Social \& Behavioral Sciences ddavidov@hsc.wvu.edu or (304) 293-4083

\section{Cover Letter}

Dear Participant,

This letter is a request for you to take part in an optional interview at your convenience about your perception and/or experience of pregnancy as a woman with an eating disorder. The purpose of this study is to better understand the intersection between eating disorders and pregnancy from the viewpoint of women with these disorders who have been pregnant, are pregnant, or want to or do not want to become pregnant. By understanding some of the unique challenges and barriers, as well as facilitators these women face, we can learn how to better help women with eating disorders during pregnancy, including helping to inform prenatal care, obstetricians, and midwives. The information you would provide is vital to helping other women who struggle with similar concerns.

This study is being conducted to fulfill requirements for a Qualitative Research Methods class project and is led by Elizabeth Claydon, MPH, MS who is a PhD student in the Department of Social and Behavioral Sciences at West Virginia University. This project is being overseen by her professor, Dr. Danielle Davidov, in the Departments of Emergency Medicine and Social and Behavioral Sciences.

If you agree to participate, you will be sent a short demographic form to complete. Then, Ms. Claydon will contact you to set up either a phone or Skype call to conduct a 45 minute to one-hour interview. 
This interview will be kept completely confidential and all data will be de-identified. Your information will always only be identified by a study ID, never your name or any other identifying information.

Your participation in this interview is completely voluntary and you may choose to withdraw at any

time. This study has been filed with West Virginia University's Institutional Review Board and approval has been obtained.

For purposes of this research, these interviews will be audio-recorded and then transcribed. Even after finishing the interview, if you do not feel comfortable with us keeping your data, you can ask that your audio-recording be deleted. No notes written by the interviewer during the interview will be kept either in that case.

Thank you so much for your time and willingness to help with this important project.

Sincerely,

Elizabeth Claydon, MPH, MS 


\section{Appendix C}

\section{Interview Protocol:}

Time of interview:

Date:

Phone/Skype

Interviewee ID:

\section{Description of the Project:}

The purpose of this study is to better understand the intersection between eating disorders and pregnancy from the viewpoint of women with these disorders who have been pregnant, are pregnant, or want to or do not want to become pregnant. By understanding some of the unique challenges and barriers, as well as facilitators these women face, we can learn how to better help women with eating disorders during pregnancy, including helping to inform prenatal care, obstetricians, and midwives. The information you provide today is vital to helping other women who struggle with similar concerns.

\section{Informed Consent:}

This interview will be kept completely confidential and all data will be de-identified. In order to ensure that any health information you share today cannot be linked back to you, if you do mention any identifying information in this interview it will be removed from any transcripts before the data is examined. Thus, your information will always only be identified by a study ID. Your participation in this interview is completely voluntary and you may choose to withdraw at any time. This study has been filed with West Virginia University's Institutional Review Board and approval has been obtained. If you have any questions as we go through the interview today, please don't hesitate to ask. If there are any questions that I ask that you do not feel comfortable answering, you are under no obligation to answer them.

For purposes of this research, these interviews will be audio-recorded and then transcribed. Even after finishing the interview, if you do not feel comfortable with us keeping your data, you can ask that your audio-recording be deleted. No notes written by the interviewer during the interview will be kept either in that case.

Interviewer prompt: Do you have any questions before we begin the interview? (If no, then: Okay, let's get started then. I am going to start recording now.

\section{Questions:}

If participant is or has been pregnant, read questions labeled A; if participant has not been pregnant, read questions labeled $B$.

A1) Let's get started with a general discussion of your history with an eating disorder.

Probe: What type of eating disorder were you diagnosed with/have had?

Probe: Can you tell me about when this began and its progression?

A2) How would you describe the status of your eating disorder when you found out you were pregnant?

A3) What was initial reaction to finding out you were pregnant? 
Probe: How did these feelings/reactions change over the course of your pregnancy?

Probe: Why, if at all, do you think these feelings changed?

A4) What was it like to have an eating disorder during your pregnancy?

Probe: Why do you think your eating disorder or eating behavior changed?

A5) What were some of the biggest challenges you faced during pregnancy?

A6) Can you describe what it was like to be weighed during your prenatal visits, given your history?

A7) Did you discuss your eating disorder/history of an eating disorder with your $\mathrm{OB} / \mathrm{midwife}$ ?

Probe: What did you tell your OB/midwife about your eating disorder/history of an eating disorder?

Probe: How would you have wanted them to change your care based on that knowledge?

A8) What challenges have you faced postpartum as a mother with an eating disorder/history of an eating disorder?

B1) Let's get started with a general discussion of your history with an eating disorder.

Probe: What type of eating disorder were you diagnosed with/have had?

Probe: Can you tell me about when this began and its progression?

B2) As it relates to your eating disorder/history of an eating disorder, can you tell me about how you feel about pregnancy?

Probe: Can you describe how you think you might feel if you found out you were pregnant now?

Probe: What are some of the concerns you have about becoming pregnant?

B3) How, if at all, do you think your eating disorder would change during pregnancy? (What do you think it would be like to have an eating disorder during pregnancy?")

Probe: for changes before and after finding out about potential pregnancy...

B4) What are your feelings about gaining weight with pregnancy and frequent weight-checks at the doctor during your pregnancy?

B5) If you become pregnant, is information about your eating disorder/history of an eating disorder something you would share with your OB/midwife?

Probe: If yes, what information about your eating disorder would you share with your $\mathrm{OB} / \mathrm{midwife}$ ?

Probe: If not, why would you not be comfortable sharing this information? 


\section{Below is a list of Referrals, Helplines, \& Support Groups} Inclusion on the list does not imply endorsement of these agencies or services. Payment for services rendered at these agencies is the sole responsibility of the patient and not the researchers of the current study.

\section{$\underline{\text { Referrals }}$}

Academy for Eating Disorders: Find a Professional http://www.aedweb.org/index.php/education/eating-disorder-information-2

\section{Helplines}

National Eating Disorder Association free, confidential Helpline

Monday - Thursday 9am-9pm, Friday $9 \mathrm{am}-5 \mathrm{pm}$

1-800-931-2237

Eating Disorders Association (UK)

Adult Helpline: 011-44-8456-341414

Youthline: 011-44-8456-347650

Adult Helpline: (open 8:30 to 20:30 weekdays)

Youthline: (open 16:00 to 18:30 weekdays)

National Suicide Prevention Lifeline

1-800-273-TALK or 1-800-SUICIDE (784-2433)

\section{Support Groups}

Study of Anorexia \& Bulimia (CSAB) Support Groups

Family \& Friends takes place on the 1 st $\&$ 3rd Wednesdays of the month.

Pursuing Recovery takes place on the 2 nd \& 4th Wednesdays of the month.

212.333.3444 ext. 256 or email: emilyrosenthal@ hotmail.com

1841 Broadway (at 60th $\mathrm{St}$ )

4th Floor - Room 407

New York, NY 10023.

Online Eating Disorder Support Group - "Lift the Shame"

"Lift the Shame" is the first web-based support group of its kind specifically targeted to offer support and resources to pregnant women and moms with eating disorders. This support group is a free, confidential online group hosted by Jena Morrow, author, speaker and activist for eating disorders awareness, and Timberline Knolls Alumnae Coordinator.

"Lift the Shame" is open to all and live on the web: 3rd Sunday of each month | 6-7 p.m. Central |7-8 p.m. eastern |4-5 p.m. Pacific

If you would like to participate, please register online at www.timberlineknolls.org 


\section{Appendix E}

\section{Demographic Information}

1. How old are you?

Years

2. Are you currently ? (circle one)

$$
\begin{aligned}
& 1 \text { - Married } \\
& 2 \text { - Living with a partner } \\
& 3 \text { - Divorced } \\
& 4-\text { Separated } \\
& 5 \text { - In a relationship } \\
& 6 \text { - Single }
\end{aligned}
$$

3. What race do you consider yourself to be?

4. What is your current height and weight (if you do not feel comfortable answering this, please leave blank: ft. in. lbs.

5. What is the highest year of school or college that you completed? (circle one)

\section{Grade School High School College/Vocational Professional/Graduate School}

6. How many children do you have? (please write 0 if none)

\section{children}

7. What year did you have your first child?

8. Are you currently employed?

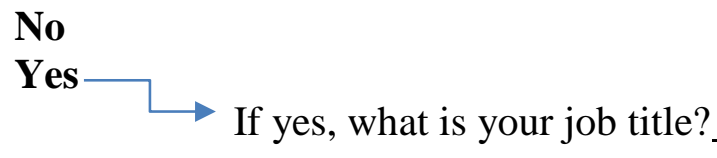




\title{
Appendix F
}

\author{
Dieting_Behaviors
}

Q1 The following survey is completely optional and inquires about your dieting behaviors and your recall of your parents' dieting behaviors. The purpose of this study is to understand the family environment of individuals with eating disorders. By understanding this, we can hope to improve prevention and early intervention efforts. The information you provide is vital to helping other individuals with eating disorders. This study is being conducted to fulfill requirements for a dissertation project and is led by Elizabeth Claydon, MPH, MS who is a $\mathrm{PhD}$ student in the Department of Social and Behavioral Sciences at West Virginia University. This project is being overseen by her professor, Dr. Keith Zullig, also in the Department Social and Behavioral Sciences. The survey will take approximately 15 minutes to complete. This survey is anonymous and cannot be linked back to you. You will have the option to provide your email address for entry to win a \$50 Amazon gift card. Your email address will be kept confidential and your data will always only be identified by a study ID any identifying information. Your participation in this survey is completely voluntary and you may choose to withdraw at any time. This study has been filed with West Virginia University's Institutional Review Board and approval has been obtained. If you agree to participate, please click 'yes' to continue to the survey. Thank you so much for your time and willingness to help with this important project. Sincerely,

Elizabeth Claydon, MPH, MSPlease contact eac0006@mix.wvu.edu with any questions.

Q2 I agree to participate in this study.

O Yes (1)

No (2)

Q3 What is your gender?

O Male (1)

O Female (2)

Transgender (3)

Q4 How old are you?

Q5 Are you Hispanic or Latino/a?

O Yes (1)

No (2)

Q6 What best describes your race?

White/Caucasian (1)

Black/African American (2)

O Asian (3)

O American Indian, Alaskan Native (4)

Native Hawaiian, Pacific Islander, East Indian (5)

Other (6) 
Q7 What eating disorders have you had (select all that apply)?

口 Past Anorexia nervosa, professionally diagnosed (1)

- Past Anorexia nervosa, self-diagnosed (2)

- Past Bulimia nervosa, professionally diagnosed (3)

- Past Bulimia nervosa, self-diagnosed (4)

- Past Binge eating disorder, professionally diagnosed (5)

Past Binge eating disorder, self-diagnosed (6)

- Past EDNOS, professionally diagnosed (7)

? Past EDNOS, self-diagnosed (8)

- Current Anorexia nervosa, professionally diagnosed (9)

Current Anorexia nervosa, self-diagnosed (10)

- Current Bulimia nervosa, professionally diagnosed (11)

Current Bulimia nervosa, self-diagnosed (12)

C Current Binge eating disorder, professionally diagnosed (13)

C Current Binge eating disorder, self-diagnosed (14)

- Current EDNOS, professionally diagnosed (15)

- Current EDNOS, self-diagnosed (16)

Q8 What is your current insurance status?

O Uninsured (1)

O Privately insured (2)

O Medicaid (3)

O Medicare (4)

Q9 What is your current height (in feet \& inches) and weight (in pounds)? (If you have not weighed yourself recently, please provide your best estimate).

Height (ft) (1)

Height (in) (2)

Weight (3)

Q10 What is the highest level of education you have completed?

C College Degree or higher (1)

O High school/GED (2)

O Less than high school (3)

Q11 What is your current annual family income?

O $\$ 0$ - $\$ 23,900$ (1)

O $\$ 24,000$ - $\$ 45,900$ (2)

O $\$ 46,000$ - $\$ 99,900(3)$

O $\$ 100,000$ - $\$ 149,900$ (4)

O $\$ 150,000+(5)$

O Prefer not to answer (6) 
Q12 Are you a parent or are you expecting a baby?

O Yes, parent (1)

Yes, expecting a baby (2)

Neither (3)

Q13 Below are five statements in which you may agree or disagree. Indicate your agreement with each item by selecting the appropriate bubble. Please be open and honest in your responding.

\begin{tabular}{|c|c|c|c|c|c|c|c|}
\hline & $\begin{array}{c}\text { Strongly } \\
\text { Disagree } \\
\text { (1) }\end{array}$ & $\begin{array}{c}\text { Disagree } \\
\text { (2) }\end{array}$ & $\begin{array}{l}\text { Somewhat } \\
\text { disagree } \\
\text { (3) }\end{array}$ & $\begin{array}{l}\text { Neither } \\
\text { agree } \\
\text { nor } \\
\text { disagree } \\
\text { (4) }\end{array}$ & $\begin{array}{l}\text { Somewhat } \\
\text { agree }(5)\end{array}$ & $\begin{array}{c}\text { Agree } \\
(6)\end{array}$ & $\begin{array}{l}\text { Strongly } \\
\text { agree } \\
(7)\end{array}$ \\
\hline $\begin{array}{l}\text { In most } \\
\text { ways my } \\
\text { life is } \\
\text { close to } \\
\text { my ideal. } \\
\text { (1) }\end{array}$ & 0 & 0 & 0 & 0 & 0 & 0 & 0 \\
\hline $\begin{array}{c}\text { The } \\
\text { conditions } \\
\text { of my life } \\
\text { are } \\
\text { excellent. } \\
\text { (2) }\end{array}$ & 0 & 0 & 0 & 0 & 0 & 0 & 0 \\
\hline $\begin{array}{l}\quad \text { I am } \\
\text { satisfied } \\
\text { with my } \\
\text { life. (3) }\end{array}$ & 0 & 0 & 0 & 0 & 0 & 0 & 0 \\
\hline $\begin{array}{l}\text { So far I } \\
\text { have } \\
\text { gotten the } \\
\text { important } \\
\text { things I } \\
\text { want in } \\
\text { life. (4) }\end{array}$ & 0 & 0 & 0 & 0 & 0 & 0 & 0 \\
\hline $\begin{array}{c}\text { If I could } \\
\text { live my } \\
\text { life over, } \\
\text { I would } \\
\text { change } \\
\text { almost } \\
\text { nothing. } \\
(5)\end{array}$ & 0 & 0 & 0 & 0 & 0 & 0 & 0 \\
\hline
\end{tabular}


Q14 Did you live with your MOTHER at least part of the time when you were a child?

O Yes (1)

No (2)

If No Is Selected, Then Skip To Did you live with your father at leas...

Q15 To your knowledge, did your mother have an eating disorder (professionally diagnosed or undiagnosed)

Yes, professionally diagnosed (1)

Yes, undiagnosed (2)

O No (3)

Unsure (4)

Q16 Did your MOTHER engage in diets specifically to lose weight (primarily for appearance-related concerns)?

O Never (1)

Almost never (2)

O Some of the time (3)

O Usually (4)

Almost always (5)

Q17 Did your MOTHER engage in 'fat talk,' that is degrading self-talk specifically about her weight, shape, or size?

O Never (1)

O Almost never (2)

O Some of the time (3)

Usually (4)

Almost always (5)

Q18 How often do you remember your MOTHER losing weight (primarily for appearance-related concerns and when she was NOT sick or pregnant) and then gaining it back?

O Never (1)

O Almost never (2)

Some of the time (3)

Usually (4)

Almost always (5)

Q19 Did your MOTHER encourage you to diet to lose weight?

O Never (1)

O Almost never (2)

Some of the time (3)

O Usually (4)

Almost always (5) 
Q20 Did your MOTHER ever encourage a sibling or close family member to diet to lose weight?

O Never (2)

Almost never (3)

Some of the time (4)

Usually (5)

Almost always (6)

Q21 Did your MOTHER ever criticize your weight, shape, or eating behaviors?

O Never (1)

Almost never (2)

O Some of the time (3)

O Usually (4)

Almost always (5)

Q22 Did your MOTHER ever criticize a sibling or close family member's weight, shape, or eating behaviors?

Never (1)

Almost never (2)

Some of the time (3)

Osually (4)

Almost always (5)

Q23 Did you live with your FATHER at least part of the time when you were a child?

O Yes (1)

No (2)

If No Is Selected, Then Skip To How old were you the first time you 1...

Q24 To your knowledge, did your father have an eating disorder (professionally diagnosed or undiagnosed)?

$\bigcirc$ Yes, professionally diagnosed (1)

Yes, undiagnosed (2)

O No (3)

Unsure (4)

Q25 Did your FATHER engage in diets specifically to lose weight (primarily for appearance-related concerns)?

O Never (1)

Almost never (2)

Some of the time (3)

Usually (4)

O Almost always (5) 
Q26 Did your FATHER engage in 'fat talk,' that is degrading self-talk specifically about his weight, shape, or size?

O Never (1)

Almost never (2)

Some of the time (3)

O Usually (4)

Almost always (5)

Q27 How often do you remember your FATHER losing weight (primarily for appearance-related concerns) - when he was not sick - and then gaining it back?

O Never (1)

Almost never (2)

Some of the time (3)

O Usually (4)

Almost always (5)

Q28 Did your FATHER encourage you to diet to lose weight?

O Never (1)

O Almost never (2)

Some of the time (3)

Usually (4)

Almost always (5)

Q29 Did your FATHER ever encourage a sibling or close family member to diet to lose weight?

Never (1)

O Almost never (2)

O Some of the time (3)

O Usually (4)

O Almost always (5)

Q30 Did your FATHER ever criticize your weight, shape, or eating behaviors?

O Never (1)

O Almost never (2)

O Some of the time (3)

O Usually (4)

Almost always (5) 
Q31 Did your FATHER ever criticize a sibling or close family member's weight, shape, or eating behaviors?

O Never (5)

Almost never (6)

Some of the time (7)

O Usually (8)

Almost always (9)

Q32 How old were you the first time you lost weight (primarily for appearance-related concerns) by dieting, or in some way by limiting how much you ate? If you are not sure, what is your best guess?

O As far back as I can remember (1)

Before grade school (2)

Sometime in elementary school (3)

O Middle school/early adolescence (4)

High school or later (5)

O Never/Not applicable (6)

Q33 Now that you are an adult (over 18), does your MOTHER encourage you to diet?

O Never (1)

Almost never (2)

Some of the time (3)

O Usually (4)

Almost always (5)

Q34 Now that you are an adult (over 18), does your MOTHER criticize your weight, shape, or eating behaviors?

O Never (1)

Almost never (2)

Some of the time (3)

O Usually (4)

Almost always (5)

Q35 Now that you are an adult (over 18), does your FATHER encourage you to diet?

O Never (1)

Almost never (2)

Some of the time (3)

O Usually (4)

O Almost always (5) 
Q36 Now that you are an adult (over 18), does your FATHER criticize your weight, shape, or eating behaviors?

O Never (1)

Almost never (2)

O Some of the time (3)

O Usually (4)

Almost always (5)

Q37 Below is a list of experiences and problems that people sometimes have. Read each item to determine how well it describes your recent experiences. Then select the option that best describes how frequently each statement applied to you during the past four weeks, including today. 


\begin{tabular}{|c|c|c|c|c|c|}
\hline & Never (1) & Rarely (2) & Sometimes (3) & Often (4) & $\begin{array}{c}\text { Very } \\
\text { often (5) }\end{array}$ \\
\hline $\begin{array}{l}\text { I did not like how } \\
\text { clothes fit the shape of } \\
\text { my body. (1) }\end{array}$ & $\mathrm{O}$ & O & O & O & $\mathrm{O}$ \\
\hline $\begin{array}{l}\text { I tried to exclude } \\
\text { "unhealthy" foods from } \\
\text { my diet. (2) }\end{array}$ & $\mathrm{O}$ & O & $\mathrm{O}$ & O & O \\
\hline $\begin{array}{c}\text { I ate when I was not } \\
\text { hungry. (3) }\end{array}$ & $\mathrm{O}$ & 0 & O & O & $\mathrm{O}$ \\
\hline $\begin{array}{l}\text { People told me that I do } \\
\text { not eat very much. (4) }\end{array}$ & O & O & O & O & O \\
\hline $\begin{array}{l}\text { I felt that I needed to } \\
\text { exercise nearly every } \\
\text { day. (5) }\end{array}$ & $\mathrm{O}$ & O & $\mathrm{O}$ & O & O \\
\hline $\begin{array}{l}\text { People would be } \\
\text { surprised if they knew } \\
\text { how little I ate. (6) }\end{array}$ & $\mathrm{O}$ & O & O & O & 0 \\
\hline $\begin{array}{l}\text { I used muscle building } \\
\text { supplements. (7) }\end{array}$ & $\mathrm{O}$ & O & O & O & $\mathrm{O}$ \\
\hline $\begin{array}{l}\text { I pushed myself } \\
\text { extremely hard when I } \\
\text { exercised. (8) }\end{array}$ & $\mathrm{O}$ & O & $\mathrm{O}$ & O & O \\
\hline $\begin{array}{l}\text { I snacked throughout the } \\
\text { evening without } \\
\text { realizing it. (9) }\end{array}$ & $\mathrm{O}$ & $\mathrm{O}$ & O & O & 0 \\
\hline $\begin{array}{l}\text { I got full more easily } \\
\text { than most people. (10) }\end{array}$ & $\mathrm{O}$ & O & O & $\mathrm{O}$ & 0 \\
\hline $\begin{array}{l}\text { I considered taking } \\
\text { diuretics to lose weight. } \\
\text { (11) }\end{array}$ & $\mathrm{O}$ & O & $\mathrm{O}$ & $\mathrm{O}$ & O \\
\hline $\begin{array}{l}\text { I tried on different } \\
\text { outfits, because I did not } \\
\text { like how I looked. (12) }\end{array}$ & $\mathrm{O}$ & O & O & O & 0 \\
\hline $\begin{array}{l}\text { I thought laxatives are a } \\
\text { good way to lose weight. } \\
\text { (13) }\end{array}$ & $\mathrm{O}$ & $\mathrm{O}$ & O & $\mathrm{O}$ & $\mathrm{O}$ \\
\hline $\begin{array}{l}\text { I thought that obese } \\
\text { people lack self-control. } \\
\text { (14) }\end{array}$ & $\mathrm{O}$ & O & O & O & O \\
\hline
\end{tabular}




\begin{tabular}{|c|c|c|c|c|c|}
\hline $\begin{array}{l}\text { I thought about taking } \\
\text { steroids as a way to get } \\
\text { more muscular. (15) }\end{array}$ & $\mathrm{O}$ & O & O & $\mathrm{O}$ & $\mathrm{O}$ \\
\hline $\begin{array}{l}\text { I used diet teas or } \\
\text { cleansing teas to lose } \\
\text { weight. (16) }\end{array}$ & $\mathrm{O}$ & O & O & $\mathrm{O}$ & O \\
\hline I used diet pills. (17) & $\mathrm{O}$ & $\mathrm{O}$ & O & 0 & 0 \\
\hline $\begin{array}{l}\text { I did not like how my } \\
\text { body looked. (18) }\end{array}$ & $\mathrm{O}$ & $\mathrm{O}$ & O & O & $\mathrm{O}$ \\
\hline $\begin{array}{l}\text { I ate until I was } \\
\text { uncomfortably full. (19) }\end{array}$ & 0 & $\mathrm{O}$ & $\mathrm{O}$ & O & O \\
\hline $\begin{array}{l}\text { I felt that overweight } \\
\text { people are lazy. }(20)\end{array}$ & $\mathrm{O}$ & $\mathrm{O}$ & O & $\mathrm{O}$ & $\mathrm{O}$ \\
\hline $\begin{array}{l}\text { I counted the calories of } \\
\text { foods I ate. }(21)\end{array}$ & $\mathrm{O}$ & $\mathrm{O}$ & $\mathrm{O}$ & O & $\mathrm{O}$ \\
\hline $\begin{array}{l}\text { I planned my days } \\
\text { around exercising. (22) }\end{array}$ & $\mathrm{O}$ & $\mathrm{O}$ & $\mathrm{O}$ & O & $\mathrm{O}$ \\
\hline $\begin{array}{l}\text { I thought my butt was } \\
\text { too big. }(23)\end{array}$ & O & $\mathrm{O}$ & O & O & O \\
\hline $\begin{array}{l}\text { I did not like the size of } \\
\text { my thighs. (24) }\end{array}$ & $\mathrm{O}$ & $\mathrm{O}$ & $\mathrm{O}$ & $\mathrm{O}$ & $\mathrm{O}$ \\
\hline $\begin{array}{l}\text { I wished the shape of my } \\
\text { body was different. (25) }\end{array}$ & $\mathrm{O}$ & $\mathrm{O}$ & O & O & O \\
\hline $\begin{array}{l}\text { I was disgusted by the } \\
\text { sight of an overweight } \\
\text { person wearing tight } \\
\text { clothes. (26) }\end{array}$ & $\mathrm{O}$ & O & O & O & O \\
\hline $\begin{array}{l}\text { I made myself vomit in } \\
\text { order to lose weight. (27) }\end{array}$ & $\mathrm{O}$ & $\mathrm{O}$ & $\mathrm{O}$ & O & $\mathrm{O}$ \\
\hline $\begin{array}{c}\text { I did not notice how } \\
\text { much I ate until after I } \\
\text { had finished eating. (28) }\end{array}$ & $\mathrm{O}$ & $\mathrm{O}$ & O & O & O \\
\hline $\begin{array}{l}\text { I considered taking a } \\
\text { muscle building } \\
\text { supplement. }(29)\end{array}$ & O & $\mathrm{O}$ & O & O & O \\
\hline $\begin{array}{l}\text { I felt that overweight } \\
\text { people are unattractive. } \\
\text { (30) }\end{array}$ & $\mathrm{O}$ & $\mathrm{O}$ & $\mathrm{O}$ & O & $\mathrm{O}$ \\
\hline $\begin{array}{l}\text { I engaged in strenuous } \\
\text { exercise at least five } \\
\text { days per week. (31) }\end{array}$ & $\mathrm{O}$ & O & $\mathrm{O}$ & O & 0 \\
\hline
\end{tabular}




\begin{tabular}{|c|c|c|c|c|c|}
\hline $\begin{array}{l}\text { I thought my muscles } \\
\text { were too small. (32) }\end{array}$ & 0 & 0 & 0 & 0 & 0 \\
\hline $\begin{array}{c}\text { I got full after eating } \\
\text { what most people would } \\
\text { consider a small amount } \\
\text { of food. (33) }\end{array}$ & 0 & 0 & 0 & 0 & 0 \\
\hline $\begin{array}{l}\text { I was not satisfied with } \\
\text { the size of my hips. (34) }\end{array}$ & 0 & 0 & 0 & 0 & 0 \\
\hline $\begin{array}{l}\text { I used protein } \\
\text { supplements. (35) }\end{array}$ & 0 & 0 & 0 & 0 & 0 \\
\hline $\begin{array}{l}\text { People encouraged me to } \\
\text { eat more. (36) }\end{array}$ & 0 & 0 & 0 & 0 & 0 \\
\hline $\begin{array}{l}\text { If someone offered me } \\
\text { food, I felt that I could } \\
\text { not resist eating it. (37) }\end{array}$ & O & 0 & 0 & 0 & 0 \\
\hline $\begin{array}{l}\text { I was disgusted by the } \\
\text { sight of obese people. } \\
\text { (38) }\end{array}$ & 0 & 0 & 0 & 0 & 0 \\
\hline $\begin{array}{l}\text { I stuffed myself with } \\
\text { food to the point of } \\
\text { feeling sick. (39) }\end{array}$ & 0 & 0 & 0 & 0 & O \\
\hline $\begin{array}{l}\text { I tried to avoid foods } \\
\text { with high calorie } \\
\text { content. }(40)\end{array}$ & 0 & 0 & 0 & 0 & 0 \\
\hline $\begin{array}{l}\text { I exercised to the point } \\
\text { of exhaustion. (41) }\end{array}$ & 0 & 0 & 0 & 0 & O \\
\hline $\begin{array}{l}\text { I used diuretics in order } \\
\text { to lose weight. (42) }\end{array}$ & 0 & 0 & 0 & 0 & 0 \\
\hline $\begin{array}{l}\text { I skipped two meals in a } \\
\text { row. (43) }\end{array}$ & 0 & 0 & 0 & 0 & 0 \\
\hline $\begin{array}{c}\text { I ate as if I was on auto- } \\
\text { pilot. (44) }\end{array}$ & 0 & 0 & 0 & 0 & 0 \\
\hline $\begin{array}{c}\text { I ate a very large amount } \\
\text { of food in a short period } \\
\text { of time (e.g., within } 2 \\
\text { hours). (45) }\end{array}$ & 0 & 0 & 0 & 0 & 0 \\
\hline
\end{tabular}

Q38 For entry into a drawing for a $\$ 50$ Amazon gift card, please provide your email address here. Q39 REFERRAL LIST

Below is a list of Referrals, Helplines, \& Support Groups. Inclusion on the list does not imply the WVU School of Public Health's endorsement of these agencies or services. Payment for services 
rendered at these agencies is the sole responsibility of the patient and not the researchers of the current study.

Referrals

Academy for Eating Disorders: Find a Professional

http://www.aedweb.org/index.php/education/eating-disorder-information-2

Helplines

National Eating Disorder Association (NEDA) free, confidential Helpline Monday - Thursday 9am9pm, Friday 9am-5pm 1-800-931-2237

Eating Disorders Association (UK) Adult Helpline: 011-44-8456-341414 Youthline: 011-44-8456347650 Adult Helpline: (open 8:30 to 20:30 weekdays) Youthline: (open 16:00 to 18:30 weekdays)

National Suicide Prevention Lifeline 1-800-273-TALK or 1-800-SUICIDE (784-2433)

\section{Support Groups}

Study of Anorexia \& Bulimia (CSAB) Support Groups Family \& Friends takes place on the 1st \& 3rd Wednesdays of the month. Pursuing Recovery takes place on the 2 nd \& 4th Wednesdays of the month. 212.333.3444 ext. 256 or email: emilyrosenthal@ hotmail.com 1841 Broadway (at 60th St) 4th Floor - Room 407 New York, NY 10023.

\section{Dieting Behaviors Scoring}

Directions: Average the scores for individual items for each Subscale. Higher scores indicate greater negative indirect or direct parental influences.

Negative Indirect Parental Influences - indirect parental influences include items around parental dieting, parental fat talk, encouragement to a sibling to diet, and criticism of a siblings' weight

\#16, \#17, \#20, \#22, \#25, \#26, \#29, \#31

Negative Direct Parental Influences - direct parental influences include items around parental encouragement of participant to diet and criticism of participant's weight (both past and current)

\#19, \#21, \#28, \#30, \#33, \#34, \#35, \#26 


\section{Appendix G}

\section{IRB-Approved Advertisement}

West Virginia University

Dieting Behaviors Study

(IRB:1609282716)

Volunteers Wanted for Research Study

\section{A chance to win a $\$ 50$ Amazon Gift Card as compensation}

Eligible participants will complete a 15-minute online survey asking about dieting behaviors of themselves and their parents.

Eligibility criteria include: English-speaking individuals (age 18 and older) with a past or present eating disorder diagnosis

\section{Cover Letter}

WVU IRB is on file

The following survey is completely optional and inquires about your dieting behaviors and your recall of your parents' dieting behaviors. The purpose of this study is to understand the family environment of individuals with eating disorders. By understanding this, we can hope to improve prevention and early intervention efforts. The information you provide is vital to helping other individuals with eating disorders.

This study is being conducted to fulfill requirements for a dissertation project and is led by Elizabeth Claydon, MPH, MS who is a PhD student in the Department of Social and Behavioral Sciences at West Virginia University. This project is being overseen by her professor, Dr. Keith Zullig, also in the Department Social and Behavioral Sciences.

The survey will take approximately 15 minutes to complete.

This survey is anonymous and cannot be linked back to you. You will have the option to provide your email address for entry to win a \$50 Amazon gift card. Your email address will be kept confidential and your data will always only be identified by a study ID any identifying information.

Your participation in this survey is completely voluntary and you may choose to withdraw at any time. This study has been filed with West Virginia University's Institutional Review Board and approval has been obtained.

If you agree to participate, please click 'yes' to continue to the survey.

Thank you so much for your time and willingness to help with this important project.

Sincerely, Elizabeth Claydon, MPH, MS

Please contact eac0006@mix.wvu.edu with any questions. 
REFERRAL LIST

Below is a list of Referrals, Helplines, \& Support Groups.

Inclusion on the list does not imply the WVU School of Public Health's endorsement of these agencies or services. Payment for services rendered at these agencies is the sole responsibility of the patient and not the researchers of the current study.

\section{$\underline{\text { Referrals }}$}

Academy for Eating Disorders: Find a Professional

http://www.aedweb.org/index.php/education/eating-disorder-information-2

\section{Helplines}

National Eating Disorder Association (NEDA) free, confidential Helpline

Monday - Thursday 9am-9pm, Friday 9am-5pm

1-800-931-2237

Eating Disorders Association (UK)

Adult Helpline: 011-44-8456-341414

Youthline: 011-44-8456-347650

Adult Helpline: (open 8:30 to 20:30 weekdays)

Youthline: (open 16:00 to 18:30 weekdays)

National Suicide Prevention Lifeline

1-800-273-TALK or 1-800-SUICIDE (784-2433)

\section{Support Groups}

Study of Anorexia \& Bulimia (CSAB) Support Groups

Family \& Friends takes place on the 1 st \& 3rd Wednesdays of the month.

Pursuing Recovery takes place on the 2 nd \& 4th Wednesdays of the month.

212.333.3444 ext. 256 or email: emilyrosenthal@ hotmail.com

1841 Broadway (at 60th $\mathrm{St}$ )

4th Floor - Room 407

New York, NY 10023. 


\section{Appendix $\mathrm{H}$}

September 16, 2016

Elizabeth Claydon, M.P.H, MS

Department of Social \& Behavioral Sciences

West Virginia University School of Public Health

RE: Cooperation in Recruiting Dissertation Participants

Dear Ms. Claydon,

I am writing to express my support in helping to assist in recruitment for one of your dissertation aims.

As the Director of the Adult Eating Disorders Partial Hospitalization Program at New York-

Presbyterian Hospital, I am happy to help with recruiting participants with an eating disorder or history of an eating disorder through our channels. We also will help advertise your questionnaire on social

media using my Twitter account, @TaraDeliberto.

I look forward to working together in assisting your recruitment.

Sincerely,

Tara Deliberto, Ph.D.

Assistant Professor of Psychology

Weill Cornell Medical College 
September 12, 2016

Elizabeth Claydon, M.P.H, MS

Department of Social \& Behavioral Sciences

West Virginia University School of Public Health

RE: Cooperation in Recruiting Dissertation Participants

Dear Ms. Claydon,

I am writing to express my support in recruitment for one of your dissertation aims. As the Clinical

Director of the UNC Center of Excellence for Eating Disorders and a member of your committee, I am happy to help with recruiting participants with an eating disorder or history of an eating disorder through our online channels. We will help advertise your questionnaire on our Facebook and Twitter pages, as well as our blog.

I look forward to working together in assisting your recruitment.

Sincerely,

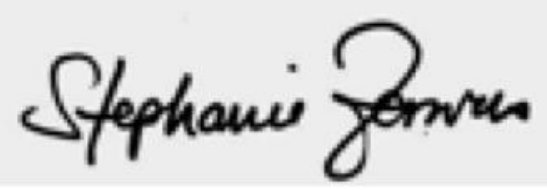

Stephanie Zerwas, Ph.D.

Associate Professor \& Clinical Director

UNC Center of Excellence for Eating Disorders

UNC School of Medicine 
August 2, 2016

Elizabeth Claydon, M.P.H, MS

Department of Social \& Behavioral Sciences

West Virginia University School of Public Health

RE: Cooperation in Recruiting Dissertation Participants

Dear Ms. Claydon,

I am writing to express my support in helping to assist in recruitment for one of your dissertation aims. As the Executive Director of Eating Recovery Center, Ohio, I am happy to help with recruiting participants with an eating disorder or history of an eating disorder through our channels.

I look forward to working together in assisting your recruitment.

Sincerely,

Ashley Solomon, PsyD, CEDS

Executive Director

Eating Recovery Center, Ohio

(513) 808-9210

asolomon@erc-ohio.com 


\section{WestVirginiaUniversity:}

SCHOOL OF MEDICINE

August $26^{\text {th }}, 2016$

Elizabeth Claydon, M.P.H, MS

Department of Social \& Behavioral Sciences

West Virginia University School of Public Health

\section{RE: Cooperation in Recruiting Dissertation Participants}

Dear Ms. Claydon,

I am writing to express my support in helping to assist in recruitment for one of your dissertation aims. As the primary psychologist for WVU's Bariatric Surgery program and Assistant Professor in the Department of Behavioral Medicine and Psychiatry, I am happy to help with recruiting participants with an eating disorder or history of an eating disorder through our channels.

I look forward to working together in assisting your recruitment.

Sincerely,

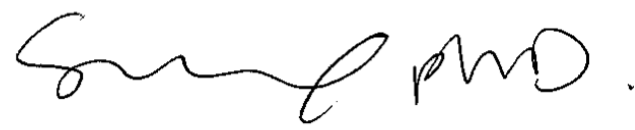

Stephanie Cox, Ph.D.

Assistant Professor

Bariatric Psychology and Eating Disorders

West Virginia University

Department of Behavioral Medicine and Psychiatry 


\section{References}

Abraham, S. F., Pettigrew, B., Boyd, C., Russell, J., \& Taylor, A. (2005). Usefulness of amenorrhoea in the diagnoses of eating disorder patients. Journal of Psychosomatic Obstetrics and Gynecology, 26(3), 211-215. https://doi.org/10.1080/01674820500064997

An, X., Yung, Y-F. (2014). Item response theory: What it is and how you can use the IRT procedure to apply it. Cary, NC: SAS Institute.

Agras, W.S. (2001). The consequences and costs of the eating disorders. Psychiatric Clinics of North America, 24(2), 371-379. https://doi.org/10.1016/S0193-953X(05)70232-X

American Psychiatric Association. (2013). Diagnostic and statistical manual of mental disorders (5th ed.). Arlington, VA: American Psychiatric Publishing.

An, X. and Yung, Y.-F. (2014), "Item Response Theory: What It Is and How You Can Use the IRT Procedure to Apply It," in Proceedings of the SAS Global Forum 2014 Conference. Retrieved from: http://support.sas.com/resources/papers/proceedings14/SAS364-2014.pdf

Bakeman, R. \& Gottman, J.M. (1997). Observing interaction: An introduction to sequential analysis ( $2^{\text {nd }}$ ed.). Cambridge: Cambridge University Press.

Bandura, A. (1986). Social foundations of thought and action: A social cognitive theory. Englewood Cliffs, N.J.: Prentice-Hall.

Bland, J. \& Altman, D. (1997). Statistics notes: Cronbach's alpha. British Medical Journal, 314, 275. https://doi.org/10.1136/bmj.314.7080.572

Britton, L.E., Martz, D.M., Bazzini, D.G., Curtin, L.A., \& LeaShomb, A. (2006). Fat talk and selfpresentation of body image: Is there a social norm for women to self-degrade? Body Image, 3, 247-254. https://doi.org/10.1016/j.bodyim.2006.05.006

Bulik, C.M. (2005). Exploring the gene-environment nexus in eating disorders. Journal of Psychiatry \& Neuroscience, 30(5), 335-339.

Bulik, C. M. Midlife Eating Disorders: Your Journey to Recovery. New York: Walker Publishing Company, 2013.

Bulik, C. M., Reba, L., Siega-Riz, A. M., \& Reichborn-Kjennerud, T. (2005). Anorexia nervosa: Definition, epidemiology, and cycle of risk. International Journal of Eating Disorders, 37 (Suppl), S2-S9. Discussion S20-21. https://doi.org/10.1002/eat.20107

Bulik, C.M., Von Holle, A., Hamer, R., Knoph Berg, C., Torgersen, L., Magnus, P., ... ReichbornKjennerud, T. (2007). Patterns of remission, continuation and incidence of broadly defined eating disorders during early pregnancy in the Norwegian Mother and Child Cohort Study 
(MoBa). Psychological Medicine, 37(8), 1109-1118.

https://doi.org/10.1017/S0033291707000724

Bulik, C. M., Von Holle, A., Siega-Riz, A. M., Torgersen, L., Lie, K. K., Hamer, R. M., ... ReichbornKjennerud, T. (2009). Birth outcomes in women with eating disorders in the Norwegian Mother and Child cohort study (MoBa). International Journal of Eating Disorders, 42(1), 9-18. https://doi.org/10.1002/eat.20578

Bulik, C. M., Hoffman, E. R., Von Holle, A., Torgersen, L., Stoltenberg, C., \& Reichborn- Kjennerud, T. (2010). Unplanned pregnancy in women with anorexia nervosa. Obstetrics and Gynecology, 116 (5), 1136-1140. https://doi.org/10.1097/AOG.0b013e3181f7efdc

Calzo, J. P., Horton, N. J., Sonneville, K. R., Swanson, S., Crosby, R. D., Micali, N., ... Field, A. E. (2016). Male Eating Disorder Symptom Patterns and Health Correlates From 13 to 26 Years of Age. Journal of the American Academy of Child and Adolescent Psychiatry, 55(8), 693-700.e2. https://doi.org/10.1016/j.jaac.2016.05.011

Campbell, M.W., Williams, J., Hampton, A., \& Wake, M. (2006). Maternal concern and perceptions of overweight in Australian preschool-aged children. Medical Journal of Australia, 184 (6), 274277.

Cappelleri, J.C., Lundy, J.J., \& Hays, R.D. (2014). Overview of classical test theory and item response theory for quantitative assessment of items in developing patient reported outcome measures. Clinical Therapeutics, 36 (5), 648-662. https://doi.org/10.1016/j.clinthera.2014.04.006

Clark, A., Skouteris, H., Wertheim, E.H., Paxton, S.J., \& Milgrom, J. (2009). My baby body: A qualitative insight into women's body-related experiences and mood during pregnancy and the postpartum. Journal of Reproductive \& Infant Psychology, 27 (4), 330-345. https://doi.org/10.1080/02646830903190904

Coffman, D.L., Balantekin, K.N., Savage, J.S. (2016). Using propensity score methods to assess causal effects of mothers' dieting behavior on daughters' early dieting behavior. Childhood obesity, 12(5), 334-340. https://doi.org/10.1089/chi.2015.0249

Costanzo, P.R., \& Woody, E.Z. (1985). Domain-specific parenting styles and their impact on the child's development of particular deviance: the example of obesity proneness. Journal of Social and Clinical Psychology, 3, 425-445. https://doi.org/10.1521/jscp.1985.3.4.425

Creswell, J. W. (2013). Qualitative Inquiry and Research Design: Choosing among Five Approaches, (3rd ed.). Thousand Oaks, CA: Sage Publications.

Easter, A., Treasure, J., \& Micali, N. (2011). Fertility and prenatal attitudes towards pregnancy in women with eating disorders: Results from the Avon Longitudinal Study of Parents and Children. BJOG: An International Journal of Obstetrics and Gynaecology, 118(12), 14911498. https://doi.org/10.1111/j.1471-0528.2011.03077.x

Engeln, R., Sladek, M.R., \& Waldron, H. (2013). Body talk among college men: Content, correlates, 
and effects. Body Image, 10 (3), 300-308. https://doi.org/10.1016/j.bodyim.2013.02.001

Fairburn, C.G. \& Harrison, P.J. (2003). Eating Disorders. The Lancet, 361(9355), 407-416. https://doi.org/10.1016/S0140-6736(03)12378-1

Faul, F., Erdfelder, E., Lang, A.G., \& Buchner, A. (2007). G*Power 3: A flexible statistical power analysis program for the social, behavioral, and biomedical sciences. Behavior Research Methods, 39, 175-191. https://doi.org/10.3758/BF03193146

F.E.A.S.T. (2009). F.E.A.S.T Position Statement: Parents do not cause eating disorders: Families are important allies during treatment. Retrieved from http://www.feasted.org/news/news.asp?id=169572

Forbush, K.T., Wildes, J.E., Pollack, L.O., Dunbar, D., Luo, J., Patterson, K. .. Watson, D. (2013). Development and validation of the Eating Pathology Symptoms Inventory (EPSI). Psychological Assessment, 25 (3), 859-878.

Frederickson, B.L. \& Roberts, T.-A. (1997). Objectification theory: Toward understanding women's lived experiences and mental health risks. Psychology of Women Quarterly, 21, 173-206.

Golden, N.H., Schneider, M., \& Wood, C., AAP Committee on Nutrition. (2016). Preventing obesity and eating disorders in adolescents. Pediatrics, 138(3), e20161649. https://doi.org/10.1542/peds.2016-1649

Huon, G.F., Lim, J., Gunewardene, A. (2000). Social influences and female adolescent dieting. Journal of Adolescence, 23, 229-232. https://doi.org/10.1006/jado.2000.0310

Jacobi, C., Hayward, C., de Zwaan, M., Kraemer, H. C., \& Agras, W. S. (2004). Coming to terms with risk factors for eating disorders: Application of risk terminology and suggestions for a general taxonomy. Psychological Bulletin, 130(1), 19-65. https://doi.org/10.1037/0033-2909.130.1.19

JMP®, Version 12.0. SAS Institute Inc., Cary, NC, 1989-2007.

Klump, K.L., Bulik, C.M., Kaye, W.H., et al. (2009). Academy for Eating Disorders position paper: Eating disorders are serious mental illnesses. International Journal of Eating Disorders, 42, 97103. https://doi.org/10.1002/eat.20589

Kroon Van Diest, A.M. \& Tylka, T.L. (2010). The Caregiver Eating Messages Scale: Development and psychometric investigation. Body Image, 7(4), 317-326. https://doi.org/10.1016/j.bodyim.2010.06.002

Lather, P. (1991). Getting smart: Feminist research and pedagogy with/in the postmodern. New York: Routledge.

Lavrakas, P. J. (2008). Encyclopedia of survey research methods Thousand Oaks, CA: SAGE Publications Ltd. https://doi.org/10.4135/9781412963947 
Le Grange, D., Lock, J., Loeb, K., \& Nicholls, D. (2010). Academy for Eating Disorders position paper: The role of the family in eating disorders. International Journal of Eating Disorders, 43 (1), 1-5. https://doi.org/10.1002/eat.20751

Lincoln, Y.S. \& Guba, E.G. (1985). Naturalistic Inquiry. Newbury Park, CA: Sage Publications.

Loewen, S. \& Plonsky. (2015). An A-Z of Applied Linguistics Research Methods, $1^{\text {st }}$ ed. Basingstroke, United Kingdom: Palgrave.

Lorasch-Gunderson, D. (2012). Relative influence of family, peers, and media on the development of eating disorders in adolescents. Master of Social Work Clinical Research Papers. Paper 66.

MacDonald, D.E., Dimitropoulos, G., Royal, S., Polanco, A., Dionne, M.M. (2015). The Family Fat Talk Questionnaire: Development and psychometric properties of fat talk behaviors within the family context. Body Image, 12, 44-52. https://doi.org/10.1016/j.bodyim.2014.10.001

Mertens, D.M. (2003). Mixed methods and the politics of human research: The transformativeemancipatory perspective. In A. Tashakkori \& C. Teddlie (Eds.), Handbook of mixed methods in social and behavioral research (pp. 135-164). Thousand Oaks, CA: Sage Publications.

Mertens, D.M. (2009). Transformative research and evaluation. New York: Guilford Press.

Micali, N., Treasure, J., \& Simonoff, E. (2007). Eating disorders symptoms in pregnancy: A longitudinal study of women with recent and past eating disorders and obesity. Journal of Psychosomatic Research, 63(3), 297-303. https://doi.org/10.1016/j.jpsychores.2007.05.003

Morgan, J. F., Lacey, J. H., \& Chung, E. (2006). Risk of postnatal depression, miscarriage, and preterm birth in bulimia nervosa: Retrospective controlled study. Psychosomatic Medicine, 68(3), 487-492. https://doi.org/10.1097/01.psy.0000221265.43407.89

Nickelson, J., Bryant, C.A., McDermott, R.J., Buhi, E.R., DeBate, R.D. (2012). A modified obesity proneness model predicts adolescent weight concerns and inability to self-regulate eating. Journal of School Health, 82 (12), 560-571. https://doi.org/ 10.1111/j.1746-1561.2012.00737.x

Olsen, V. (2011). Feminist qualitative research in the Millenium's first decade: Developments, challenges, prospects. In N. K. Denzin \& Y. S. Lincoln (Eds.), The SAGE handbook of qualitative research ( $4^{\text {th }}$ ed., pp. 129-146). Thousand Oaks, CA: Sage Publications.

Reynolds, W. (1982). Development of reliable and valid short forms of the Marlowe-crowne social desirability scale. Journal of Clinical Psychology, 38 (1), 119-125. https://doi.org/10.1002/1097-4679(198201)38:1<119::AID-JCLP2270380118>3.0.CO;2-I

Rodgers, R.F., Karine, F., Henri, C. (2009a). Gender differences in parental influences on adolescent body dissatisfaction and disordered eating. Sex Roles, 61, 837-849. https://doi.org/10.1007/s11199-009-9690-9

Rodgers, R.F., Paxton, S.J., Chabrol, H. (2009b). Effects of parental comments on body dissatisfaction 
and eating disturbance in young adults: a sociocultural model. Body Image, 6(3):171-177. https://doi.org/10.1016/j.bodyim.2009.04.004

Rodgers, R.F., Paxton, S.J., McLean, S.A. (2014). A biopsychosocial model of body image concerns and disordered eating in early adolescent girls. Journal of Youth and Adolescence, 43(5), 814823. https://doi.org/10.1007/s10964-013-0013-7

Rohde, P., Stice, E., \& Nathan Marti, C. (2015). Development and predictive effects of eating disorder risk factors during adolescence: Implications for prevention efforts. International Journal of Eating Disorders, 48(2), 187-198. https://doi.org/10.1002/eat.22270

Royal, S., MacDonald, D.E., Dionne, M.M. (2013). Development and validation of the Fat Talk Questionnaire. Body Image, 10, 62-69. https://doi.org/10.1016/j.bodyim.2012.10.003

Runfola, C.D., Zucker, N.L., Holle, A.V., Mazzeo, S., Hodges, E.A., Perrin, E.M., ... Bulik, C.M. (2013). NURTURE: Development and pilot testing of a novel parenting intervention for mothers with histories of an eating disorder. International Journal of Eating Disorders, 47(1), 1-12. https://doi.org/10.1002/eat.22178

Saldãna, J. (2009). The coding manual for qualitative researchers. London: Sage Publications.

Scaglioni, S., Salvioni, M., Galimberti, C. (2008). Influence of parental attitudes in the development of children eating behaviour. British Journal of Nutrition, 99, S22-S25. https:/doi.org/10.1017/S0007114508892471

Schaumberg, K., Welch, E., Breithaupt, L., Hübel, C., Baker, J.H., Munn-Chernoff, M.A., ... Bulik, C.M. (2017). The science behind the Academy for Eating Disorders' Nine Truths About Eating Disorders. European Eating Disorders Review, 25(6), 432-450. https://doi.org/10.1002/erv.2553

Stice, E. (1998). Modeling of eating pathology and social reinforcement of the thin ideal predict the onset of bulimic symptoms. Behavioral Research Therapy, 36, 931-944. https://doi.org/10.1016/S0005-7967(98)00074-6

Tierney, S., Fox, J.R.E., Butterfield C., Stringer, E., \& Furber C. (2011). Treading the tightrope between motherhood and an eating disorder. International Journal of Nursing Studies, 48, 1223-1233.

Quiles Marcos, Y., Quiles Sebastian, M.J., Pamies Aubalat, L., Botella Ausina, J., \& Treasure, J. (2013). Peer and family influence in eating disorders: A meta-analysis. European Psychiatry, 28, 199-206. https://doi.org/10.1016/j.eurpsy.2012.03.005

Wansink, B., Latimer, L.A., Pope, L. (2017). "Don't eat so much:” how parent comments relate to female weight satisfaction. Eating and Weight Disorders: 1-7. https://doi.org/10.1007/s40519$\underline{016-0292-6}$ 
Yang, F.M., Kao, S.T. (2014). Item response theory for measurement validity. Shanghai Archives of Psychiatry, 26(3), 171-177.

Zerwas, S. \& Bulik, C.M. (2016). Maternal eating disorders and parenting: Towards genetically informed models. Conference presentation: International Conference on Eating Disorders.

Zerwas, S. \& Claydon, E. (2014). Eating Disorders Across the Lifespan: From Menstruation to Menopause. (pp. 237-261). In Barnes, D.L., ed. Women's reproductive mental health across the lifespan. New York: Springer Publishing. 